\title{
Tesis recomendada para su publicación. Indumentaria e identidad: análisis de la vestimenta de la mujer indígena desde el Diseño. El caso del pueblo chibuleo (Tungurahua, Ecuador 1990-2016)
}

Aylen Medina Robalino ${ }^{(1)}$

\begin{abstract}
Resumen: En esta tesis se abordan los usos y transformaciones de la indumentaria de la mujer chibuleo entre los años 1990 y 2016. A partir del análisis de las transformaciones de la indumentaria acaecidas en ese proceso, se identifican y analizan tres tipologías vestimentarias. A su vez, y como parte del análisis, se relacionan dichas tipologías con tres momentos históricos, sociales y políticos. Estos hitos fueron, en primer lugar, los levantamientos indígenas de 1990, con el consecuente reconocimiento constitucional de los derechos de la etnia. En segundo lugar, la creación de instituciones educativas bilingües, en específico la Unidad Educativa del Milenio Chibuleo, y en último lugar, la creación de cooperativas de ahorro y crédito. Este proceso histórico, cuyo hilo conductor fue la lucha y la reivindicación de los derechos - relatada por los chibuleos como "el respeto adquirido"-, está íntimamente relacionado con el uso y transformaciones vestimentarias de este pueblo. Particularmente, se estudia en la presente tesis a los grupos de mujeres identificadas como las mamas, las profesoras y las de las cooperativas.
\end{abstract}

Palabras Clave: diseño de indumentaria - chibuleo - identidad - transformaciones - tipologías vestimentarias.

[Resúmenes en inglés y portugués en las páginas 305-306]

(1) Doctora en Diseño (Facultad de Diseño y Comunicación, Universidad de Palermo, Argentina). Ingeniera en Diseño de Modas (Universidad Cristiana Latinoamericana, Ecuador). Mg. en Docencia y Currículo para la Educación Superior (Universidad Técnica de Ambato, Ecuador). Cargo actual: Profesora Titular e Investigadora (Universidad Técnica de Ambato Ecuador). aylenkmedina@uta.edu.ec 


\section{Introducción}

En la presente tesis analizo el vínculo entre indumentaria e identidad, a partir de la indagación de la vestimenta de las mujeres indígenas del pueblo chibuleo, ubicado en la provincia de Tungurahua, Ecuador, entre los años 1990 y 2016.

Dentro de esta periodización abarco un conjunto de hitos históricos, que son los siguientes: los levantamientos de la década de 1990, donde el uso de la vestimenta chibuleo se constituyó en un medio de identificación -indígena-, y de diferenciación - con lo no indígena-; el reconocimiento constitucional de los pueblos indígenas como sujetos políticos dentro de las cartas magnas de 1998 y de 2008, en las que se particulariza el uso de la vestimenta de cada pueblo como un derecho; y la aplicación de los artículos constitucionales a través de políticas públicas orientadas a la formación de instituciones educativas bilingües - como parte del cumplimiento de derechos indígenas-, y a la creación de financieras indígenas.

Los levantamientos nacionales de junio de 1990, encabezados por el movimiento indígena para exigir el cumplimiento de sus derechos, marcan el inicio de un proceso de revitalización del uso de las prendas de las mujeres chibuleo como elementos identificatorios. Este proceso se cierra, a los fines de este trabajo, en el año 2016, con la última etapa de exploración etnográfica, dos años después de que el gobierno inaugurara la Unidad Educativa del Milenio Chibuleo (UEM Chibuleo), en el que profesoras y estudiantes indígenas acuden con la indumentaria chibuleo de manera cotidiana a desempeñar sus actividades profesionales.

El abordaje de esta temática exigió un cruce interdisciplinario que articuló aportes del Diseño de Indumentaria y la Antropología. Uno de los supuestos principales en los que me apoyé en esta investigación, fue asumir que los usos de la indumentaria identificatoria del pueblo chibuleo, por parte de las mujeres en los distintos roles que desempeñan cotidianamente, expresan construcciones identitarias. Sostengo entonces que las transformaciones de Diseño en los objetos vestimentarios, se desarrollan a partir de sus funciones prácticas y estéticas, en consonancia con su función simbólica

La indumentaria de la mujer chibuleo, sus transformaciones y continuidades, dan cuenta de la dinámica interétnica y de las distintas significaciones que adquiere la identidad chibuleo en el devenir histórico social y político. En este sentido, el Diseño del artefacto vestimentario en los arquetipos de la mujer chibuleo, se construye como un diacrítico de la resignificación dialéctica indumentaria identidad.

Los chibuleo pertenecen a los cuatro pueblos indígenas de nacionalidad kichwa identificados y reconocidos en la provincia de Tungurahua de la Sierra central ecuatoriana. Esta etnia tiene una población de 5.383 personas $^{1}$ en todo el país, de las cuales un aproximado de $4.087^{2}$ habitan en siete comunidades ${ }^{3}$ de la parroquia rural Juan Benigno Vela del cantón Ambato. La mayoría de los chibuleos residen en la comunidad de Chibuleo San Francisco, en la que se desarrolla la mayor parte de los estudios etnográficos de esta investigación. A los fines de esta tesis, he identificado tres grupos de mujeres, en función de su pertenencia etaria y su profesión o actividad cotidiana. Estos grupos, cuyas denominaciones corresponden a categorías nativas, son: "las mamas", "las profesoras" y "las de las coope- 
rativas". La vestimenta chibuleo incluye las prendas y accesorios indígenas cuyo uso se ha transmitido de generación en generación, en combinación con prendas y accesorios no indígenas apropiados, y en algunos casos innovados en sus relaciones interétnicas (Bonfil Batalla, 1991). En la parte inferior, portan un anaco o anacos, que se colocan envueltos y formando pliegues, sujetos a la cintura con uno o varios chumbis - fajas-. En la parte superior, las mujeres se cubren con una camisa o blusa - en reemplazo del tupulli-. Sobre éstas, se ponen uno o varios rebozos o bayetas, en un uso alternado o complementario con la lishta. Todas estas prendas son mantos que rodean la espalda y se sujetan con un tupu - prendedor - de plata. Para complementar el atuendo, las mujeres portan sombreros, además de orejeras y wallkas — collares- que se suspenden de las orejas y el cuello respectivamente.

La identificación de la vestimenta con la identidad étnica es una relación muy marcada en los chibuleo, principalmente en las mujeres. Esto lo observé principalmente a partir de la lucha por los derechos de la etnia. Otro espacio, en este caso institucional ampliamente ligado al uso vestimentario, estuvo marcado por la generación de la Unidad Educativa del Milenio Chibuleo y de las cooperativas de ahorro y crédito.

El presente trabajo lo inscribo en la línea de investigación Cruces entre Cultura y Diseño, en tanto analizo desde el campo del Diseño cómo se transformó la indumentaria de las mujeres chibuleo en diferentes contextos y momentos históricos, así como el sentido e identidad del vestido "como un artefacto del diseño" (Fernández, 2016a, p. 11).

El marco teórico en el que sustento el presente trabajo, se articula entre el campo del Diseño y de la Antropología. Tres aportes resultaron sustanciales para el abordaje propuesto. En primer lugar, las reflexiones de Avenburg y Matarrese (2019) ofrecieron un marco explicativo para comprender los cruces entre cultura, Antropología y Diseño. En segunda instancia, los aportes de Laura Zambrini (2019) respecto a la relación entre indumentaria y género, constituyeron una base teórica fundamental para entender la incidencia de la indumentaria chibuleo en los procesos de autoadscripción y diferenciación de las mujeres de esta comunidad, a la par de los nuevos roles que comenzaron a ocupar.

Cabe aclarar que el abordaje que propongo, consistente en analizar los usos y transformaciones de la vestimenta chibuleo desde el Diseño en articulación con la Antropología, constituye un área de vacancia que aún no ha sido analizado, según doy cuenta en los antecedentes. Más aún, hallé escasa bibliografía académica acerca de este pueblo en términos generales, pese a su importancia dentro de Ecuador, y más escasa aún en términos de estudios sobre indumentaria. En efecto, tuve que analizar bibliografía acerca de la indumentaria andina en Ecuador y a nivel latinoamericano para acercarme a los chibuleo. Si bien el pueblo chibuleo ha sido objeto de estudio en tesis de grado - y en algunos casos de tesis de posgrado, principalmente de maestría-, estas investigaciones se han enfocado, en su mayoría, en las finanzas y administración de las cooperativas de ahorro y crédito, además de educación bilingüe y, en otros casos, dentro de las ciencias sociales que ocasionalmente abordan la indumentaria. Sin embargo, no constituyen antecedentes confiables, en tanto no se apoyan en marcos teóricos consolidados, sus listas de referencias bibliográficas remiten con frecuencia a artículos de difusión general en Internet, y con menor frecuencia a algún artículo científico. Además, estos estudios se dedican escasamente a 
la indumentaria de los chibuleo. La limitación bibliográfica con la que me enfrenté en la presente investigación demandó profundizar el trabajo de campo.

Habida cuenta de lo expuesto, la tesis que desarrollo se inscribe en un área de vacancia dentro del campo del Diseño, lo que le otorga un carácter innovador y constituye un aporte a las investigaciones de este campo.

Desde el ámbito del Diseño, se ha estudiado a la indumentaria indígena a partir de la apariencia, generalmente como algo superfluo, puramente estético y en su mayoría vinculado al fenómeno de la moda, sin destacar sus funciones comunicativas en relación con la identidad étnica. En lugar de, como sostiene Fernández (2015a, 2016a), estudiarla a través de la profundidad de la apariencia que incluye tanto la función estética como la función simbólica del vestido. Si bien destaco la importancia de los análisis de esta autora en el transcurso de la tesis, resulta pertinente aclarar que se fundamentan principalmente desde las concepciones de Occidente (Fernández, 2018), a diferencia de esta tesis, en la que procuro posicionarme desde la perspectiva de los pueblos indígenas, en específico de los chibuleo.

Desde la Antropología, el vínculo entre el vestido, la identidad y el Diseño ha sido analizado escasamente. En este sentido, retomo el desafío planteado por Roach y Eicher (1992) respecto a la dificultad de desarrollar una teoría del vestido como comunicador de identidad, que permita explicar los hechos sociales que inciden en las transformaciones del vestido a la luz de la historia. En específico, me refiero a la identidad étnica que expresa la pertenencia, adscripción y autoadscripción a un grupo (Barth, 1976), así como al vestido como el elemento cultural más visible (Roach y Eicher, 1992) de identificación y diferenciación, al interior del grupo y con los otros.

El análisis de caso que estudio en esta tesis, contribuye al desarrollo de una teoría del vestido como comunicador de la identidad indígena, desde la perspectiva del Diseño. La relación dialéctica entre identidad e indumentaria que propongo, pretende dar cuenta del carácter histórico y en constante transformación del uso vestimentario, lo que en definitiva expresa la imposibilidad de tomar a la vestimenta como un objeto inmutable y ahistórico. Al mismo tiempo, expresa su ineludible imbricación con el entramado histórico, político y social en el que habitan las mujeres que la portan.

La pregunta problema de investigación, que constituye el eje de articulación de la presente tesis, es: ¿de qué manera los usos y transformaciones vestimentarias de la mujer chibuleo, analizados desde el Diseño, pueden dar cuenta de los procesos de construcción identitaria La hipótesis que sustento en la presente investigación, afirma que los usos indumentarios de la mujer chibuleo, analizados desde el Diseño, permiten dar cuenta de las transformaciones identitarias de este pueblo. La relación dialéctica indumentaria-identidad que definí anteriormente, evidencia cómo la indumentaria entendida como artefacto de Diseño, se constituye históricamente en un elemento diacrítico de su identidad grupal, estableciendo fronteras internas y externas que condicionan sus prácticas políticas, económicas, sociales y culturales.

El objetivo general de la investigación es analizar la indumentaria de la mujer chibuleo desde el Diseño, tanto los usos según los diferentes roles que asume la mujer cuanto sus transformaciones dentro del período de estudio (1990-2016). 
Los objetivos específicos son, en primer lugar, identificar y describir los hitos históricos en los usos y transformaciones de la indumentaria de la mujer chibuleo en relación con su identidad entre 1990 y 2016. En segunda instancia, relevar los usos de la indumentaria cotidiana desde los distintos roles que asumen las mujeres chibuleo y cómo dan cuenta de sus construcciones identitarias. En tercer lugar, se propone examinar las transformaciones de Diseño en los objetos vestimentarios que portan las mujeres chibuleo y los vínculos indumentarios que se establecen con los no indígenas. En cuarta y última instancia, analizar el Diseño del artefacto vestimentario de la mujer chibuleo como elemento diacrítico de la identidad de este pueblo y evidencia de su proceso de resignificación histórica.

El desarrollo de la tesis se estructura en cuatro capítulos. En el capítulo 1, doy cuenta del marco metodológico en el que se sustenta la tesis. Asimismo, se presentan las características de la zona en la que se asientan los chibuleo, la diversificación económica de este pueblo y el tipo de prendas y accesorios que forman parte de la indumentaria de la mujer chibuleo. Por su parte, en el capítulo 2 analizo los hitos históricos que incidieron en los usos y transformaciones de la indumentaria de la mujer chibuleo entre 1990 y 2016 . Por un lado, presento los levantamientos indígenas nacionales en los que tuvo participación el pueblo y el consecuente reconocimiento constitucional de la etnia. Por el otro, doy cuenta de los cambios de actividad económica de los chibuleo y su participación en la educación bilingüe, ambos suscitados a partir del reconocimiento constitucional y en estrecho vínculo con las transformaciones de la vestimenta.

En el capítulo 3, estudio los usos cotidianos de la indumentaria a partir de los distintos roles que asumen las mujeres chibuleo y los diversos modos en que expresan sus construcciones identitarias. En este apartado analizo los usos vestimentarios de los grupos de mujeres constituidos por "las mamas", "las profesoras" y "las de las cooperativas" en sus lugares cotidianos de trabajo. Asimismo, examino las transformaciones de Diseño en los objetos vestimentarios que portan las mujeres chibuleo y los vínculos indumentarios que se establecen con los no indígenas. Expongo las transformaciones de las prendas - anaco, chumbi, rebozo, bayeta, lishta, camisa y blusa-y los accesorios - sombrero, tupu, wallkas y orejeras-, dentro de los grupos de mujeres chibuleo, así como las que se generan en sus relaciones interétnicas.

Por último, en el capítulo 4 analizo el Diseño del artefacto vestimentario de la mujer chibuleo como elemento diacrítico de la identidad de este pueblo y evidencia de su resignificación dialéctica. Explico el Diseño indumentario de la mujer chibuleo y sus transformaciones - cambio, combinación, adaptación, adopción, readopción, alteración de los usos, y traslado o subversión de la ocasión de uso-, que registro en un análisis articulado del Diseño de Indumentaria y la Antropología. 


\section{Capítulo 1: Indumentaria e identidad chibuleo}

Este capítulo tiene por objeto presentar a los chibuleo, describiendo las particularidades del espacio geográfico en el que se ubican, así como explicitando las estrategias de diversificación económica que han desarrollado en el período de estudio, destacando asimismo el rol que ocupa la mujer en estas actividades.

En segundo lugar, se expone la metodología en la que se sustenta la tesis, y el marco teórico en el que se inscribe. Además, se desarrollan las técnicas metodológicas aplicadas en el trabajo de campo, y las continuas reorientaciones de esta tesis en el cruce y retroalimentación entre marco teórico y la perspectiva de los actores (Guber, 2012; Matarrese, 2011). En tercer término, se inicia el desarrollo del recorrido teórico que guiará la investigación, explorando los conceptos y elementos del campo del Diseño que, en su articulación con las teorizaciones propias de la construcción de identidad étnica, permiten explicar los fenómenos de estudio propuestos. Desde el Diseño, se analiza a la indumentaria o a los objetos, principalmente, como artefactos. El concepto de identidad étnica es estudiado desde la perspectiva de la Antropología interpretativa propuesta por Geertz. Por último, se expone el estudio de las prendas y accesorios de la indumentaria de la mujer.

\subsection{Los chibuleo}

El pueblo chibuleo está localizado al suroeste del cantón Ambato ${ }^{4}$ (Caluña et al., 2008; Guerrero, 1990; Rowe, 1998), en la provincia de Tungurahua ${ }^{5}$ (Figura 1). Ubicado a una altura de 3000 metros sobre el nivel del mar, tiene un clima frío y lluvioso con repentinos cambios climáticos (Guerrero, 1990).

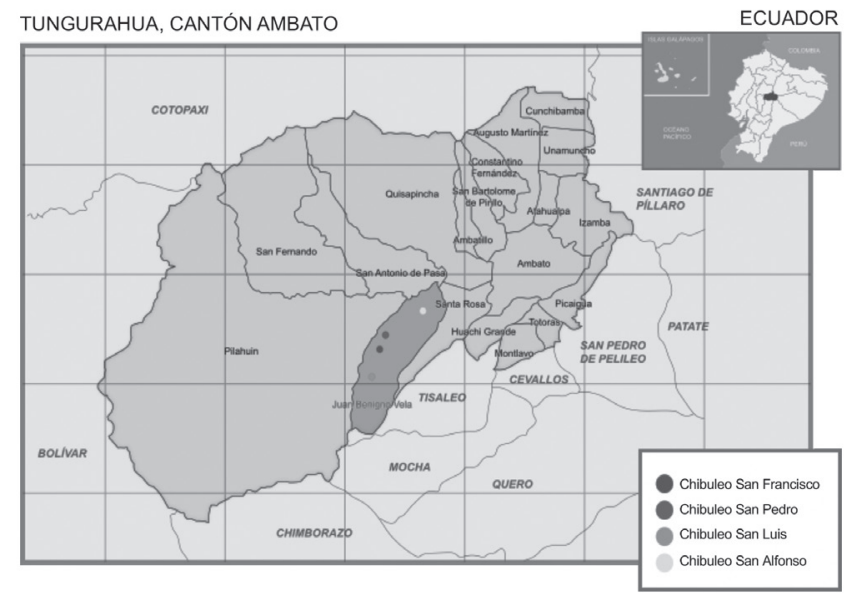

Figura 1. Ubicación geográfica de las comunidades Chibuleo en Tungurahua. Fuente: Elaboración propia. 
Las comunidades chibuleo han permanecido en la misma zona, es decir, al suroeste del cantón Ambato, aunque con desplazamientos internos, desde antes de la conquista española (Rowe, 1998). Dentro de esta localización, las comunidades se vincularon, desde la colonia, a la parroquia de Santa Rosa (Guerrero, 1990).

Los chibuleo se ubican en las comunidades Chibuleo San Francisco, Chibuleo San Pedro, Chibuleo San Luis y Chibuleo San Alfonso (Caluña et al., 2008). Este pueblo indígena destaca, principalmente, por dos factores. La primera es su activa participación en la reivindicación de los derechos de su etnia, iniciada en los levantamientos de 1990 y sostenida desde entonces. La segunda refiere al proceso de diversificación económica que desarrolla desde la década de 1970, como producto de las dinámicas de desarrollo implementadas en la provincia de Tungurahua.

Los chibuleo, residen en un terreno alto y frío, que no permite la diversificación de los cultivos. Sus habitantes, mayoritariamente, se dedican a la producción de ajo, cebolla y variedades de papas (Naranjo, 1992; Guerrero, 1990). Estas particularidades del suelo constituyen un elemento distintivo de Tungurahua.

Las características territoriales de Tungurahua, como la estructura de la tenencia de tierras, la ubicación de la provincia y principalmente de Ambato, que es el centro de comercio interregional (Ospina et al., 2011a), y las dinámicas económicas tungurahuenses, son tres características que se interrelacionan e influyen en el mencionado proceso de diversificación económica de los chibuleo. Históricamente, la provincia de Tungurahua se destaca por la temprana desaparición de las haciendas y la consolidación de la tenencia de tierra basada en pequeñas propiedades. Estas últimas, cumplen un rol destacado dentro de las condiciones favorables que se le atribuyen al dinamismo comercial de la provincia. Durante el siglo XX, específicamente entre las décadas de 1920 y 1930, la subdivisión de la propiedad por el mercado de tierras se aceleró. Los chibuleo destinaron parte de sus parcelas y tierras comunales a cultivos de ajo y cebolla (Guerrero, 1990; Naranjo, 1992). Asimismo, debido a sus vías de acceso cercanas a la ciudad de Ambato, podían comercializar estos productos en las ferias y mercados, incorporándose de esta forma a la dinámica económica de la provincia.

Desde mediados del siglo XX, Ambato continuó su crecimiento y centralización de la producción y el comercio, y se constituyó en el centro de comercio de la Sierra central, apoyado en las dinámicas económicas y la tenencia de tierras tungurahuenses. Los chibuleo, por su ubicación cercana a las ferias y mercados de la ciudad, se vieron influenciados tempranamente por estas dinámicas económicas, así como también por el sistema de tenencia de tierras.

La red de ferias tungurahuenses generó que el mercado nacional se desplazara a Ambato, incentivando la producción en esta zona. Como consecuencia de este desplazamiento, se redujeron los costos de transporte e intermediación de los productores directos, favoreciendo particularmente a quienes se ubicaban en las cercanías de estas zonas. Hacia 1970, en la feria de Ambato, los compradores podían obtener las mercancías del productor local de manera directa, a precios más accesibles.

La red de ferias tungurahuenses y la corta distancia a la que se ubican los chibuleos de la ciudad de Ambato, constituyó una oportunidad para este grupo. Por una parte, comercia- 
lizan en la ciudad sus productos cosechados, y también los obtenidos a través de la intermediación de los indígenas pilahuin. Por la otra, a partir la conexión comercial de larga distancia que Tungurahua establece con otras provincias, tienen la posibilidad de dirigirse a otras ciudades, e incorporar nuevas estrategias comerciales.

En la dinámica económica de Tungurahua, las familias se dedican a estas dos fases, de producción y comercialización. La cercanía de los productores a la red de ferias, constituyó un elemento definitorio en esta relación, en tanto facilitó el acceso directo al comercio. Una de las modalidades en que los chibuleos desarrollan esta dinámica, es mediante la producción de ajo y cebolla, que luego comercializan desarrollando actividades de intermediación con zonas indígenas más altas, en las que el acceso es limitado. El cambio de productores a comerciantes, además de la intermediación que ejercen en Tungurahua, le imprimió, tanto al pueblo chibuleo como a la zona, una diversificación económica que se constituyó como una de sus dinámicas distintivas.

El manejo exitoso, hecho por los chibuleo, de las actividades económicas, les permitió acumular un capital significativo. Dicho capital fue reinvertido fundamentalmente en dos núcleos: la profesionalización de sus hijos, por un lado, y la formación de cooperativas de ahorro y crédito indígenas, por el otro. Puntualmente, las mujeres son las promotoras de la diversificación económica chibuleo, por estar inmersas en las dinámicas económicas de Tungurahua. Si bien ya en la década de 1960, tenían una presencia mayoritaria en esta provincia en términos poblacionales ${ }^{6}$, entre 1990 y 2001 esta presencia se acentúa entre la población económicamente activa (PEA) con respecto al promedio nacional (Ospina et al., 2011b).

En Tungurahua, las mujeres "constituyen una base fundamental para la innovación, la experimentación económica y la diversificación productiva" (Ospina et al., 2011b, p. 182). Este fenómeno se produjo con el cambio paulatino, pero sostenido, de los roles desempeñados por hombres y mujeres como proveedores económicos de las familias en la zona occidental $^{7}$ de la provincia.

Los hombres, al no encontrar en la agricultura ${ }^{8}$ fuentes de ingreso económico que les permitieran sostener a sus familias, buscaron actividades de empleo no agrícola, fuera de la comunidad. Mientras tanto, las mujeres se quedaron a cargo de estas actividades, e iniciaron otras complementarias, como la crianza de animales, la venta informal de productos agrícolas y artesanías, además de la creación de bancos comunales (Ospina et al., 2011b). Es decir, que las mujeres se insertaron en actividades económicas de menor tamaño, menor rentabilidad y reciente creación.

El papel subordinado de las mujeres en la familia chibuleo, resulta funcional a la generación de trabajos complementarios, lo que las fue convirtiendo en "protagonistas de una serie de emprendimientos de diversificación” (Carrión, 2011, p. 241). Estos emprendimientos se conformaban por negocios autónomos, pequeños y de experimentación, así como actividades riesgosas en las que se desconoce las posibilidades de acierto. Los negocios exitosos pasan a manos de los hombres, pues según el criterio de estos, al transformarse en negocios principales tienen mejor porvenir bajo su dirección (Ospina et al., 2011b). Es decir, que mientras las actividades económicas complementarias son pequeñas, las desempeñan mujeres, y las que prosperan pasan a ser dirigidas por los hombres. 
Un ejemplo de lo expuesto en el párrafo anterior son los bancos comunales ${ }^{9}$ indígenas, que siendo dirigidos inicialmente por mujeres, una vez que progresan desembocan en "la formación de cooperativas de ahorro y crédito [que] es siempre una actividad masculina en las regiones indígenas" (Ospina, y otros, 2011b, p. 181). Es el caso de la cooperativa de ahorro y crédito Mushuc Runa, que "se originó en su experiencia como banco comunal, donde es fundamental el papel de las mujeres" (Carrión, 2011, p. 242), y hoy es la entidad financiera indígena más destacada - al menos dentro de la provincia-, dirigida por un chibuleo.

Habiendo presentado al pueblo chibuleo, su ubicación geográfica y sus dinámicas económicas, y puntualizado el rol de la mujer en dicho circuito, a continuación desarrollo las diversas elecciones y reorientaciones metodológicas que realicé.

\subsection{Puntos de partida. Consideraciones metodológicas}

El estudio de la indumentaria de la mujer indígena, a través del caso del pueblo chibuleo, que propongo, se desarrolla desde una metodología de investigación interpretativa (Ynoub, 2015), y por ende, es de carácter cualitativo (Hernández, Fernández y Baptista, 2014; Ynoub, 2015). Es ampliamente reconocida la utilidad de las investigaciones cualitativas para el análisis de investigaciones en Diseño (García, 2016; Margolin, 2005; Vilchis, 2016), dado que "por lo general son estudios que abordan asuntos [...] antropológicos de modo que involucran sujetos humanos como objeto de esas investigaciones" (Ynoub, 2015, p. 181). En este caso, analizo los usos y transformaciones vestimentarias de la mujer chibuleo, considerando las prácticas del vestir desde una posición subjetiva, y a la indumentaria como objeto - artefacto- de diseño.

En este sentido, la tesis se inscribe dentro de las investigaciones sobre Diseño (Margolin, 2005, 2012; Manzini, 2015; Milton y Rodgers, 2013; Simón, 2016) "que ayuda[n] a comprender la naturaleza del diseño" (Manzini, 2015, p.50). La estrategia metodológica que utilizo se desarrolla "desde los datos a la teoría" (Ynoub, 2015, p. 40), direccionamiento que avanza mediante inferencia inductiva, en tanto la interpretación general surge de los casos particulares (Ynoub, 2015), y es una estrategia propia del paradigma cualitativo.

Las hipótesis sustantivas y de trabajo que formulo, son interpretativas, en tanto establecen vínculos significantes entre la indumentaria y los hechos que reivindican la identidad chibuleo. Las hipótesis generadas, acorde al avance de la investigación de la indumentaria chibuleo desde el Diseño, dieron paso a continuos replanteos teóricos y conceptuales, fundamentados en las diversas instancias del trabajo etnográfico. Hipótesis de las que se desprenden objetivos tanto generales como específicos, que partieron de la descripción y la explicación (Ynoub, 2015), para modelar los objetivos interpretativos.

Asimismo, se utilizó el método etnográfico propuesto por Guber (2012), entendiéndolo como "el conjunto de actividades que suele designarse como 'trabajo de campo', y cuyo resultado se emplea como evidencia para la descripción” (p. 19). En el método etnográfico, los actores y el investigador interactúan. Los primeros son "los privilegiados a la hora de expresar en palabras y en prácticas el sentido de su vida, su cotidianidad, sus hechos extraordinarios y su devenir" (Guber, 2012, p. 19). Mientras que, el investigador, es "un 
sujeto cognoscente que deberá recorrer el arduo camino del des-conocimiento al reconocimiento" (Guber, 2012, p. 19). En este sentido, el investigador hace un acercamiento a la realidad que analiza para aprender de ella, con el fin de interpretar-describir una cultura y hacerla comprensible ante quienes no pertenecen a ésta.

A través de la etnografía, fue posible establecer descripciones y explicaciones para la interpretación de los datos recogidos, identificando categorías nativas tales como: las mamas, las profesoras, las de las cooperativas, respeto, vestimenta propia, vestimenta de la cultura y uniforme propio. Dichas categorías son explicadas y analizadas en profundidad a lo largo de la tesis. Como parte de la retroalimentación entre la teoría y el trabajo de campo, se originaron continuas reformulaciones (Guber, 2012; Matarrese, 2011), que me llevaron a pensar que estaba de vuelta al inicio.

Como es propio del método etnográfico, se trabajó con informantes clave. Primero identifiqué a los referentes chibuleo - que cuentan con la anuencia de la comunidad-, todos hombres, a excepción de una mujer. En segundo lugar, a partir de las sugerencias de mis referentes chibuleo, fui contactando a otras mujeres que podían proporcionar más datos, o ampliar la información sobre los chibuleo y la indumentaria, como parte de la técnica de la bola de nieve, muestra en cadena o por redes (Creswell, 2013b; Hektner, 2010; Henderson, 2009; Miles y Huberman, 1994).

Las técnicas que utilizo son la observación participante (García, 2016; Guber, 2012; Hernández et al., 2014; Ynoub, 2015), la participación observante (Guber, 2012) y la entrevista; técnicas que aportan al "proceso de diseño en dos momentos: uno de registro y otro de sistematización” (García, 2016, p. 218). Respecto a las entrevistas, por un lado aplico la "entrevista en profundidad o no dirigida" (Guber, 2012, p. 40) y, por el otro, con menor énfasis, recurro a entrevistas semiestructuradas (Hernández et al., 2014; Ynoub, 2015) con una guía de preguntas y el conocimiento del tema, que me permitió introducir preguntas adicionales para aclarar conceptos y obtener información (Hernández et al., 2014; Ynoub, 2015), más allá de lo advertido en un primer momento.

Una vez establecidas las decisiones metodológicas pertinentes, a continuación se explica el proceso en profundidad, y las continuas reformulaciones entre los datos y la teoría que implicaron un retorno al momento inicial.

\subsubsection{De vuelta al inicio}

A finales del año 2014 y con el objetivo de indagar los usos de la vestimenta de la mujer chibuleo, inicié mis visitas de campo en la comunidad de Chibuleo San Francisco, ubicada a unos 16 kilómetros de la ciudad de Ambato. La elección de Chibuleo San Francisco se debió a dos razones: esta comunidad es la central del pueblo y alberga la mayor población chibuleo; además, allí se inauguró — en mi primer día de visita—, una de las Unidades Educativas del Milenio ${ }^{10}$ indígenas creadas por el gobierno, la Unidad Educativa del Milenio (UEM) Chibuleo.

Analizar la indumentaria de la mujer chibuleo implicó un proceso constante de reformulación que he denominado "de vuelta al inicio". Al empezar la investigación doctoral, mi 
registro de la vestimenta chibuleo se relacionaba con fiestas y costumbres, principalmente en instituciones educativas, y en las cooperativas de ahorro y crédito chibuleo. A través de diversas estadías de campo, descubrí que mis interlocutores relacionaban el uso de la indumentaria chibuleo, por un lado, con la lucha indígena por la reivindicación de sus derechos, y la consecuente formación de instituciones, que si bien garantizan el derecho a la educación bilingüe e intercultural, también norman el uso vestimentario al interior de las mismas. Por el otro, con taytas y mamas, que son indígenas que aún portan lo que en términos chibuleo puede considerarse vestimenta indígena ${ }^{11}$.

En mi primer día de trabajo etnográfico, el 14 de noviembre de 2014, en las afueras de la UEM Chibuleo - día de inauguración oficial y en el que se esperaba la visita del, por ese entonces, presidente de la República del Ecuador, Rafael Correa-, toda la comunidad portaba vestimenta propia: era un día de fiesta. Desde mi automóvil, tomaba fotos sin permiso, ya que me intimidaba que mi esposo y yo fuéramos los únicos con vestidos no indígenas. Cuando decidí bajar del auto, y solicitar permiso para tomar fotos —impulsada por la insistencia de mi esposo-, en su mayoría me encontré con personas amables y dispuestas a permitirme fotografiarlas.

Así ocurrió con un grupo de personas, que subían la cuesta por las afueras del costado de la UEM Chibuleo, y que en mis registros quedó testimoniado de la siguiente manera:

Una vez que vencí el temor, me acerqué a un grupo de chibuleos y pedí que me dejaran tomar una foto. Se trataba de cuatro integrantes de una misma familia, tres mujeres y un hombre todos con vestimenta propia, excepto por la de menor edad -13 años aproximadamente-. Esta última portaba casi en su totalidad prendas no indígenas, solo un rebozo era de procedencia chibuleo y lo utilizaba enrollado en la cabeza para cubrirse del intenso sol del mediodía. Para la foto las mujeres chibuleo se acomodaron su vestimenta y quitaron el rebozo de la cabeza de la joven de menor edad. Este hecho despertó mi curiosidad y pregunté por qué no portaba vestimenta chibuleo. La respuesta que me dieron fue que "ella ya no viste así después de la escuela". (Notas de campo, Chibuleo San Francisco, noviembre 2014)

Luego de varias visitas realizadas durante el trabajo de campo, comprendí que el hecho de permitirme tomar fotos sin poner ningún impedimento, no era fortuito. Aquel día, el 14 de noviembre de 2014, todos vestían con la mayoría de las prendas y accesorios de la vestimenta propia, a diferencia de otros días. Los chibuleo no siempre estaban dispuestos a dejarse fotografiar, excepto cuando portaban vestimenta propia, y me lo hicieron saber en reiteradas ocasiones, de formas verbales y no verbales. Para la fotografía se deshacían de prendas no indígenas, como las chompas, y se acomodaban las indígenas, como el rebozo, la bayeta y la lishta, en el caso de las mujeres; y el poncho, en el caso de los hombres. La investigación de campo demandó el estudio de tres ámbitos. El primero está formado por las comunidades del pueblo: Chibuleo San Francisco, Chibuleo San Pedro y Chibuleo San Luis. El segundo ámbito fue la entidad educativa UEM Chibuleo. El tercero estuvo constituido por tres entidades financieras, las cooperativas de ahorro y crédito: Mushuc Runa, Chibuleo y Kullki Wasi. 
La primera etapa, desarrollada entre los años 2014 - noviembre - y 2015 —enero, febrero, junio-, estuvo enfocada en estudiar la vestimenta de la mujer chibuleo, y los cambios sociales ocurridos en el pueblo desde el levantamiento de 1990. En esta etapa se desarrollaron entrevistas, por una parte, a dirigentes comunitarios y políticos chibuleo que son autoridades del pueblo; por la otra, a representantes de la cooperativa Mushuc Runa, que a su vez son líderes comunitarios, uno de ellos incluso ex concejal de la ciudad de Ambato. El análisis de la información surgida de las entrevistas, fue complementado con el estudio de fuentes secundarias tales como fotografías y documentos de la época.

En una segunda instancia, desarrollada en el año 2016 - enero, abril y mayo- en concomitancia con el relevamiento bibliográfico y principalmente hemerográfico -en razón de la escasa bibliografía referida a los chibuleo que se mencionó en la Introducción-, realicé entrevistas en profundidad a autoridades educativas, y también efectué una segunda ronda de entrevistas a los dirigentes políticos y comunitarios. Lo anterior tuvo el fin de cruzar datos, así como de formular y reformular preguntas. Este trabajo fue, asimismo, complementado con observación participante en las comunidades del pueblo, y en la UEM Chibuleo.

En la tercera etapa investigativa - entre octubre y diciembre de 2016-, estudié los nexos de la indumentaria con las instituciones educativas y financieras, y con las comunidades del pueblo. Asimismo, comencé a observar e indagar los usos vestimentarios normados por las entidades, y los aceptados por los chibuleo, a través de entrevistas en profundidad, y observación participante, en el pueblo y en las instituciones.

Todo estudio en campo requiere de interlocutores y, para el año 2014, mis visitas a las comunidades chibuleo para observar sistemáticamente la indumentaria de las mujeres del pueblo, resultaron insuficientes. La investigación demandaba relacionarme con personas que pudieran proporcionar datos certeros respecto a los chibuleo. La forma en que inicié los contactos con quienes se convertirían en mis informantes clave chibuleo, fue a través de una red de referencias y recomendaciones que procedió de dos personas amigas. La primera que proveyó información acerca de autoridades del pueblo, y la segunda me puso en contacto con líderes comunitarios, que a su vez eran representantes de la Cooperativa de Ahorro y Crédito Mushuc Runa —entidad financiera indígena-. Así comenzó la primera etapa del trabajo en campo.

En esta etapa, entonces, por un lado trabajé con dos autoridades del pueblo: mama Tránsito Manobanda ${ }^{12}$, presidenta de la Unión de Organizaciones del Pueblo de Chibuleo (UNOPUCH), y Agustín Punina ${ }^{13}$, técnico de la Unidad de los Movimientos Indígenas y Campesinos de Tungurahua (UMICT). Ellos, a su vez, me contactaron con el tayta Juan José Lligalo ${ }^{14}$, referido como una autoridad del pueblo, además de una persona idónea para abordar los temas indumentarios.

La indagación en campo fue distinta de lo que supuse a priori. Si bien la aplicación de la entrevista en profundidad, que planteé para iniciar la investigación, no implicaba formular un cuestionario semi estructurado - y mucho menos estructurado-, precisé varios puntos a tratar en forma de preguntas, con la finalidad de que las entrevistas condujeran a explorar las variables que me interesaba indagar.

Sin embargo, resultó prácticamente imposible seguir el ritmo de los cuestionarios, ya que las respuestas ofrecidas por las autoridades chibuleo - mama Tránsito Manobanda y Agustín Punina-, y principalmente las de del tayta Juan José Lligalo, por momentos 
referían a aspectos que no respondían tanto a mis intereses de investigación. Más aún, el tayta, antes que hablar acerca de lo que yo insistentemente preguntaba, se empeñaba en relatar su historia de vida, que según mi perspectiva y desesperación del momento, nada tenía que ver con la vestimenta. Sólo las preguntas iniciales fueron de utilidad, como disparadoras e hilos conductores. Luego surgieron otras dudas, pues como lo indica Guber (2012), en "la entrevista etnográfica el investigador formula preguntas cuyas respuestas se convierten en nuevas preguntas" (p.77).

Asimismo, luego de leer varios escritos que reflexionan sobre la experiencia etnográfica (Bourgois, 2010; Guber, 2013; Matarrese, 2011), decidí escuchar con atención la historia del tayta, que había estado atravesada por su participación en los levantamientos indígenas de 1990 y las dirigencias políticas, la educación bilingüe y las cooperativas. Relato que de momento no pude valorar en su justo peso, pero posteriormente comprendí que había sido en dicho transcurso histórico, en el que cobró un nuevo sentido la indumentaria de las mujeres chibuleo. Además, escuchar su historia constituyó la clave para obtener su confianza, y ello condujo a que las intervenciones en las siguientes entrevistas fueran más fluidas.

Los contactos que siguieron dentro del pueblo tuvieron su norte en las necesidades mismas de la investigación. Mis continuas visitas al tayta Juan José Lligalo, en su lugar de trabajo, demandaron mi presentación con el Rector de UEM Chibuleo, Alberto Guapiza$\mathrm{ca}^{15}$, quien en una siguiente instancia investigativa facilitó mi acceso a la unidad educativa - personal administrativo, docentes y estudiantes-, y proporcionó documentación para el desarrollo de la labor de campo.

Además, la presentación directa con Luis Alfonso Chango ${ }^{16}$, gerente de la Cooperativa de Ahorro y Crédito Mushuc Runa, y con quien era su mano derecha, Bernardo Tuza ${ }^{17}$ - ex concejal de la ciudad-, me abrió las puertas para desarrollar mi pesquisa con las trabajadoras de la institución, respecto a los usos de la indumentaria chibuleo. Es así como logré conversar con Isabel Capúz ${ }^{18}$, a quien sus compañeras de trabajo reconocían y referenciaban como portadora de vestimenta chibuleo original y completa. Para mi sorpresa, ella no era chibuleo sino pilahuín, ${ }^{19}$ casada con uno de los hijos del tayta Nazario Caluña. Fue Isabel Capúz quien posteriormente me presentó con una de las autoridades educativas, su esposo Tupac Caluña ${ }^{20}$.

En suma, con todos los datos de campo obtenidos en esta primera etapa, luego de un ejercicio reflexivo, la investigación se direccionó no sólo a indagar la indumentaria a partir del levantamiento de 1990 y sus consecuencias sino a incorporar otros hitos e instituciones como los mencionados. Estas constantes reformulaciones teóricas, y la ansiedad de avanzar con el proyecto doctoral, sólo me permitían pensar que estaba de vuelta en el inicio. En la segunda instancia de campo, que inicié en enero 2016, trabajé con las autoridades educativas, como los ya mencionados Alberto Guapizaca y Tupac Caluña. Estudié el tema de la indumentaria en el marco del acceso a la educación bilingüe y superior, como el resultado de una de las reivindicaciones indígenas plasmadas en la Constitución, fruto de los levantamientos de la década de 1990. Asimismo, pude sopesar la destacada labor de las instituciones financieras y las instituciones educativas bilingües que, según expresa Tupac Caluña, han estado "rescatando de generación en generación costumbres y tradiciones de acá del pueblo chibuleo" (Entrevista con T. Caluña, Chibuleo San Francisco, 2016). 
En esta instancia realicé observaciones con y sin participación. Incluirme en las actividades del sujeto observado requirió confianza, y en ese sentido tardé más de un año de trabajo con la comunidad, hasta verme un día sentada en el patio de tierra y césped de la casa de uno de mis informantes, pelando papas junto a una familiar suya, una warmi kuna —es decir, adulta - chibuleo. En aquel entonces, preparábamos comida para las personas que estaban por llegar al pueblo, para grabar un segmento del programa televisivo PluriTV y mostrar, según sus palabras, "las costumbres y tradiciones" de los chibuleo.

Días más tarde, fui invitada por otro informante a su domicilio. Llegué muy temprano en la mañana y observé el ambiente previo a la entrevista, que difirió significativamente del que reinó durante la entrevista misma, hecho que registré en mi cuaderno de campo, del modo que recupero a continuación:

Es la fiesta de Reyes Magos en Chibuleo, y encuentro a mi futuro entrevistado preparando a su hijo para que participe en la cabalgata. Mi impertinencia hace que intente tomar fotos de este acto familiar, en el que el padre - mi entrevistado- porta indumentaria no indígena, la madre vestimenta propia de casa - un poco desgastada - y el hijo vestimenta propia nueva - de fiesta-. Sin embargo, mi informante en forma respetuosa me dice que no los retrate en ese momento y me conduce a su sala. Al cabo de media hora, se presenta para la entrevista con la vestimenta propia: había abandonado las prendas no indígenas y me pedía disculpas por haberme hecho esperar. Mi curiosidad no dejó escapar el hecho de que estaba con otra indumentaria e hice el comentario de que se había molestado demasiado cambiándose, a lo que él respondió: "es que han de decir no es chibuleo". En ese momento sólo pude pensar en la importancia que le daba a la indumentaria para identificarse como chibuleo y la forma en que este hecho podía ser enlazado a mi tesis. Su esposa - quien mantenía el atuendo inicial— siguió sigilosamente el transcurso de la entrevista fuera del alcance de la cámara, pero con ciertas intervenciones para complementar respuestas, atendiendo en estas ocasiones al pedido de su marido. (Notas de campo, Chibuleo San Francisco, enero de 2016)

Con el tiempo, al involucrarme en las actividades de los chibuleo y experimentar su cotidianidad, comprendí la importancia de mantenerme cerca del sujeto de estudio, para registrar lo que Malinowski (1975) denominaba "los imponderables de la vida real" (p. 36), ya que ello colaboraba en el desarrollo del trabajo de campo a partir de los actores, y no desde el sesgo del investigador. Asimismo, el relevamiento hemerográfico corroboró y nutrió los datos proporcionados por informantes clave, para identificar los hitos representativos de los chibuleo, que intervinieron en la transformación y uso de la indumentaria en las instituciones.

Hasta ese momento, los resultados de la investigación apuntaban a la política indigenista suscitada por la reivindicación de derechos, y destacaban el uso vestimentario normado en las instituciones UEM Chibuleo y entidades financieras chibuleo. El trabajo que realicé una vez desarrollado el campo, fue, tal como menciona Hermite "un cuidadoso ciclo de 
escrituras, lecturas y reescrituras organizando en temas, jerarquías y relaciones de la información recogida" (IDES, 2001, p. 77). En efecto, desgrabé entrevistas, desarrollé cuadros comparativos e identifiqué términos nativos - como respeto y uniforme propio- que surgieron como denominadores comunes en las entrevistas. A partir de este análisis, cobró relevancia el uso normado de la vestimenta en las instituciones, y el disciplinamiento de los cuerpos (Foucault, 2015) que éste implica.

En definitiva, luego de más de dos años investigando a nivel bibliográfico y en campo, logré generar nuevas reflexiones etnográficas que, junto con el análisis de la estructura metodológica de la tesis de mi directora, Dra. Marina Matarrese (2011), me permitieron identificar que el proceso de vuelta al inicio que había experimentado formaba parte del proceso. Mi estudio de campo finalmente había avanzado, y las reformulaciones teóricas a desarrollar eran indiscutibles. Todo el camino recorrido durante la investigación doctoral me había conducido hasta ese punto. El próximo paso era, entonces, regresar al campo. En una última etapa, la investigación en campo requirió indagar los usos indumentarios y sus transformaciones de manera simultánea en los tres ámbitos: comunidades del pueblo, instituciones educativas y entidades financieras. En este punto fue necesario, por un lado, contar con más referentes de mamas chibuleo, así como informantes profesoras de la UEM Chibuleo, y mujeres de las cooperativas que testimoniaran los usos indumentarios cotidianos. El análisis relacionado con estas informantes es detallado en el capítulo 3.

Por el otro, fue necesario analizar instituciones financieras chibuleo destacadas además de Mushuc Runa, que dieran cuenta de usos normados de la vestimenta. Inicié una nueva ronda de entrevistas con el tayta Juan José Lligalo, seguida por otras con autoridades del pueblo, y también con las autoridades educativas. El procesamiento del contenido de estas entrevistas reforzó la noción del liderazgo de Mushuc Runa, Chibuleo y Kullki Wasi, entre las cooperativas de ahorro y crédito más destacadas.

Asimismo, trabajé con referentes chibuleo mujeres, como la mama Andrea Pacari, esposa del tayta Juan José Lligalo; mama Juana Til, esposa del tayta Nazario Caluña; y mama Juana Pandashina, esposa de Cristóbal Caluña. Resultó importante el hecho de que tanto las mamas como las profesoras de la UEM Chibuleo, refirieron a Martha Lligalo ${ }^{21}$ como la persona que inició las transformaciones de la indumentaria en el pueblo.

Luego de reconocer en las etapas anteriores la importancia de no encarar directamente el tema, es decir, "no ir al grano", para así obtener una mejor fluidez del relato (Guber, 2012, p. 80), continué con las entrevistas en profundidad, pero en este caso formuladas a partir de las categorías nativas, lo que me permitió, como indica Guber, "el descubrimiento de las preguntas significativas según el universo cultural de los informantes [...] para llegar a conocer los sentidos locales" (p. 80), y desarrollar el proceso etnográfico articulando las entrevistas con la observación participante.

En definitiva, en mis estancias de campo anteriores, cuando refería a la indumentaria de la mujer chibuleo y sus transformaciones, mis informantes se detenían en temas que en su momento no parecían tener un fuerte vínculo con mis estudios. Fueron escasos los datos etnográficos recopilados respecto a las formas en que se había transformado la indumentaria. En cambio, obtuve información respecto a la lucha indígena por el acceso a derechos, la relevancia de los levantamientos de 1990 en el reconocimiento constitucional 
y la labor de las instituciones financieras - cooperativas de ahorro y crédito indígenas- y la UEM Chibuleo, que luego lograría vincular con las transformaciones de los usos vestimentarios. A continuación, se presentan las prendas y accesorios de la mujer chibuleo, a partir de la bibliografía disponible del pueblo, que se complementan con los estudios de otros pueblos andinos.

\subsection{Tipología indumentaria de la mujer chibuleo}

La vestimenta de la mujer chibuleo, constituye un diacrítico identitario (Barth, 1976). Defino como indumentaria chibuleo, o vestimenta chibuleo, a las prendas y accesorios que portan las mujeres, y que ellas consideran parte de la vestimenta propia. Estas prendas son: anaco, chumbi, rebozo, bayeta, lishta, tupulli y camisa. Los accesorios son: sombrero, tupu, wallkas y orejeras (Ver Figura 2).

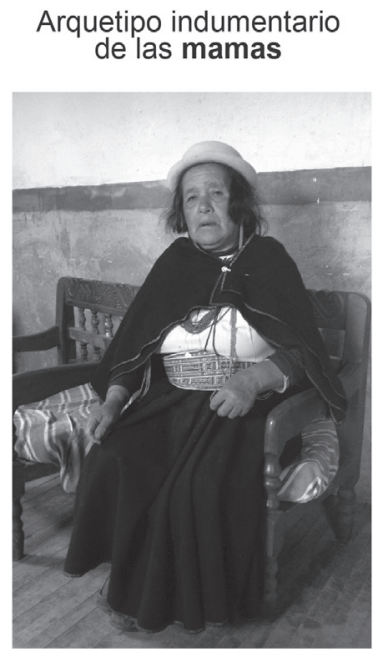

Vestimenta propia

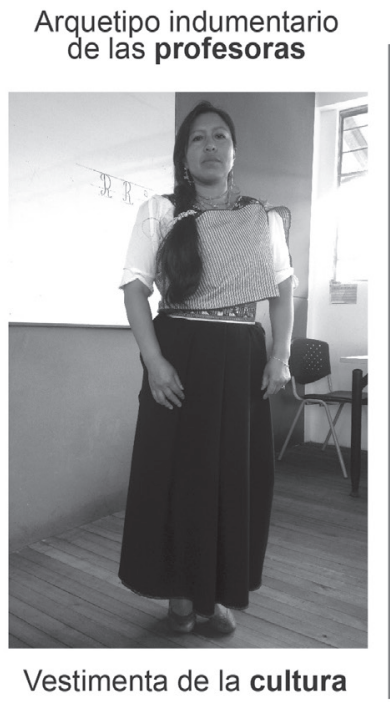

Arquetipo indumentario de las mujeres de las cooperativas

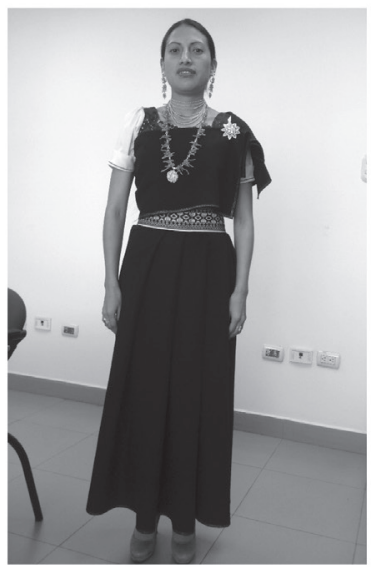

Uniforme propio

Figura 2. Tipología indumentaria de los tres arquetipos vestimentarios de las chibuleo. Las mamas con vestimenta propia, las profesoras con vestimenta de la cultura y las mujeres de las cooperativas con uniforme propio (Fuente: Elaboración propia). 


\subsubsection{Anaco}

$\mathrm{El}$ anaco es una prenda utilizada por las culturas surandinas. Habitualmente es de color enteramente negro o azul22 (Camelo, 1994; Jaramillo, 1990; Vicuña, 2008); sin embargo, también puede tener líneas de colores en sentido horizontal (Vicuña, 2008).

Con respecto al uso del anaco por parte de los chibuleo, en los estudios de Rowe (1998) se describen como faldas envueltas (anaku), de una medida aproximada de 76 centímetros de ancho y 3 metros de largo, con bordados hechos a máquina. Con frecuencia presentan una decoración sencilla, pero algunos tienen bordes más complejos.

En cuanto al color de los anacos chibuleo, los estudios realizados por Rowe (1998) en 1988 encuentran que generalmente eran de color azul marino y en ocasiones negro, colores que coinciden con los usados por los indígenas otavalos (Jaramillo, 1990). Sin embargo, Caluña et al. (2008), además de estos dos colores, menciona que el atuendo chibuleo era, originariamente, de color negro-café, ya que es el color de la lana de borrego, denominado jergueta (Caluña et al., 2008, p. 30) ${ }^{23}$.

De este modo, es posible afirmar que la tendencia al uso de color negro o azul en las comunidades chibuleo, en prendas de materiales sintéticos, no sólo tiene relación con la industrialización de los tejidos y prendas andinas; también se vincula a un cambio de estatus (Bourdieu, 2012), evidenciado en el color y tipo de tejido, elementos que expresan un tipo diferente de capital económico (Bourdieu, 2012) dentro de la jerarquía indígena. Respecto al material de los anacos chibuleo, Rowe (1998) identifica que el tejido de acrílico se introduce a fines de la década de 1970, cuando se reemplaza el material de fibra natural animal por fibra sintética. Sin embargo, en el desarrollo de mis investigaciones etnográficas, pude advertir que en la práctica existe una coexistencia de los dos materiales. En efecto, en 2016 las mujeres utilizaban anacos tejidos en acrílico, y algunas mamas conservaban anacos de lana de borrego.

Otra característica importante del anaco chibuleo es su forma de uso. Rowe (1998) sostiene que, entre fines de la década de 1980 e inicios de la década de 1990, las mujeres portaban entre cuatro y siete anacos, de forma rectangular y confeccionados en lana o acrílico, en color azul o negro, con filos bordados de costura recta o en zigzag realizados a máquina. Cada uno se coloca formando pliegues en la parte superior, y cubren hasta las rodillas o, máximo, hasta media pantorrilla.

\subsubsection{Chumbi}

El chumbi $i^{24}$ es una faja que forma parte de la indumentaria de hombres y mujeres (Vicuña, 2008) ${ }^{25}$. Rowe (1998), en sus análisis etnográficos, describe el uso del chumbi en relación con el anaco - con pliegues - que lo sostiene. Es decir, que la mujer chibuleo utiliza el chumbi para envolver y sostener el anaco, evidenciando una de las funciones prácticas o de utilidad del objeto vestimentario (Fernández, 2015a; Lobäch, 1981). 
El estudio específico de la indumentaria chibuleo que hace Rowe (1998), señala dos tipologías de chumbis: cuando menciona la forma en que las mujeres se colocan este accesorio una faja más ancha se coloca primero (jatun chumbi Q.) y luego dos más pequeñas (uchilla maki chumbi Q.) [...] o dos o incluso tres de cada una pueden ser usadas.

Para el caso del jatun chumbi, Rowe (1998) muestra una fotografía de una faja de $297 \mathrm{~cm}$. x 9,5 cm. de dimensión, y para uchilla maki chumbi, otra de $285 \mathrm{~cm}$ x 7,5 cm, ambas de algodón color blanco y tejido liso de acrílico de color. Es decir que su diferencia radica en las dimensiones, ya que los materiales utilizados son los mismos.

Sin embargo, Rowe (2011) en sus estudios acerca de los pueblos Otavalo, Pichincha y Chimborazo, aborda la utilización de la mama chumbi como una faja interior ancha. Los que se usan en Otavalo, Pichincha y Chimborazo Central son rojos con bordes verdes y tienen cuatro orillos y una pesada trama de cabuya (a veces de algodón). La wawa chumbi se utiliza como una faja larga y estrecha sobre la mama chumbi. Estos dos nombres de chumbi mencionados por Rowe (2011), para referirse a otros pueblos distintos de los chibuleo, coinciden con lo relevado en mis estudios etnográficos.

\subsubsection{Rebozo o bayeta y lishta}

El rebozo es un manto rectangular utilizado a modo de chal (Camelo, 1994; Karasik, 2010; Rowe, 2011). Esta prenda fue identificada y mencionada por primera vez en México, mientras que en Ecuador su uso es más reciente (Rowe, 2011).

Los estudios de Rowe (2011) en Ecuador, definen a la bayeta como un tejido grueso de lana tejida, y sostienen que el nombre de tela equivalente en inglés es baize [paño]. El mismo término se usa a veces para el chal de una mujer indígena en Ecuador. Por lo expuesto, de aquí en adelante me referiré a los términos rebozo o bayeta de manera indistinta, para referirme a esta prenda utilizada por las mujeres chibuleo, si bien no puede afirmarse lo mismo respecto a los materiales.

El material con el que se realizan estas prendas, para la época de mis estudios etnográficos (2014-2016), ya no es el tejido de lana. Rowe (2011), respecto a los chibuleo, sostiene que para la década de 1970 los chales o mantos eran tejidos en lana negra, y para los alrededores de 1979, este material es cambiado por acrílico de color azul y negro. En definitiva, el material de fibra natural animal — lana - utilizado para tejer el rebozo, se sustituye por una fibra sintética.

Otro manto o chal utilizado por las mujeres chibuleo es la lishta ${ }^{26}$. En los estudios de Caluña et al. (2008) sobre los chibuleo, se refiere al uso de esta prenda de rayas rosas o verdes, que se utiliza debajo del rebozo, "prendidas con dos tupus de plata" (p. 32).

Los autores que describen las características de la fachalina son Jaramillo (1990), Maldonado (2012) y Rowe (1998), todos ellos respecto a vestimenta de comunidades que se encuentran en Ecuador. Rowe (1998) indica que la fachalina es un chal de mujer y vestimenta en el área de Otavalo y que este nombre se usa también en Zumbagua, Cotopaxi. Jaramillo (1990) menciona que en Otavalo las mujeres "cubren la espalda con la fachalina, pieza de tela rectangular que se anuda a la altura del pecho" (p. 137). Por su parte, Maldonado (2012) sostiene que la fachalina es una "manta pequeña que las mujeres llevan sobre los hombros" (p. 41). 
Es decir, estos tres autores coinciden en que la fachalina es un chal o manto utilizado por la mujer andina sobre sus hombros, cubriendo su espalda. Características que coinciden con la lishta, pero que también comparte con el rebozo.

En cuanto al material de la fachalina, Jaramillo (1990) menciona que el uso de algodón ha sido gradualmente reemplazado por otros materiales, como el paño en color blanco, azul o negro (Jaramillo, 1990, p. 137). El tipo de tejido de trama y urdimbre de la fachalina, da como resultado una tela listada o a rayas, que es la característica más representativa de la lishta, y lo que la diferencia del rebozo.

La conexión entre la fachalina y la lishta se comprende con el aporte de Rowe (1998) quien sostiene que fachalina es el nombre utilizado en Licto, al este de Chimborazo, para referirse a la misma prenda que las mujeres chibuleo denominan como chal a rayas o lishta. La lishta chibuleo es la fachallina o fachalina a rayas ${ }^{27}$, por lo que en esta investigación se utilizan como sinónimos.

\subsubsection{De tupulli a camisa}

El tupulli y la camisa son prendas que han utilizado los chibuleo en diferentes épocas. En primer lugar, se describe la morfología del tupulli - prenda indígena-, para luego explicar el reemplazo de esta prenda por la camisa que utilizan en la actualidad — prenda no indígena apropiada por los chibuleo-, como un paso previo a exponer las transformaciones de la camisa entre 1990-2016 en el capítulo 3.

Rowe $(1998,2011)$ se refiere al tupulli como tupullina, y la describe como ropa de mujer de uso incaico, envuelta horizontalmente, clavada en cada hombro con un tupu. Descripción que concuerda con el tupulli chibuleo registrado en mis datos etnográficos.

Los estudios de Caluña et al. (2008), específicos del pueblo chibuleo, describen al tupulli utilizado por las mujeres como "una tela de lana borrego de color negro que tomaba la forma de camisa y a los dos hombros prendidos con un tupu pequeño" (p.31). A partir de lo expuesto, se puede describir al tupulli como una manta de lana de borrego que las mujeres se colocaban sujetándola con un tupu en cada hombro, simulando la forma de una camisa. Esta prenda, antecesora de la camisa, fue utilizada hasta la década de 1950.

Los datos bibliográficos que muestran la época en la que se realiza el cambio de la camisa por el tupulli chibuleo, son escasos. Sin embargo, al sumarlos a los estudios etnográficos, es posible caracterizar estos cambios. Por una parte, las investigaciones de Buitrón (1964) permiten establecer que para la década de 1940, en Ecuador aún se utilizaba el tupulli, y de manera simultánea la camisa. Este mismo autor aclara que la manta de lana que se envuelve, es decir el tupulli, es una prenda indígena utilizada antes que la camisa. Por la otra, aun cuando Caluña et al. (2008) no especifica la fecha, sí menciona que entre los chibuleo el tupulli cambia por una "camisa con bordados en los hombros y cuello con hilos de colores" (Caluña, Tisalema y Caluña, 2008, p. 31). A fin de complementar estos datos, y aproximarme al momento histórico en que aparece la camisa en el repertorio indumentario de la mujer chibuleo, recurro a lo expuesto por uno de mis informantes, quien con respecto al uso indumentario de su madre afirma: 
... ella se casó con el tupulli, después que mi padre no sé... habían comprado de un lugar algo así entonces se adaptan tonces sería hace unos 40 o 50 años, 55 años $(1976$ o 1966, 1961) ha de ser que... se ha cambiado esto. (Entrevista con T. Caluña, Chibuleo San Francisco, enero 2016)

Entonces, según Tupac Caluña la camisa aparece entre los chibuleo hacia las décadas de 1960 y 1970, dato que se corrobora con lo expuesto por Agustín Punina: "desde los años '70 o ‘60 se empezó a utilizar las camisas. Porque a... hasta esos años solamente se utilizó el... tupulli” (Entrevista con A. Punina, Chibuleo San Pedro, enero 2016). Es decir que, alrededor de las décadas de 1960 y 1970, se puede situar el inicio del uso de la camisa, entre las chibuleo, de manera alternada con el tupulli.

Sin embargo, el tupulli termina siendo reemplazado definitivamente por la camisa. Tal es así que para 1988, el tupulli ya no forma parte de la indumentaria de la mujer. Para el inicio del recorte histórico de mi investigación, en 1990, el tupulli tampoco es parte de la vestimenta de mujer, y para el último año de mi investigación etnográfica en 2016, las mujeres no sólo no usan tupulli, sino que en muchos casos ni siquiera conocían su existencia. Se evidencia entonces el reemplazo de una prenda por otra. La camisa, que no formaba parte del repertorio indumentario indígena, es adoptada ${ }^{28}$ por las mujeres chibuleo, y transita un proceso de apropiación. También, al incorporarles bordados relacionados a la Pachamama, se produce una innovación (Bonfil Batalla, 1991) en la camisa.

Los estudios de Rowe (2011) indican que la camisa era parte del prototipo europeo rural, sin embargo, este uso de la camisa sigue vigente en la vestimenta propia de las mujeres chibuleo, como doy cuenta a través de mis estudios etnográficos desarrollados en el capítulo 3. Los datos con los que se cuenta respecto de las camisas portadas por las mujeres chibuleo, se registran en los estudios etnográficos de Rowe (1998), desarrollados en 1988. Para esta época la camisa de la mujer chibuleo tiene las siguientes características: manga corta, blanca, de algodón o de tejido sintético, con bordados florales uncidos a un cuadrado. La blusa es relativamente corta, se extiende lo suficiente para ser cubierta por el anaco ${ }^{29}$. Además, la autora señala que la camisa tenía una abertura vertical en el frente, y que el bordado era generalmente de hilo acrílico.

Respecto al material utilizado en las camisas chibuleo, Rowe (1998) en sus estudios de 1988, indica que podían ser de algodón o de tejido sintético, es decir que se utilizaba tanto la fibra natural como la sintética. Las camisas portadas por las mujeres chibuleo en 1988 es el dato más cercano a la década de 1990, fecha de inicio del recorte histórico propuesta en la presente investigación. Por esta razón, y a partir de lo expuesto en párrafos anteriores, infiero las características de la camisa para esta época: manga corta sin puño, cuello redondo con una abertura vertical en el centro frente, y otra abertura en la espalda, de color blanco confeccionada en telas de fibra natural o artificial, y que cuenta con bordados en el cuello y mangas. 


\subsubsection{Accesorios}

Entre los accesorios portados por la mujer chibuleo, a continuación se describen cuatro: el sombrero, el tupu, las wallkas y las orejeras. La bibliografía con la que se cuenta en la mayoría de los casos es escasa, aunque los estudios acerca de los accesorios portados por mujeres en otros pueblos surandinos, echan luz respecto de las chibuleo.

El sombrero de los chibuleo (Caluña et al., 2008; Rowe 1998, 2011) tiene formas, colores y texturas variadas, que identifican el lugar de procedencia de quienes lo portan y en ocasiones incluso el tipo de trabajo que realizan (Maldonado, 2012). Los registros con los que se cuenta respecto al sombrero de los chibuleo refieren a Caluña et al. (2008) y Rowe (1998, 2011). Según los estudios de Rowe (1998), el sombrero es portado tanto por hombres como por mujeres, sin variaciones en el estilo. Para explicar la morfología del sombrero, esta misma autora hace una comparación con los pueblos cercanos a los chibuleo, como los angaguana y pilahuin.

En sus estudios, Rowe (1998) advierte que el sombrero de los angaguana es de corona alta y borde estrecho, por lo que es diferente a los de los otros dos pueblos mencionados. Mientras que las diferencias entre el sombrero hecho de lana de fieltro de los chibuleo y pilahuín, parecen consistir sólo de detalles tales como el color del hilo alrededor de la base de la corona del sombrero, azul marino para el primer pueblo, y rojo, púrpura o verde para el segundo. El sombrero chibuleo tiene copa redonda, de lana de fieltro color blanco, borde elevado que curva hacia arriba, con un hilo azul amarrado alrededor de la copa o corona (Rowe, 2011). Estas características del sombrero descritas por Rowe $(1998,2011)$ a partir de sus estudios etnográficos de fines de la década de 1980, son similares a las registradas durante mis estudios etnográficos realizados entre 2014 y 2016. A éstas se suman otras particularidades del sombrero, expuestas tanto por Caluña et al. (2008) como por Rowe (2011) que consisten en su copa redonda y su color blanco.

Si bien se advierte que el sombrero no presenta transformaciones entre fines de la década de 1980 y el año 2016, este accesorio atraviesa un proceso de desuso por parte de ciertas mujeres, y de readopción en marcos insitucionales, que puede ser interpretado como un proceso de resistencia indígena, como expongo en el capítulo 3.

En segundo lugar, destaca el $t u p u^{30}$. El tupu chibuleo es un prendedor de plata, de cabeza redonda con detalles de vidrio en el centro, y cuerpo en forma de un alfiler recto que termina en punta, que sirve para entretejer y sujetar los extremos de las prendas (Cataluña et al. 2008; Rowe (1998), cumpliendo así una función de utilidad o función práctica (Fernández, 2015a; Lobäch, 1981). Asimismo Rowe (1998), hace referencia al uso de más de un tupu simultáneamente. Al utilizar dos tupus, estos se conectan con un cordón trenzado que se enrolla en cada tupu, y el sobrante queda colgando, o es colocado hacia atrás por encima del hombro izquierdo.

En tercer lugar, dentro de los accesorios incluyo a las wallkas y orejeras. La wallka -o las wallkas - , son collares que portan las mujeres andinas del Ecuador (Caluña et al., 2008; Jaramillo, 1990; Quinatoa, 2013; Rowe, 1998). Entre los chibuleo, Caluña et al. (2008) 
manifiesta que las wallkas son de color rojo, al igual que las orejeras, debido en este caso al spondylus o coral, que también formaba parte de los materiales originales en los que se confeccionaban. Esto concuerda con los datos aportados por mis interlocutores en los estudios etnográficos.

Las wallkas portadas por las mujeres chibuleo, según Rowe (1998), son collares de múltiples hebras de pequeñas cuentas rojas, con algunas cuentas blancas intercaladas. Es decir, que esta autora advierte que el color rojo es predominante en las wallkas. Las múltiples hebras que contienen las wallkas expuestas por Rowe (1998), son definidas por Caluña et al. (2008) como vueltas, y este indica que la cantidad de vueltas era proporcional a la riqueza material de la persona que la portara (p. 32). En resumen, las wallkas chibuleo son collares de varias hebras o vueltas, compuestas por cuentas o mullos, predominantemente de color rojo.

Durante mis investigaciones etnográficas entre los chibuleo, advierto la utilización predominante de plástico, antes que el spondylus (llamado coral por mis interlocutores), tanto en referencia a las wallkas como a las orejeras. Según sostiene Rowe (1998), esta joya se dice que se les compró a los otavalos que llegaron a la comunidad. Estas similitudes evidencian, en efecto, un proceso de adopción interétnica. Las orejeras chibuleo son descritas por Caluña et al. (2008), como aros confeccionados en coral con una jiga en la punta, cuya longitud expresa la posición económica de la mujer, al igual que las wallkas chibuleo. Infiero que esto se debe al costo del material natural del que están hechos ambos accesorios, y sea por mayor cantidad de vueltas, en el caso de las wallkas, o por mayor longitud, en el caso de las orejeras, es necesario utilizar más material, lo que redunda en un incremento de su precio.

Estos accesorios, al igual que los tupus y las prendas de la vestimenta propia chibuleo, presentan transformaciones entre los años 1990 y 2016, que se exponen detalladamente en el capítulo 3. Una vez descriptas las diversas características de la vestimenta de la mujer chibuleo, se comienza el abordaje de sus usos y transformaciones, en concomitancia con la construcción de su identidad, entre 1990 y 2016, que expongo en los siguientes capítulos.

\section{Capítulo 2: Hitos de la transformación dialéctica indumentaria-identidad chibuleo}

El presente capítulo identifica los hitos históricos que han incidido en los usos y transformaciones de la indumentaria de la mujer chibuleo, entre 1990 y 2016, en relación con su construcción identitaria. Para ello, en los siguientes apartados se explica, por una parte, la forma en que los indígenas construyen y representan su identidad en concomitancia con la vestimenta. Por la otra, se efectúa un recorrido por los acontecimientos más destacados, ocurridos en Ecuador en el período mencionado, que son referidos por los chibuleo como hitos en la transformación de su identidad. En esta clave se analiza la relación entre la identidad étnica, y el uso indumentario por parte de la mujer, poniendo de relieve los matices del uso en la esfera pública y privada.

De esta manera, se analiza la importancia que adquiere la vestimenta, al ser portada durante los denominados levantamientos indígenas; y el reconocimiento constitucional en el que se impulsa el uso de la vestimenta, y los símbolos de los pueblos y nacionalidades 
indígenas del Ecuador, como un derecho. Asimismo, se analizan las instituciones chibuleo que se forjan como producto de los levantamientos, y el reconocimiento constitucional de los derechos indígenas. Dentro de cada uno de estos hitos, se pone en evidencia la construcción de las categorías vestimentarias y su relación con las categorías identitarias, que en conjunto destacan la función simbólica del objeto de Diseño indumentario.

\subsection{La indumentaria en la construcción identitaria. Breve cronología de la histo- ria de la indumentaria indígena chibuleo: del período colonial a la década de 1990}

La indumentaria indígena se ha desarrollado como elemento de resistencia, en una trama histórica de lucha, frente a la dominación de otros grupos. Este carácter dinámico, denota que la vestimenta adquiere diferentes significaciones en su devenir histórico, social y político, del mismo modo en que también es dinámica la transformación en la representación del pueblo chibuleo, al interior del grupo, y con respecto a los otros (Barth, 1976).

En este segmento analizo tres grandes procesos históricos, que definieron la relación indumentaria-identidad: las prescripciones del período colonial, las revueltas del siglo XVIII y los levantamientos de fines del siglo XX.

Durante el período colonial, los españoles reglamentaron el uso de la vestimenta, prohibiendo a los indígenas portar lo que se denominaba el traje hidalgo español (Karasik, 2010) e imponiéndoles el uso de vestimenta campesina española (Anawalt, 2008). En los Andes y luego de la conquista, también se prohíbe el uso del vestido tradicional. Según Anawalt (2008), esto respondía al interés por reprimir la identidad indígena y desculturalizar a la población. Esta prohibición hizo hincapié en "la túnica y el manto masculinos, ambos emblemáticos de la cultura andina” (Anawalt, 2008, p. 463). Para 1572 -alrededor de cuarenta años después de la conquista española en los Andes- se obligó a adoptar la indumentaria de los campesinos españoles, que consistía en pantalón, chaqueta y chaleco para el atuendo masculino, imponiéndose además la vestimenta de las campesinas españolas a las mujeres (Anawalt, 2008, p. 463). Sin embargo, luego de conquistar los Andes, los españoles se dirigieron a la zona de la Costa, lo que explica el hecho de que la vestimenta indígena, se conservara en las zonas altas montañosas, como en la que residen los chibuleo.

Después de siglos de dominación, en 1780 tienen lugar las rebeliones indígenas andinas, tras las cuales se acentúan aún más las restricciones del uso de prendas originarias. En efecto, un nuevo decreto, más estricto que el anterior, prohibió el uso de vestimenta indígena. Pero lo que ocurrió en la práctica, fue una combinación de las formas española y nativa. Los hombres cambiaron la túnica indígena por una chaqueta corta, pantalón hasta las rodillas y sombreros estilo español, mientras que las mujeres, en lugar de su vestido envolvente, comenzaron a usar faldas y camisas. Sin embargo, los indígenas continuaron tejiendo y usando accesorios prehispánicos (Anawalt, 2008, pp. 464-465).

La utilización de la vestimenta indígena, en combinación con la no indígena, es una amalgama que caracteriza la indumentaria portada en el presente siglo XXI, adaptándose a ma-

teriales, formas y tintes novedosos. Sin embargo, es posible hallar una vestimenta similar a la del Siglo XVIII, en determinadas regiones andinas más conservadoras. 
Estos hechos explican las continuidades y transformaciones de la vestimenta indígena, que muestran una variación de prácticas, como ser el desuso parcial de esta indumentaria, la adopción de indumentaria no indígena al repertorio indígena, y el cambio - o reemplazode unas prendas por otras, incluso antes de la independencia de las naciones conquistadas. El intento de las autoridades españolas por prohibir la vestimenta indígena, partía de la creencia en un conjunto de representaciones sobre los indígenas como salvajes, primitivos, exóticos (Jackson, 1995; Theodossopoulos, 2012; Ulloa, 2005, Ramos, 1994). Estas representaciones legitimaron la necesidad de la conquista que, si bien fue presentada como una cruzada civilizatoria contra los salvajes, se orientó principalmente a dominar a estos grupos y sus costumbres, tal como Matarrese lo expone para el caso del Chaco Argentino (Matarrese, 2013). Esta representación de los indígenas perdura hasta comienzos del siglo XVIII (Ulloa, 2005). Luego de que las naciones se independizaran de los españoles en el siglo XIX, insertándose en el período republicano (Ulloa, 2005; Ayala, 2012), los indígenas continuaron en una situación de subordinación respecto a las élites locales, en tanto no tenían acceso a la toma de decisiones políticas, así como tampoco a la igualdad de derechos y servicios socioeconómicos. Esto lleva a autores como Ulloa a afirmar que "los indígenas fueron excluidos del proceso de construcción de nación como pueblos" (2005, p. 95). Esta continuidad en la exclusión se sostiene también con respecto a los mestizos (Briones, 1998; Grossberg, 1992). A finales del siglo XX, —en particular desde la década de 1970—, se inicia un proceso de revitalización de su identidad, apoyado por organismos internacionales en el marco de la lucha por la reivindicación de sus derechos y su inclusión en las constituciones de los Estados-Nación con acceso a una ciudadanía plena (Iturralde, 2000, Jackson, 1995; Ulloa, 2005). De la mano de estas luchas los indígenas comienzan a mantener, modificar o eliminar sus prácticas culturales (Jackson, 1995), y a resignificar su otredad (Ulloa, 2005). Es en este proceso, que la indumentaria atraviesa una serie de transformaciones y comienza a vigorizarse la vestimenta indígena (Karasik, 2010).

En efecto, en la segunda mitad del Siglo XX, los chibuleo inician un proceso de readopción de la vestimenta indígena, tal como fue el caso de los kayapó de Brasil (Turner, 1991), y de los emberá de Panamá (Theodossopoulos, 2012) —aunque este caso transcurrió en el Siglo XXI-. Si bien estos grupos no son referentes andinos, constituyen ejemplos paradigmáticos de grupos étnicos que construyen su identidad y autorrepresentan su cultura ${ }^{31}$ a partir del uso y transformaciones de su vestimenta como diacríticos (Barth, 1976).

La autorrepresentación, que es parte de su autoadscripción indígena (Barth, 1976), se relaciona de manera estrecha con el reconocimiento de las etnias como actores políticos. Este reconocimiento, a su vez está articulado con los cambios constitucionales y las estrategias desarrolladas en ámbitos nacionales e internacionales, a través de organismos estatales y multilaterales, para posicionar a estos pueblos dentro de la sociedad y con acceso a una ciudadanía plena, lejos de la idea de que necesitan ser representados por otros (Ulloa, 2005). Los movimientos indígenas, tanto nacionales como internacionales, inciden en la forma en que se conceptualiza la cultura, así como en la legislación que rige cada Estado- Nación (Jackson, 1995). Los pueblos indígenas muestran cambios importantes desde los inicios de 1970, sobre todo desde su incorporación efectiva al Estado-Nación constituyendo estratégicamente su identidad indígena de manera dinámica. No es fortuito, entonces, el hecho 
de que los indígenas readopten el uso de su "vestido étnico" (Eicher, 2000; Hansen, 2004), o lo hayan mantenido, como parte de su reafirmación identitaria (Jackson, 1995).

En este sentido, la vestimenta se convierte en un vehículo de identidad étnica y un símbolo del acceso a derechos —educación, participación social y política-, como indígenas con la capacidad de autorrepresentarse, y los posiciona lejos de la concepción del indígena primitivo, incivilizado o el "buen salvaje" necesitado de protección (Prieto, Cuminao, Flores, Maldonado y Pequeño, 2005).

La construcción de la identidad indígena involucra un doble proceso que implica la representación de los indígenas por los otros y por ellos mismos. De allí que se desplieguen estrategias de lucha sociopolítica dentro de la comunidad y fuera de ella.

En esta tesis se estudia a los chibuleo desde la década de 1990, cuando comienzan este proceso de autorrepresentación y construcción de su identidad, a partir de una etnicidad que se traslada desde el ámbito privado hacia la esfera pública (Weaver, 1984). Identidad que se articula con los levantamientos de la década mencionada, y los consecuentes cambios constitucionales de 1998 y 2008, que reconocen los derechos de los pueblos y nacionalidades indígenas del Ecuador, convirtiéndola en una etnicidad pública (Weaver, 1984). Es decir, que los chibuleo se autorrepresentan en el marco de las negociaciones al interior de la comunidad y en su relación con el Estado-Nación. En este contexto, la indumentaria chibuleo aparece como un medio de autorrepresentación y de autoadscripción del grupo étnico, en un contexto de reconocimiento público de sus capacidades y agencia políticas. En efecto, y aun cuando los indígenas reafirman su identidad, con elementos vestimentarios indígenas, cabe aclarar que éstos son móviles (Abramoff, 2001; Barth, 1976; Beckett, 1998; Bonfil Batalla, 1991; Femenías, 2013; Jackson, 1995), y como tales, se transforman en concomitancia con la indumentaria. Como expuse en los primeros párrafos de este apartado, las transformaciones ocurren a partir de las reglamentaciones y prohibiciones del uso y no uso de la vestimenta indígena. Este grupo étnico, marcado por una situación de colonización, continuó subalternizado de forma posterior a la independencia de las naciones del dominio español, y es aquí donde portar indumentaria indígena se convirtió en un emblema de inferioridad (Karasik, 2010). Sin embargo, a partir de la revitalización y lucha por el reconocimiento y cuando los Estados-Nación comenzaron a incluir a los indígenas como actores sociales plenos dentro de las constituciones, se inició también un proceso de revitalización de la indumentaria indígena, una revalorización que más bien promueve el uso de la vestimenta y el mantenimiento de las diferencias, en un marco de reivindicación de derechos históricamente negados.

Estas transformaciones vestimentarias se vieron reflejadas en los desusos, adopciones, cambios, reemplazos, adaptaciones, readopciones y también en la continuidad del uso de prendas que, si bien mantienen de manera parcial o total su forma, son modificadas por la introducción de nuevos materiales, y nuevas técnicas de producción industrial.

A continuación, se analiza el rol que desempeña la mujer portadora de la vestimenta indígena, para enriquecer la comprensión de la relación indumentaria-identidad, por ser ella quien ha mantenido su vestimenta propia — según los términos nativos—, con mayor frecuencia que los hombres. 


\subsection{Levantamientos indígenas de la década de 1990: la importancia de la vesti- menta propia}

Los denominados levamientos nacionales indígenas de la década de 1990, son el escenario en el cual los chibuleo, advierten la importancia de portar la vestimenta propia. Estos levantamientos, que se suscitan a nivel nacional, son fundamentales para dar cuenta de la presencia y protagonismo público de los pueblos indígenas. Allí, la mujer chibuleo utiliza su vestimenta propia, mientras demanda el respeto por los derechos indígenas.-

Los levantamientos de la década de 1990 en Ecuador, se ubican en un contexto político más amplio - regional e internacional—, que permitió devolverle la voz a una diversidad de las minorías sociales. A través de sus reclamos, estas minorías presionaron a los Estados latinoamericanos para "ejercer una identidad diferenciada" (Spadafora, Gómez y Matarrese, 2010, p. 238), como en el caso de los pueblos originarios argentinos y sus reclamos territoriales. Estos procesos incidieron y tensionaron el ordenamiento jurídico sobre el que se sostenían los Estados-Nación latinoamericanos, exigiendo reformas constitucionales orientadas al cumplimiento de los derechos de los pueblos indígenas (Iturralde, 1997; Spadafora et al., 2010).

A nivel latinoamericano, estos levantamientos implicaron reuniones secretas entre los indígenas, caminatas nocturnas para llegar a los lugares de encuentro, y precarias y dificultosas condiciones materiales de existencia - que implicaron que esta lucha estuviera regada de obstáculos, como lo indica Rodas (2009) en su libro Tránsito Amaguaña, su testimonio $^{32}$ - . Los hombres y mujeres chibuleo, enfrentaron estos mismos desafíos, llevando a sus hijos a las reuniones y levantamientos, entre otros. Una informante chibuleo, Martha Lligalo, hija de uno de los tres líderes indígenas del pueblo y del movimiento indígena provincial y nacional, recuerda esas largas caminatas en la noche y a escondidas, durante la década de 1980. Ella recuerda, que siendo menor a 5 años, acudía con su padre a las reuniones en las que se gestaron las organizaciones indígenas promotoras del levantamiento de 1990.

En Ecuador, la participación de la mujer en estos eventos fue de suma importancia. A nivel nacional, fueron ellas quienes se adelantaban en las marchas, incluso "llevando en sus espaldas o aún en sus vientres a sus hijos y se enfrentaban a los militares y policías [...] un hecho político sin precedentes en la historia del país" (De la Torre, 2010, p. 13), que marca la presencia e importancia de la mujer indígena.

De acuerdo a mis relevamientos etnográficos, durante los levantamientos, los hombres fueron la voz de los chibuleo, según afirman los taytas y corroboran las mamas ${ }^{33}$. Las mujeres, por su parte, cumplieron un rol fundamental, ya que les permitió ingresar a la ciudad sin ser reprimidas, tal como lo indica una de mis interlocutoras:

... siempre las mujeres éramos primero, los hombres eran atrás para que no le repriman o cojan [...] porque a las mujeres los policías no nos maltrataban mucho, en cambio a los hombres les maltrataban, les pegaban, les llevaban presos. Tonces ellos eran más atrás, las mujeres éramos primeras, esa era la táctica de nosotros, entonces siempre íbamos las mujeres primero. (Entrevista a M. Lligalo, Chibuleo San Francisco, noviembre de 2016) 
La intervención estratégica de las mujeres chibuleo en Tungurahua, abrió paso al resto de la población indígena al interior de la ciudad. De anaco, chumbi, rebozo y sombrero, ocuparon las calles de Ambato durante los levantamientos de la década de 1990. Las mujeres chibuleo, con su vestimenta propia, marcaron el espacio físico, y como consecuencia de este proceso de reivindicación, su indumentaria se transformó en un diacrítico identitario (Barth, 1976). A partir de entonces, evidenció su existencia y aportó en el reconocimiento de su etnia como sujetos políticos, y parte de un mismo Estado-Nación. De ahí que la vestimenta propia represente el respeto y que la indumentaria, en tanto objeto de diseño, y analizando su función simbólica (Fernández, 2015a; Lobäch, 1981) para esta etnia, sea una herramienta de reclamo de respeto.

El conjunto de prendas y accesorios que portaron las mujeres chibuleo en ese entonces, constituye su vestimenta propia. Es denominada de esta manera por taytas, mamas, dirigentes educativos y políticos. También las mujeres que trabajan en instituciones educativas y financieras utilizan el término vestimenta propia para definir el uso de la vestimenta chibuleo durante los levantamientos indígenas de la década de 1990. Cabe destacar que para el 2016, continúa en uso por parte de las mujeres que participaron en este evento.

Esta vestimenta está compuesta de anacos, cuya longitud se extiende desde la cintura hasta cubrir la rodilla; chumbis, que envuelven y sujetan los anacos; rebozos y lishtas, que cubren la espalda y se sujetan en el centro del pecho, con una longitud que excede la cadera; y finalmente la camisa, como parte de sus prendas. Dentro de los accesorios se observan los sombreros y los zapatos de taco bajo (Ver Figura 2).

También en las entrevistas se menciona el uso de wallkas, orejeras, shigras y sacos o suéteres - como lo definen mis informantes-, durante el levantamiento. Así, uno de los taytas menciona el estado de la vestimenta con la que las mujeres acudieron a estos eventos: "algunos con nuevos, algunos con usaditos pero bien elegantes bien vestiditas, pero así... así como está mi esposa” (Entrevista a J. Lligalo, Chibuleo San Francisco, abril de 2016). Una vez mencionada la importancia de la mujer en los levantamientos indígenas, y la tipología indumentaria definida como vestimenta propia, es preciso indicar que las intervenciones más destacadas de los chibuleo en esta serie de eventos de la década de 1990, son los ocurridos en los años 1990, 1992 y 1994, según consta en la bibliografía y hemerografía de referencia, y constatan mis interlocutores. Estos acontecimientos se detallan en los siguientes apartados.

\subsubsection{Levantamiento de 1990: el primer levantamiento nacional}

El autodenominado - por las organizaciones indígenas- levantamiento indígena (Almeida, y otros, 1992) de 1990, fue una acción conjunta del movimiento indígena nacional, que radicó en la toma de la plaza de Santo Domingo, ubicada en Quito, capital del Ecuador, el 28 de mayo de 1990. La mencionada toma se expandió rápido y principalmente en las provincias de la sierra (Almeida y otros, 1992, p. 30). La demanda central de estos movimientos, era el "reconocimiento del Ecuador como Estado plurinacional, y en consecuencia, la necesidad de una transformación profunda” (Benítez y Garcés, 2014, p. 268). 
Esta manifestación constituyó, sin duda, un hito clave en la historia política y social ecuatoriana, en tanto marcó el inicio de un proceso de reafirmación de la identidad étnica -a nivel nacional - , y de los chibuleo —en particular-. El levantamiento de 1990, es el resultado de un proceso de reacción de los indígenas, respecto a la histórica exclusión a la que han sido sometidos.

Este levantamiento por el reconocimiento de los derechos colectivos, visibiliza la articulación a nivel Estado-Nación del movimiento indígena (Almeida, Arrobo y Ojeda, 2005; Almeida, 2008). En el marco de esta manifestación, particularmente las mujeres portaron la vestimenta propia de cada pueblo, y desde esa marca identitaria disputaron su presencia en el espacio público (De la Torre, 2010; Almeida et al., 1992).

El levantamiento indígena de 1990, fue precedido por tres eventos importantes, que marcaron la historia y articulación de la política indígena ecuatoriana: en primer lugar, la conformación de la Confederación de las Nacionalidades Indígenas del Ecuador (CONAIE) ${ }^{34}$ en 1986. En segundo lugar, la propuesta de la CONAIE de elevar un proyecto de ley de nacionalidades indígenas al Congreso Nacional, en 1988, que no fue acogido. En tercer lugar, la firma del Convenio 169 de la Organización Internacional del Trabajo (OIT) ${ }^{35}$. Estos hechos contribuyeron al reconocimiento de los derechos indígenas ${ }^{36}$ en Ecuador, y consolidaron la organización de los pueblos indígenas y su participación política hacia 1990. De los eventos precedentes, se destaca la conformación de la CONAIE; esta se convirtió en la principal impulsora del levantamiento y, más ampliamente, ha ubicado al movimiento indígena en la agenda política del Estado-Nación, con su consigna de cambiar la visión de la sociedad ecuatoriana respecto al indígena (Cruz, 2010).

El levantamiento de 1990 hizo públicas las demandas indicadas en el programa "Mandato por la Defensa de la Vida y las Nacionalidades Indígenas" (Almeida, Arrobo y Ojeda, 2005). En este programa, los pueblos originarios piden inicialmente que se resuelvan los conflictos de tierras ${ }^{37}$, y se implemente la educación intercultural bilingüe como un derecho (Almeida et al., 1992; Porras, 2005). Alcanza una mayor proporción al cuestionar la carta constitucional del Ecuador con respecto a la plurinacionalidad, a través de un proceso reivindicatorio, que solicitó la reformulación del artículo 1, donde se reconozca al Estado ecuatoriano como plurinacional (Almeida, y otros, 1992, p. 25).

Así también, en el levantamiento de 1990, como menciona Luis Macas - líder indígena nacional- se demandaba "el respeto a nuestro pensamiento, formas organizativas propias y práctica política [...] así como el respeto a nuestros valores culturales" (Almeida, y otros, 1992 , p. 26) ${ }^{38}$, estos últimos contienen, de forma implícita, a la vestimenta indígena.

Enfatizo en este punto el respeto como una categoría nativa, identificada entre los chibuleo, y de la que hacen uso líderes indígenas nacionales, y que se articula con el uso de la vestimenta. Este uso indumentario, en el marco del respeto, si bien tiene sus raíces en el levantamiento de 1990, trasciende hasta el presente siglo XXI. Es en este sentido que De la Torre (2010), autora indígena, se refiere a las mujeres que con su presencia, y el uso de sus vestidos, aportaron al cambio del rostro histórico de los indígenas. Para ella, las generaciones nuevas asumen paulatinamente su misión social, siempre desde el respeto.

Lo antedicho da cuenta de un esfuerzo conjunto, para resignificar la democracia y la justicia indígena. Desde este punto, las mujeres indígenas "como sujetos políticos toman el 
escenario público para expresar sus demandas a través de sus propias interlocuciones con las sociedades y los estados nacionales a nivel político, o cualquier espacio que le ha tocado asumir" (De la Torre, 2010, p. 19). Es decir que la lucha por el respeto, que en 1990 implicó la incursión de la mujer indígena portadora de la vestimenta propia en el espacio público, ha trascendido a las nuevas generaciones.

Al respecto Prieto et al. (2005) mencionan que: "mientras se busca el respeto como pueblo culturalmente diverso se labra el respeto de las mujeres en el marco de sus relaciones con los miembros de las sociedades indígenas y mestizas" (p. 168). Es decir, que el respeto demandado, implicaba reconfigurar las relaciones interétnicas dentro de la sociedad ecuatoriana en clave de un respeto cuya construcción es permanente.

Dentro de todo este contexto, uno de los puntos centrales que articuló el levantamiento de 1990 - y que adquiere relevancia para el presente estudio-, fue la "necesidad de fortalecer la identidad étnica" (Tello, 2012, p.75). El levantamiento constituyó un momento clave en la consolidación de la identidad chibuleo; y en la vestimenta propia, y marcó el uso indumentario como un aporte al reconocimiento identitario y su posterior fortalecimiento. De este modo, el levantamiento que comenzó con demandas ligadas a la tenencia de la tierra, se expandió hacia otras reivindicaciones, todas en el marco de la demanda de respeto hacia la etnia y a sus prácticas culturales, entre las que está implícito el uso de su indumentaria. Como resultado de la coincidencia de la lucha por las tierras en provincias de la sierra, y las reivindicaciones de índole político que mantenía la CONAIE para reformar el EstadoNación, se produce en Quito la toma de la Plaza de Santo Domingo, el 28 de mayo de $1990^{39}$. Es en este lugar que los indígenas demandan un diálogo ${ }^{40}$ con el presidente de turno, Rodrigo Borja, con la finalidad de tratar asuntos referentes a "la situación agraria, la crisis económica, la declaratoria del Estado como plurinacional” (Porras, 2005, p. 222). Para el diálogo solicitado, los representantes de los pueblos originarios proponían la conformación de una comisión mediadora integrada por autoridades religiosas, activistas de derechos humanos, de la justicia y la paz de Ecuador, bajo la advertencia de que en caso de no ser atendidos, se realizaría el paro nacional los días 4, 5 y 6 de junio de 1990, según lo había acordado la CONAIE, en su V Asamblea Nacional del 25 de abril de 1990. (Almeida et al., 1992; Porras, 2005).

Ante esta situación, el gobierno tuvo dos tipos de respuesta: por un lado, el menosprecio y la indiferencia inicial al movimiento indígena; y por el otro, una atención clientelar a los requerimientos para la solución del conflicto de unas pocas comunidades y no de su totalidad. Como consecuencia, los días 4, 5, 6 y 7 de junio se llevaron adelante las medidas de fuerza del movimiento (Porras, 2005; Almeida et al., 1992) en la mayoría de las provincias de la Sierra y algunas de la Amazonía; principalmente en Cotopaxi, Tungurahua, Bolívar, Chimborazo, y con menor intensidad en Imbabura, Cañar, Azuay y regiones amazónicas como Napo y Pastaza. Los medios de comunicación, que en primera instancia ignoraron estos acontecimientos, conforme pasaban los días y los indígenas ponían en evidencia su fortaleza, fueron incrementando su cobertura.

Los levantamientos a nivel nacional implicaron la "obstaculización de carreteras, desabastecimiento de los mercados en las ciudades, concentraciones, marchas y actos esporádicos de violencia" (Porras, 2005, p. 222). Entre los hechos de mayor importancia estratégica, se 
encuentran el secuestro de treinta y un policías y militares, y la agresión a los dueños de la hacienda El Charrón, en Chimborazo.

Por una parte, la CONAIE denunciaba la militarización de carreteras y algunas comunidades (Porras, 2005; Almeida, 1992). Por la otra, los asociados de la cámara de agricultura, ganadería e industrias y los hacendados, expresaban su voz contraria a las protestas indígenas, y reclamaban acciones inmediatas por parte del Estado, anticipando que en caso de no ser atendidos, se organizarían para defenderse.

Para establecer acuerdos entre los indígenas y el gobierno, respecto de las peticiones expresadas durante el levantamiento, se conformó el "Mandato por la defensa de la vida y por los derechos de los indígenas" (Porras, 2005, p. 225). La Iglesia, como parte de la comisión mediadora propuesta por los representantes de los pueblos originarios, tuvo que intervenir constantemente. Finalmente, los acuerdos alcanzados fueron escasos y ninguno refería específicamente a la cuestión indígena, por lo que continuaron los levantamientos indígenas nacionales durante la década.

A nivel provincial, en Tungurahua, el 6 de junio de 1990 se realizó una concentración en su capital, Ambato, a la que concurrieron diez mil indígenas para dialogar con el gobernador respecto de una serie de pedidos, que iban desde "el congelamiento de los precios de los productos de primera necesidad, hasta la liberación de indígenas detenidos por las protestas de esos días" (Porras, 2005, p. 224).

Estos hechos quedaron testimoniados en el diario de campo del tayta Juan José Lligalo, quien da lectura a éste durante una de mis entrevistas. Este tayta, junto a sus coidearios — su hermano Juan Lligalo y Nazario Caluña, también taytas chibuleo-, alientan el levantamiento en su pueblo desde el domingo 3 de junio de 1990, evento que inicia junto a otras comunidades indígenas en el cantón Ambato al siguiente día, lunes 4 . El martes 5, segundo día del levantamiento, surge una invitación al diálogo en el estadio Bellavista por parte del Gobernador Callejas, hacia los indígenas - a través del tayta Juan José-, diálogo que se interrumpe ante la negativa indígena de escuchar sólo discursos del gobernador, y la consecuente decisión de continuar con la paralización. El jueves 7 de junio de 1990 se proclama el fin del levantamiento local con una marcha hacia la gobernación de Ambato que estremece a la sociedad, como lo indica el tayta:

... cosa que hacen temblar a los mestizos de la ciudad en una marcha que concentramos en la calle frente al estadio Bellavista y nos dirigimos hacia la gobernación donde en verdad nos encontramos a un diálogo y nos... y nos suscribimos un acta de compromiso que existen para la historia en nuestros archivos de las tres organizaciones. (Entrevista con J. J. Lligalo, Chibuleo San Francisco, abril de 2016)

Si bien durante el levantamiento indígena, como ya expuse, el hombre fue la voz chibuleo, las mujeres cumplieron un rol fundamental al constituirse en la estrategia de ingreso a la ciudad — poniéndose al frente de las marchas (De la Torre, 2010) —, y al evidenciar la presencia del pueblo a través de la indumentaria portada. La intervención estratégica de las mujeres chibuleo en Tungurahua, durante los levantamientos, abrió paso al resto de la 
población en su entrada a la ciudad. Así lo manifiestan los testimonios de taytas y mamas chibuleo, al relatar el levantamiento de 1990:

... nuestra estrategia era que adelante las mujeres, $[. .$.$] ya dijimos nosotros por$ favor ustedes, a ustedes nadie va a hacer nada, ellas tumbaron a la policía, botaron los cascos al suelo y los pasaron a la ciudad así tumbando a las autoridades. O sea comenzó el diálogo en el año 90, era un gran levantamiento indígena, desde ahí que se ha cambiado por completo... hasta ahí a nosotros los indígenas nos consideraban como animales. (Entrevista con J. J. Lligalo, Chibuleo San Francisco, abril de 2016)

Las mujeres de los levantamientos, que abrieron paso al resto de la población, y que actualmente forman parte del grupo de las mamas chibuleo, constituyeron un eje fundamental en estos eventos. Su participación fue considerada estratégica para posicionar a la mujer como representante chibuleo. Más aún, Martha Lligalo, una informante, advierten la importancia de portar la vestimenta propia por parte de las mujeres a diferencia de los hombres, que en este evento no estaban vestidos de chibuleo:

Todos éramos indígenas, habían sí habían varones que se... se vistieron y ya... varones más que todo los varones se vistieron ya de mestizos, ¿por qué? porque había mucho discrimen, viendo a los indígenas se burlaban, quitaban el sombrero y todo y entonces los jóvenes empezaron a cambiar. Tonces ahí nos dimos cuenta y todo mundo hasta ahora nos sabemos burlar a los chicos diciendo que... como se llama... como ya se visten de mestizos, no le toman ni en cuenta, [... por ejemplo en la ciudad en el primer levantamiento había muchísima gente de la ciudad que nos apoyaron bastante ¿no? En esa temporada cuando bajaron de las comunidades a las ciudades, no tenían almuerzo, los señores de la ciudad dieron almuerzo a la gente indígena, dieron agua, dieron fruta... las señoras del mercado principalmente, tonces ayudaron a hacer comida todo eso. Tonces a los chicos que estaban vestidos de mestizos no les querían dar pues. No les quería dar a ellos ¡no! a ellos ¡no! ¡dijo no! esto es... son solo para indígenas. Ellos [los hombres chibuleo vestidos de mestizos] también decían: nooo, nosotros también somos indígenas. Decían no porque usted no está vestido de indígena. Tonces las mujeres siempre hemos mantenido nosotros no hemos cambiado. (Entrevista a M. Lligalo, Chibuleo San Francisco, noviembre de 2016)

Es decir que los chibuleo, no sólo necesitaron la articulación al interior de su etnia para ser reconocidos durante el levantamiento de 1990: también necesitaron vestirse de indígenas para ser identificados como tales, y obtener apoyo de los grupos mestizos en la ciudad. Desde este evento, los chibuleo advierten la importancia de portar vestimenta propia, un uso que se extiende para los siguientes levantamientos nacionales, de 1992 y 1994, en los que los chibuleo participan de manera activa. 
El desuso de la vestimenta propia por parte de los hombres, además de las burlas por parte de los no indígenas, como señaló Martha Lligalo en la entrevista, es un hecho que se explica también a través de lo expuesto por Almeida et al., cuando hace referencia a los indígenas como los más pobres del Ecuador, fruto de la herencia del colonialismo interno y la inacción de los gobiernos:

... tras las transformaciones de los 70s, el patrón de consumo indígena se había modificado sustancialmente y dependía cada vez más del mercado capitalista. La nueva vestimenta - el pantalón, la camisa, la chompa, los zapatos de caucho, la gorra de camionero- se adquiría en el mercado, ya no eran el poncho o las alpargatas que elaboraba artesanalmente la comunidad. (Almeida et al., 1992, p. 123)

El precio de las prendas es un factor determinante en el cambio de patrón de consumo indígena, ya que la vestimenta mestiza masculina, mencionada por Almeida et al. (1992), tiene un precio mucho menor a los costos que implica la vestimenta propia, lo que hace más accesible la adquisición de la indumentaria mestiza, si bien no es el único factor influyente. El desconocimiento - por parte de los mestizos-, de los indígenas que no portaban su vestimenta propia, concuerda con lo dicho por Karasik (2010): "en Ecuador el corte de la trenza masculina, el abandono del poncho y el cambio del quechua por el castellano se consideran señal de abandono de la identidad indígena" (p. 271). Es claro entonces lo que ocurre durante los levantamientos de 1990: la relación entre vestimenta e identidad se fortalece ante la mirada indígena, en tanto los identifica, y a su vez permite el reconocimiento de los otros.

El levantamiento de 1990 trastocó el escenario político ecuatoriano, situando a los pueblos indígenas como "sujetos sociales y actores políticos" (Iturralde, 2000, p. 24), y a la CONAIE como un actor político con capacidad de manifestar los deseos del sector, negociar con el gobierno, e influir en la institucionalidad pública y la legislación. Este levantamiento fue clave para la construcción y maduración del movimiento indígena, además de que dio visibilidad al carácter excluyente de la democracia reinante; también mostró como el modelo económico vigente perpetraba una situación de injusticia e inequidad para los sectores subalternos, como los pueblos indígenas (Tello, 2012).

El movimiento se convierte en la voz de las clases populares frente al Estado-Nación, y se constituye en un sujeto político que representa y plantea propuestas de transformación. Además, evidencia la necesidad de construir una sociedad nacional que respete prácticas culturales diversas, cuestionando el carácter excluyente del modelo económico de la época (Tello, 2012). El levantamiento de 1990 permitió el planteamiento de la necesidad de reestructurar el régimen democrático, en la medida que se reivindicó no sólo el reconocimiento de las identidades étnicas, sino, sobre todo, su demanda de participación política. 


\subsubsection{Levantamiento de 1992: 500 años de resistencia}

El año 1992 fue el escenario de una marcha indígena que demandaba la legalización de los territorios de las nacionalidades de la Amazonía, y la oportunidad para evidenciar la importancia de vías de integración de los pueblos y nacionalidades indígenas en las estructuras de decisión nacional.

Como resultado de estas acciones, se articuló el apoyo de varios pueblos indígenas y el compromiso del presidente ecuatoriano Rodrigo Borja (1988-1992), para el reconocimiento de algunos territorios del Oriente (Tello, 2014). Esta marcha, que se dio en el mes de abril, constituyó el preámbulo para las movilizaciones de octubre de ese mismo año.

En este nuevo escenario de movilización, se desarrolla un levantamiento nacional indígena similar al de 1990, en el que la mujer portadora de la vestimenta propia se destacó nuevamente, como puntal de la estrategia de entrada a la ciudad. En esta ocasión, el levantamiento fue en "rechazo a la conmemoración de los 500 años del descubrimiento de América" (Benítez y Garcés, 2014, pp.268-269). Este contexto permitió sensibilizar a la sociedad, respecto a la discriminación y explotación de los pueblos indígenas desde la conquista, articulando este hecho con las políticas de ajuste económico implementadas desde los años 1980, que afectaban a toda la población (Tello, 2014).

Este levantamiento dio lugar a que en las provincias ecuatorianas se desarrollasen protestas, que les permitieran demandar justicia y equidad acorde a la realidad indígena, como había sucedido dos años atrás. En Tungurahua, el levantamiento indígena que inició el jueves 8 de octubre de 1992, llegó a una instancia de diálogo que se desarrolló en el estadio Bellavista, el domingo 11 del mismo mes, entre los indígenas de Chibuleo, Kisapincha, Pasa, San Fernando, Llangagua, Pilahuin, Apatuc, Angaguano Alto y Bajo, Salasakas, Tisaleo — grupos tungurahuenses-, y autoridades de la provincia, entre ellos el gobernador Santiago Barriga. Durante esta negociación, los indígenas se indignaron por los ofrecimientos del gobernador de regalarles arroz y azúcar, entre otros. Este hecho está testimoniado en el diario de campo del tayta chibuleo Juan José Lligalo, quien al ser la voz indígena tungurahuense respondió a lo ofrecido del siguiente modo: “ ¡Carajo, no queremos arroz, azúcar! [...] verás señor economista Santiago usted tiene barriga y nosotros también tenemos barriga y por eso nos preocupamos" (Entrevista con J. J. Lligalo, Chibuleo San Francisco, abril de 2016). La solución no residía en ofrecerles mercaderías; el problema radicaba, según lo expresa el tayta, en que "todavía no había justicia [...] nuestros dirigentes en Quito arreglaron el rebajo de gas y gasolina quedó hasta ahí [...] el precio hasta ahí se ha respetado" (Entrevista con J. J. Lligalo, Chibuleo San Francisco, abril de 2016). A pesar de estos desacuerdos, como resultado del diálogo, se firmaron compromisos entre ambas partes.

Esta intervención causó tal impacto que fue registrada por la prensa local con el titular "Eco del levantamiento indígena", que incluía una foto del tayta chibuleo con vestimenta propia - poncho, camisa y sombrero- acompañada de una bajada que decía: "Juan José Lligalo, que se hallaba junto a los integrantes de la coordinadora provincial del paro indígena y comunicadores, se levantó para pedir 'punto de orden' al Gobernador, economista Santiago Barriga" (El Heraldo, 13 de octubre de 1992). 
Para esta época, los chibuleo habían advertido la importancia de portar vestimenta propia, en tanto contribuía al proceso de reafirmación identitaria. Según lo menciona Martha Lligalo, acudió al levantamiento incluso cargando a su hijo con bayeta. Asimismo, indicaba que en esta época "empezó más ya la organización de las mujeres, estaba dirigiendo un grupo de mujeres ya en la ciudad de Ambato" (Entrevista con M. Lligalo, Chibuleo San Francisco, noviembre de 2016). Es decir que hacia 1992, la mujer comenzaba a tener una mayor participación y visibilidad, tanto al interior del grupo como frente a los otros no indígenas.

El lunes 12 de octubre de 1992, aun cuando este día era el principal en la feria de Ambato, esta fue levantada y reemplazada por una marcha pacífica en la ciudad. Al igual que en 1990, el levantamiento de 1992 terminó con la ocupación del espacio público por los indígenas - en las principales calles de Ambato-, portando vestimenta propia; fenómeno que también se observará en el levantamiento de 1994.

\subsubsection{Levantamiento de 1994: movilización nacional por la vida}

En 1994, durante el gobierno de Sixto Durán Ballén (1992-1996), se recrudeció la implementación de medidas neoliberales, en un proceso similar a lo que sucedía en otros países latinoamericanos. El movimiento indígena, a través de los mismos mecanismos de protesta que en 1992 y con alcances parecidos al levantamiento de 1990, exigió la derogatoria de la Reforma de la Ley de Desarrollo Agrario, ley que favorecía la explotación empresarial y la disolución de las tierras comunales (Benítez y Garcés, 2014).

Como consecuencia de las manifestaciones, los indígenas lograron que se archivara la ley y, según indica Tello (2012), avanzaron "en un proyecto para el reconocimiento de la posesión ancestral de los territorios indígenas y la concesión de los correspondientes títulos de propiedad" (p. 79), demanda puntual que apareció inicialmente en el levantamiento de 1990. Con los resultados obtenidos en el levantamiento de 1994, parece clausurarse la primera fase del movimiento de reivindicación y demanda indígena (Guerrero y Ospina, 2005), que a partir de 1995, comienza a concentrarse en las estructuras estatales.

La negociación que propició el levantamiento de 1994, en un inicio se centró en los artículos de expropiación. Sin embargo, el objetivo de la CONAIE era "legitimar su discurso y demostrar su capacidad de representación de los indígenas y, de esta manera, ubicarse en el plexo de la esfera pública" (Guerrero, 2008, p. 147). Este no era el primer intento de la CONAIE de manifestar la representatividad del movimiento político indígena, ya que como se expuso previamente, la decisión de llevar a cabo el levantamiento de 1990 había sido una decisión de esta organización, en su afán por convertirse en "la principal organizadora política del indigenismo ecuatoriano" (Guerrero, 2008, p. 121).

Esta reafirmación pública durante los levantamientos $-\mathrm{y}$ de ahí en adelante-, requirió marcadores étnicos como el vestido, el sombrero y el idioma, es decir, diacríticos que identificaran al pueblo y sus dirigentes. En efecto, la indumentaria fue utilizada como "un mecanismo estratégico y consciente de autoidentificación", para los dirigentes indígenas; a su vez, para las lideresas, se utilizó como "una estrategia política de posicionamiento público de la diferencia” (Pequeño, 2007, pp. 112-116). El uso de la vestimenta propia tras- 
ciende el espacio privado, para situarse en la esfera de la representación política pública, encabezada por líderes y lideresas indígenas.

El levantamiento de 1994, al igual que los levantamientos anteriores, se encuentra registrado en el diario de campo del tayta Juan José Lligalo y en la memoria de los chibuleo como una "movilización nacional por la vida" (Entrevista con J. J. Lligalo, Chibuleo San Francisco, mayo de 2016). Luego de varias reuniones, el día jueves 17 de junio en Santa Rosa, los indígenas de esta parroquia, junto con la de Juan Benigno Vela, decidieron volverse a levantar y unirse a las protestas a nivel nacional. El sábado se abrió la posibilidad del diálogo, en la ciudad de Ambato, con el Subsecretario del Ministerio de Agricultura, Ganadería, Acuacultura y Pesca (MAGAP), y con las autoridades de la provincia de Tungurahua, así como también con los coroneles de Cotopaxi. Sin embargo, no se alcanzó acuerdo alguno. El domingo 19 de junio de 1994 continuaron las negociaciones, a través de representantes de la CONAIE, como lo indica Juan José Lligalo:

La sesión del diálogo se realizó en el teatro del Colegio Pio X de Atocha donde se hizo un debate muy fuerte con Gobernador y jefes del Batallón 38 Ambato. Los mensajes hechos por el presidente Luis Macas no fueron aceptados por estas ignorantes autoridades. Así, se sentó el vicepresidente de la CONAIE Rafael Pandan, dio su brillante exposición que fue aplaudido a cada rato por la multitud del Señor Alcalde, No pudo llegar, habló directamente por el teléfono Luis Macas dijo: el problema no está en... en mí, sino en los indígenas en general, lo que tiene culpa es el Señor Sixto [...]. La gente quedan con mucho amor a la movilización. El siguiente día lunes 20 de junio se cerró por completo la feria de Ambato, por lo que seguramente se rascaron los gamonales, todos los mercados se hicieron vacíos. (Entrevista con J. J. Lligalo, Chibuleo San Francisco, mayo de 2016)

Estas reuniones ocurridas en Ambato, muestran la participación de los indígenas tungurahuenses - en particular de los chibuleo-, en conjunto con la CONAIE, en el levantamiento nacional. Así también ponen en evidencia la resistencia indígena a la opresión del gobierno, que se manifiesta en la paralización de las ciudades y el desabastecimiento de alimentos producido por el cierre de los mercados.

El uso de la vestimenta propia durante este tercer levantamiento fue fundamental, en tanto, como lo indica Juan José Lligalo, "nosotros los indígenas tenemos la esencia, de raíces porque nuestra vestimenta nos hace diferencia" (Entrevista con J. J. Lligalo, Chibuleo San Francisco, mayo de 2016). Es decir que portar la vestimenta propia era una declaración pública de su identidad.

El levantamiento de 1994 - que a nivel nacional fue registrado como los sucesos ligados a la derogatoria de la Reforma de la Ley de Desarrollo Agrario-, para los indígenas chibuleo fue una movilización nacional por la vida, en la que más allá de la derogatoria de una ley, se exigía el respeto de los derechos indígenas.

Los levantamientos de los años 1990, 1992 y 1994, que se fundieron en reclamos por justicia y respeto indígena, coincidían en demandar la legalización del territorio indígena y 
el reconocimiento de su propia identidad. Como se mencionó anteriormente, el respeto fue un factor sustancial para las comunidades involucradas, como recuerda el tayta Juan José Lligalo "desde ahí ya no hubo más [...] nosotros hemos conseguido ¡el gran respeto!” (Entrevista con J. J. Lligalo, Chibuleo San Francisco, mayo de 2016).

Los levantamientos ${ }^{41}$ marcaron el comienzo de una nueva etapa, en la que los chibuleo podían ser respetados en sus prácticas y costumbres, siendo la vestimenta propia uno de los significantes más visibles de este proceso. Durante estos eventos, los grupos indígenas eran liderados por mujeres que, portando su vestimenta propia, adelantaban las marchas y se enfrentan a los militares y policías que intentaban impedir su ingreso a las ciudades. En este escenario, las mujeres retomaron un lugar protagónico - luego de siglos de opresión- en la lucha indígena, convirtiéndose en protagonistas del nacimiento de una nueva etapa en la que los indígenas serían reconocidos como sujetos políticos. Y esto lo lograron mediante una redefinición del campo político, a partir de sus símbolos, discursos y estrategias (De la Torre, 2010). Uno de estos símbolos fue la vestimenta propia.

La estrategia adoptada por el movimiento indígena, basada en las movilizaciones, fue una medida de presión para mantener alerta tanto al gobierno, como a la sociedad mestiza. A partir de los levantamientos de 1990, la sociedad urbana-mestiza tomó conciencia tanto de la existencia de los indígenas - con los que habían estado compartiendo la misma comunidad nacional-, como de los graves problemas que acarreaba ignorar su existencia, de la forma en que se había hecho hasta entonces (Almeida y otros, 1992; Porras, 2005). Las demandas del movimiento indígena acceden a la agenda gubernamental luego de los tres levantamientos, logrando la implementación de la educación bilingüe y la participación indígena en la educación superior (Almeida et al., 1992; Porras, 2005). Este proceso de reconocimiento e inclusión, se tradujo también en la ocupación por parte de los indígenas, de puestos de trabajo en instituciones públicas y privadas, capacitación en gestión política, e incluso su posicionamiento como dirigentes nacionales.

En estos nuevos escenarios, el o la indígena según Guerrero (2008) "puede encausarse en una carrera de 'líder' vestido de poncho o anaco". Para convertirse en líder, "ya no necesita enmascararse en el ropaje, el discurso y los gestos de un ciudadano blanco-mestizo dedicado a la política, como ocurría hasta hace apenas un par de décadas". (p.141). Es en este proceso que las mujeres pueden portar su vestimenta propia en los roles que desempeñan, transformándola en una marca visible del reconocimiento étnico, un diacrítico (Barth, 1976).

De ahí que la vestimenta propia de las chibuleo representa el respeto, que retomando a Fernández (2015a) y Lobäch (1981), indicaría que la indumentaria, en tanto objeto de Diseño, tiene para nuestro caso la función simbólica de representar un reposicionamiento a nivel nacional de su pertenencia étnica, que fue también acompañada de la incorporación de algunas demandas en la legislación nacional.

Pueden entenderse, entonces, los motivos que los chibuleo tienen para portar su vestimenta propia, y que este uso se extienda hasta el año 2016 -último registro etnográfico-, aunque con adaptaciones al contexto de uso (Roach y Eicher, 1992), e incluso de la obligación (Foucault, 2015). 


\subsubsection{Implicaciones políticas de la transformación de la vestimenta propia}

El cuerpo de la mujer indígena con vestimenta propia, como reseñé anteriormente, se convierte en un elemento consciente de autoidentificación, que convierte al cuerpo "vestido y adornado" en un "territorio cultural y político, en donde se inscribe la identidad étnicoracial" (Pequeño, 2007, p. 116). De la Torre (2010) identifica que una prenda en particular, el anaco, se ha convertido, para las mujeres indígenas, en mucho más que un atuendo; e "un acto político de denuncia y demanda" (p. 3). Portar la vestimenta propia es, entonces, una estrategia de autoidentificación, un acto político que denuncia la invisibilización del grupo étnico por parte del Estado-Nación y de la sociedad ecuatoriana.

La vestimenta propia, portada por mujeres chibuleo en el espacio público durante los levantamientos, es similar a la portada en su comunidad, excepto por la propensión al uso de las prendas más nuevas que poseían, con la intención de presentarse "bien elegantes, bien vestiditas" (Entrevista con J. J. Lligalo, Chibuleo San Francisco, abril de 2016). Para las extensas jornadas de los levantamientos, las mujeres iban preparadas, según lo indica este tayta: "unas cargadas shigritas con cucachui, otras [...] de repente cuando toca sentar en levantamiento... ahí van llevando a hacer shuéter a hacer shigra, a tejer alguna cosa" (Entrevista con J. J. Lligalo, Chibuleo San Francisco, abril de 2016).

Las respuestas de mis informantes, respecto a los cambios que ha experimentado la vestimenta propia desde 1990, coinciden en una negativa enfática, como si el cambio de su vestimenta implicara dejar de ser chibuleo, como si la palabra cambio fuese un sinónimo de usar vestimenta mestiza. Según Sánchez (2013) “el cambio vestimentario y su función individualizadora tienen en las sociedades andinas una relevancia y significación muy particulares" (p. 29). Se comprende entonces la resistencia a admitir cualquier cambio.

El conservar su vestimenta es un asunto de identificación, de reafirmación de la identidad. Sin embargo, al indagar de manera más profunda, los mismos interlocutores comenzaban a reconocer las transformaciones y las readopciones de indumentarias indígenas y las adopciones de prendas mestizas, que justificaban debido al clima.

Algunos de los cambios que pueden identificarse entre los levantamientos y el presente, se evidencian en la longitud de las prendas y los materiales:

... la forma de diseño de la ropa del traje antes era... hasta la lishta hemos hecho ya cortitas las lishtas eran hasta acá [...], así ya entonces poníamos las bayetas también todos esto tapado [...] tonces con eso vivían con eso ponía y encima una jerga que decían una jergueta que decían una bayeta... entonces sí se ha transformado bastante. (Entrevista con MLL, Chibuleo San Francisco, noviembre de 2016)

Un ejemplo de readopción los constituyen los tupus, accesorios indígenas prácticamente en desuso para la época del levantamiento de 1990, que se vuelven a usar: "últimamente hemos estado recuperando casi unos 10 años por ahí estamos recuperando los tupus, [...] [antes] eran solo para las personas que tienen dinero" (Entrevista con M. Lligalo, Chibuleo San Francisco, noviembre de 2016). 
La adopción de prendas mestizas, justificadas por el clima frío de Chibuleo y el cambio en el material de prendas como el rebozo - anteriormente hecha de lana de borrego-, está condensada en la chompa - prenda occidental deportiva conocida también como buzoy que se adoptan en el contacto interétnico. Fueron, entonces, los acontecimientos de los 90 los que convirtieron a la vestimenta propia, en un elemento clave del fortalecimiento de la identidad, contexto en el cual surgen readopciones de prendas y/o complementos indígenas en desuso.

En este punto puedo advertir que la función simbólica (Fernández, 2015a; Lobäch, 1981) de la vestimenta propia que representa el respeto, se articula con la función estética y la función de utilidad o práctica (Fernández, 2015a; Lobäch, 1981) de este objeto de Diseño. Por una parte, surgen transformaciones morfológicas como las del anaco; readopciones, como la de la lishta y el tupu, y la adopción de prendas no indígenas. Por la otra, estas modificaciones permiten a las mujeres adaptarse a nuevos contextos de uso.

Los levantamientos no fueron la única forma de alcanzar "la autoafirmación de las nacionalidades y pueblos" (Almeida, 2008, p. 118). Se luchó por el cambio constitucional para la inclusión de los derechos colectivos de las nacionalidades y pueblos indígenas en la Carta Magna. En la Constitución de 1998 "por primera vez se formularon los principios, derechos y libertades demandados por los indígenas" (Almeida, 2008, pp. 118-119), lo que estableció un documento constitucional más democrático y que marcó el camino para acciones futuras.

\subsection{La indumentaria en el reconocimiento constitucional}

Los "pueblos y nacionalidades indígenas" de Ecuador, como se define en las constituciones de la República del Ecuador de 1998 y 2008, hacen uso de su vestimenta de procedencia étnica, como un medio de identificación y diferencia (Barth, 1976) entre ellos y frente a los otros - no indígenas-. "La identificación entre indumentaria e identidad étnica es muy frecuente en los países con presencia indígena" (Karasik, 2010, p. 271). Esta vestimenta, si bien se asocia al cambio cultural histórico (Sánchez Parga, 2013), también responde a factores de orden político que se plasman en derechos dentro de las normas supremas; tales son los casos de Ecuador y Bolivia.

A partir de la década de 1990, los levantamientos indígenas en Latinoamérica y sus demandas por la reivindicación de los derechos étnicos, condujeron a la revisión de las cartas magnas de los países andinos (Briones, 2005; Iturralde, 1997; Ramos, 1994; Spadafora et al., 2010). En efecto, la constitución del año 2008 en Ecuador, y la del año 2009 en Bolivia, reconocen la plurinacionalidad y los derechos de los pueblos indígenas y mencionan a la vestimenta como uno de los derechos de los pueblos indígenas ${ }^{42}$.

La apertura de los gobiernos respecto a la denominada cuestión indígena y la actualidad de las reformas constitucionales de Ecuador y Bolivia son factores determinantes en el establecimiento de la participación de los pueblos indígenas en el Estado-Nación. La Constitución de 1998 de la República del Ecuador constituye el puntal de lanza del proceso de inclusión de los derechos indígenas, que tiene como detonante las manifestaciones nacionales de 1997. 
Es recién en la Constitución de la República del Ecuador de 2008 que se reconoce al Ecuador como un Estado Plurinacional, lo que permite que "los derechos colectivos de los pueblos indígenas tengan garantía de ejecución y aplicación” (Benítez y Garcés , 2014, p. 271). En adelante me centraré en la mencionada Constitución de 2008 y en los artículos que refieren a la vestimenta de los pueblos indígenas. La Constitución define a Ecuador como un Estado único e indivisible, constituido por comunidades, pueblos y nacionalidades indígenas, pueblo afroecuatoriano, pueblo montubio y comunas (Artículo $\mathrm{N}^{\circ}$ 56). En el artículo $\mathrm{N}^{\circ} 57$ reconoce y garantiza específicamente los derechos colectivos de comunas, comunidades, pueblos y nacionalidades indígenas, por lo que este artículo, enmarcado en el capítulo cuarto respecto de los "derechos de las comunidades, pueblos y nacionalidades", confiere protagonismo al grupo indígena dentro de la Constitución y obliga a respetarlos en todos los campos de interacción.

El Estado plurinacional ecuatoriano plasma, en la Carta Magna de 2008, el derecho de las comunidades, pueblos y nacionalidades a fortalecer su identidad y sentido de pertenencia, como textualmente indica en el artículo $\mathrm{N}^{\circ}$ 57: "1. Mantener, desarrollar y fortalecer libremente su identidad, sentido de pertenencia, tradiciones ancestrales y formas de organización social" (Carta Magna, 2008). Este sentido de pertenencia se visibiliza al portar la vestimenta propia, como una de las costumbres y símbolos étnicos que fortalece la identidad (Yépez, 2015).

Este mismo artículo es directo y preciso respecto a la posición del Estado en el uso de la vestimenta, como un derecho colectivo de las comunidades, pueblos y nacionalidades: "Impulsar el uso de las vestimentas, los símbolos y los emblemas que los identifiquen" (Carta Magna, 2008, art. 57, inc 19). Este articulado, al ser parte de la Norma Suprema, incita a su aplicación tanto en la esfera pública como en la privada, según el ámbito de interacción que corresponda.

La vestimenta que se identifica dentro de los derechos de los pueblos y nacionalidades indígenas, expuestos en la norma constitucional, refiere a lo que Eicher (2000) y Hansen (2004) denominan como "vestido étnico". Este vestido surge a partir de la comparación de unos grupos con otros, y sus significados se construyen en el devenir histórico y político de los pueblos. Este vestido étnico, en el caso de los chibuleo, es el que ellos denominan como vestimenta propia. En vista de que la vestimenta es un símbolo de identidad étnica y que constituye un medio de comunicación, es importante mencionar el punto 1 del artículo $\mathrm{N}^{\circ} 16$ de la Constitución de 2008, que promueve el derecho de las personas a mostrar su pertenencia a pueblos y nacionalidades a través de la indumentaria, en tanto medio de comunicación y símbolo de identidad.

Los artículos constitucionales se concretaron, asimismo, en políticas para su aplicación conjunta con el Plan Nacional del Buen Vivir (PNBV) 2013-2017 "Construir espacios de encuentro común y fortalecer la identidad nacional, las identidades diversas, la plurinacionalidad y la interculturalidad", que en su quinto objetivo incluye a la vestimenta dentro de las costumbres que comunican identidades. Más específicamente, los incisos 5.2, 5.7 y 5.7.b reconocen a la indumentaria como parte de la memoria colectiva de los pueblos (Yépez, 2015) y como un medio de difusión de su pertinencia cultural. 
Articulando la ley con la práctica indígena, sostengo que los chibuleo son uno de los pueblos que muestra su pertenencia a través de la indumentaria. Las mujeres de este pueblo, principalmente las mamas, utilizan cotidianamente en sus comunidades la vestimenta propia. Caso similar ocurre con las profesoras y estudiantes de la Unidad Educativa del Milenio (UEM) Chibuleo, que utilizan este tipo de vestimenta diariamente; las profesoras como vestimenta de la cultura y los estudiantes como uniforme de la cultura, como explico más adelante (Ver Figura 2).

Este uso indumentario guarda relación con los artículos de la Constitución que promueven el uso de la vestimenta de las comunidades, pueblos y nacionalidades indígenas, y decantan en políticas educativas —inmersas en las políticas más amplias del PNBV 20132017-, como las establecidas en el Modelo de Educación Intercultural Bilingüe (MOSEIB), y otras entidades del sector económico a través de sus reglamentos internos.

La utilización de la vestimenta propia en la institución educativa no dependió exclusivamente de la aplicación de una normativa, pero sí le otorgó un marco de legitimidad por fuera de la comunidad. De ahí que se pueda poner en relieve la imbricación entre las prácticas identitarias indígenas, en este caso el uso indumentario, y las políticas públicas que las incentivan. Asimismo, en entidades privadas del sector económico, como las cooperativas de ahorro y crédito Mushuc Runa, Chibuleo y Kullki Wasi, fundadas por los chibuleos y reconocidas por el pueblo como las de mayor importancia, el uso de la vestimenta está normado en sus reglamentos internos de trabajo. Reglamentos que exigen a sus trabajadores desempeñar sus tareas con uniforme ${ }^{43}$, basados en los artículos constitucionales referentes a los derechos de los pueblos indígenas. Este uniforme es, entonces, una derivación de la vestimenta propia, o vestimenta que identifica a un pueblo, como consta en la Carta Magna, y a la que se le realizan adaptaciones morfológicas que estandarizan su uso, y a la que eventualmente se le suman prendas mestizas con identificativos institucionales. Se estimuló, así un proceso de revitalización indígena que comenzó a tornarse más visible en muchas naciones latinoamericanas en los últimos veinte años del Siglo XX (Iturralde, 2000).

En los chibuleo esta revitalización se evidencia en las transformaciones de prendas femeninas, como las camisas, la permanencia del anaco e incluso en volver a usar prendas como la lishta, que se encontraba en desuso; lo que Karasik (2010) denomina readopciones. La indumentaria acompaña el proceso de revitalización de los pueblos indígenas, se readopta y transforma para adaptarse a nuevos contextos en los que incursiona la mujer indígena y, en el caso particular de las chibuleo, en los ámbitos laborales en los que participa, con el surgimiento de instituciones educativas y financieras.

Las mujeres indígenas, que portan la vestimenta de su procedencia como lideresas políticas ${ }^{44}$, y como profesionales que se insertan en el sector laboral en puestos a los que sólo accedían los no indígenas, evidencia "el creciente interés entre sectores intelectuales y políticos indígenas por enfatizar su vestimenta y estimular la reproducción cultural de sus colectividades" (Pequeño, 2007, p. 106). La vestimenta indígena "dado el nuevo contexto histórico, político y social del renacer étnico [...] adquiere el sentido de estrategia identitaria [...] un símbolo manifiesto de pertenencia" (Pequeño, 2007, p. 106). 
La participación laboral de las mujeres en instituciones públicas y privadas —en el caso particular de los chibuleo en la institución educativa UEM Chibuleo y en las cooperativas de ahorro y crédito-, tiene un trasfondo que se vincula estrechamente con el uso de la vestimenta de procedencia.

El uso de la vestimenta indígena en espacios educativos, durante años fue motivo de burla por parte de los mestizos, como señalan Guerrero y Ospina (2005) respecto a la educación superior. Esto es confirmado por dos de mis informantes en el caso del uso del sombrero chibuleo, una de ellas recuerda estas escenas sufridas como estudiante en una institución educativa secundaria (Entrevista con M. Lligalo, Chibuleo San Francisco, noviembre 2016); y el otro recuerdo lo refiere una dirigente indígena, mientras viajaba en el transporte público para dirigirse a su trabajo en la CONAIE (Entrevista con A. Punina, Ambato, enero 2015) Por estas razones y otras, como la necesidad de aceptación, algunas mujeres indígenas dejaron de usar esta vestimenta en el ámbito educativo, retomando su uso a partir de los procesos políticos reflexivos de lucha por el reconocimiento de sus derechos.

El uso de su vestimenta propia les generaba por un lado posibles situaciones de hostigamiento por parte de los no indígenas como expuse en el párrafo anterior. Por el otro si no uso también acarreaba inconvenientes, como en el caso de una mujer indígena a quien inicialmente le negaron una beca educativa en tanto suponían que no era indígena debido a que no portaba la vestimenta de su procedencia.

Si bien el portar vestimenta indígena en el ámbito educativo - como estudiantes-, y en el laboral-profesional, compone en el 2016 un escenario distinto al que se enfrentaron las mujeres indígenas durante los levantamientos de la década de 1990, en todo caso, el portar la vestimenta indígena es un significante político que expresa la revitalización identitaria. Regresar al uso de la vestimenta indígena es un "regreso social de la identidad india [...] una afirmación de la voluntad de ser indios y hacerse respetar como tales" (Guerrero y Ospina, 2005, p. 178).

Las experiencias de discriminación sufridas por las mujeres indígenas, que accedían a la educación portando vestimenta indígena, han sido subvertidas y resignificadas a través de su rol profesional, convirtiendo a la educación en "una herramienta para frenar los atropellos", así como un estímulo para "superarse a través del estudio" y ocupar cargos intelectuales antes que físicos (Prieto, Cuminao, Flores, Maldonado y Pequeño, 2005, p. 171). En este sentido, la vestimenta expresa el aumento del capital cultural de las mujeres que se desempeñan en estas instituciones. La educación se ha convertido así en una herramienta "para impulsar y producir reflexiones acerca de la identidad étnica" (Pequeño, 2007, p. 110) y visibilizar a la mujer indígena ecuatoriana en el espacio académico y profesional. Hasta este punto, puede notarse que el uso de la vestimenta indígena, es retomado por las mujeres profesoras luego de la obtención de un título universitario, para mostrar la resignificación étnica en el espacio educativo. Sin embargo, con la educación bilingüe, el reconocimiento de los indígenas en las cartas magnas de 1998 y 2008 y la adecuación a prerrogativas internacionales de inclusión indígena, se marca un nuevo rumbo de la educación en la vida indígena. Las nuevas generaciones de indígenas acceden a una educación en la que se promueven sus prácticas comunitarias y, con ello, el uso de la vestimenta es normado desde la educación básica. En este contexto, las profesoras bilingües portan vestimenta propia y se transforman en modelos a seguir para sus estudiantes. 


\subsection{Indumentaria e instituciones chibuleo}

El acceso de la mujer indígena al ámbito laboral ha sido difícil, más aun al conservar su vestimenta propia. Sin embargo, en las comunidades chibuleo, las instituciones educativas y financieras promueven su participación en estos espacios. Para las chibuleo, el portar la vestimenta indígena en las instituciones, también resignifica su identidad de manera positiva, al mostrar su participación en espacios laborales fuera del campo. Es decir que la indumentaria es una estrategia de posicionamiento público sumamente fructífera. En los siguientes apartados analizo la manera en que surgen las instituciones mencionadas y el lugar que ocupa la indumentaria en ellas.

\subsubsection{Vestimenta de la cultura y uniforme de la cultura en la UEM Chibuleo}

En este apartado estudio la formación de la Unidad Educativa del Milenio Chibuleo, que agrupa educación inicial, educación general básica, bachillerato general unificado y bachillerato internacional. En esta institución, se porta vestimenta denominada, según las categorías nativas, vestimenta de la cultura y uniforme de la cultura.

El acceso a la educación para las mujeres indígenas ha sido difícil "por razones culturales y económicas” (Prieto, Cuminao, Flores, Maldonado y Pequeño, 2005, p. 170). En Ecuador, así como en otros países latinoamericanos, la educación pública extiende su cobertura a partir de los años cincuenta en el marco de políticas desarrollistas (Ossenbach, 1999).

La expansión de la educación ocurrió como respuesta a las demandas indígenas, puntualmente desde fines de la década de 1940. Destacan las escuelas en la provincia de Pichincha, promovidas por líderes como Dolores Cacuango ${ }^{45}$ y maestras normalistas afiliadas al Partido Comunista (Prieto, Cuminao, Flores, Maldonado y Pequeño, 2005).

La educación bilingüe inicia en "un contexto ideológico de integración y asimilación" (Abram, 2004, p. 3), con la intención — por parte de los Estados-Nación-, de desarrollar programas que redujeran el aislamiento de los pueblos indígenas. Esta primera fase fue implementada principalmente por el Instituto Lingüístico de Verano (ILV), las iglesias, las comunidades y las ONG. El fortalecimiento organizativo de los pueblos indígenas en países de Latinoamérica, sumado a la atención que obtuvieron en 1992, hace que los indígenas comiencen a ver cristalizada una de sus reivindicaciones con la educación bilingüe, y también a asumirla como una estrategia para revitalizar su tradición, lengua y cultura (Abram, 2004, p. 1).

La formación de la UEM Chibuleo, inaugurada el 12 de noviembre de 2014, marca la importancia de portar la vestimenta del pueblo. En tanto, por una parte, se norma el uso de la vestimenta con pertinencia cultural - término adoptado por el Estado- para los estudiantes y los profesores indígenas bilingües que internalizan el uso de esta indumentaria, como vestimenta de la cultura.

La UEM Chibuleo es el resultado de los avances educativos de una nación intercultural que posibilita el mismo acceso a la educación a las minorías étnicas. Esta institución forma parte de las Unidades Educativas del Milenio, que surgen a partir de la Declaración del 
Milenio de Naciones Unidas (2000), que destaca la necesidad de crear instituciones que satisfagan las necesidades económicas y sociales de los ciudadanos.

Su implementación en Ecuador, obedece a una política gubernamental que tiene como fin mejorar la calidad de la educación pública y ofrecerla a sectores marginados, lo que explica su implementación en zonas rurales, históricamente excluidas de los servicios educativos. Según manifiesta el Ministerio de Educación (2012) la finalidad del proyecto ha sido mejorar la calidad de los servicios educativos, al dotar de infraestructura educativa integral, recursos físicos y tecnológicos a estas unidades y que se transformen en el referente de un modelo educativo del tercer milenio.

Desde el Estado se pretende que su oferta educativa complemente las necesidades de la comunidad, y aborde la Educación General Básica y el Bachillerato. Para ello, el Ministerio de Educación (2012) promueve en las UEM como parte de la implementación de su Plan Educativo Institucional (PEI) de forma participativa, con el fin de respetar así las diversas características culturales, sociales y económicas.

La UEM Chibuleo tiene sus antecedentes en la década de 1940, en el tiempo de las escuelas de Dolores Cacuango y la lucha por alfabetizar a la población indígena en su propio idioma. Esta serie de instituciones, que se desarrollaron en la comunidad de San Francisco de Chibuleo, decantan en la UEM inaugurada en 2014.

La implementación del currículo de la EIB se sintetizó en el MOSEIB de 1993, que reconocía los contextos culturales y planteaba, dentro del proyecto la integración a la familia, la comunidad, las formas de organización y los saberes (González, 2011). La EIB hundía sus raíces en la intencionalidad política de los movimientos indígenas, respecto a la construcción de un Estado plurinacional. "La EIB representa una fractura real con la escuela moderna, que se asienta en las bases del Estado homogéneo liberal” (González, 2011, p. 54). La UEM Chibuleo constituye un referente nacional de la educación intercultural bilingüe e incrementó su trascendencia al ser la primera institución de estas características en implementar la política de guardianas de la lengua (Ministerio de Educación, 2014). Como afirma el rector de la institución "digamos somos guardianes de la lengua kichwa [...], somos modelos para el país, lo que se haga aquí o deje de hacer aquí, va a influir con la educación en el país para los otros pueblos de indígenas" (Entrevista con A. Guapizaca, Chibuleo San Francisco, marzo 2016). En esta intervención mi informante marca la importancia de esta institución chibuleo, que además de preservar el idioma, preserva la vestimenta como una marca de identidad.

Esta política se aplica para las UEM ubicadas en los sectores de mayor concentración de cada nacionalidad y que tienen la misión de "fortalecer, conservar, promover la lengua ancestral, así como de custodiar las cosmovisiones de las nacionalidades y establecer un diálogo constante entre los saberes ancestrales y el conocimiento occidental" (Ministerio de Educación, 2014).

En el plan decenal de educación (2016-2025) del Ecuador se orientó al fortalecimiento de la MOSEIB para el uso de la lengua y el currículo nacional, complementado con la enseñanza de saberes y conocimientos de cada pueblo y nacionalidad. Para ello, se apoyaron en las unidades "guardianas de la lengua". Estas instituciones, según lo indica el mismo plan, "son referentes en la aplicación del modelo pedagógico, preservan las lenguas ancestrales 
y la cultura propia de cada nacionalidad". Hacia 2015, se encontraban en funcionamiento dos UEM guardianas de la lengua, de las nacionalidades kichwa y shuar, como la UEM Chibuleo (Plan decenal de educación 2016-2025, p.114).

El objetivo de esta política era fortalecer la Educación Intercultural Bilingüe (EIB) en instituciones en las que se aplicaba el MOSEIB. En este sentido, la Unidad Educativa del Milenio Chibuleo es la encargada de preservar la lengua, conocimientos y saberes ancestrales de la nacionalidad kichwa (Ministerio de Educación, 2014).

Dentro de la UEM Chibuleo, la vestimenta juega un papel destacado, en tanto esta es la forma más visible para identificar a los individuos como parte de un grupo étnico determinado, siendo "uno de los símbolos de identidad étnica más reconocibles" (Benítez y Garcés, 2014, p. 187) en Ecuador. A través de mis informantes y la revisión de documentación de la institución, identifico que esta vestimenta, según las categorías nativas es definida como vestimenta de la cultura para el grupo de las profesoras, y como uniforme de la cultura para los estudiantes, como explico a continuación.

Portar la vestimenta de procedencia étnica para acudir a clases, es uno de los compromisos que deben asumir los estudiantes de la UEM Chibuleo, como lo identifico a través de una revisión de documentos institucionales. Por una parte, al interior de la UEM Chibuleo, en su código de convivencia del PEI 2013-2014, se expresa que, en relación con los principios del Sumak Kawsay (Buen Vivir), los estudiantes deben portar "con orgullo la vestimenta de su pueblo, nacionalidad y de su cultura” (PEI 2013-2014). Asimismo, el código establece el uso de un uniforme compuesto por prendas mestizas para los no indígenas.

Entonces, antes que la unidad educativa de Chibuleo se transforme en UEM en el año 2014, la institución ya incluía en su documentación oficial el uso de la vestimenta de su pueblo para los estudiantes que acudieran a sus aulas. Así lo corrobora también el PEI 2011-2012 y lo expresado por uno de mis informantes clave en la UEM: "aquí por ejemplo: los chicos hablan kichwa [...] desde inicial... entonces en la vida, en la práctica” (Entrevista con A. Guapizaca, Chibuleo San Francisco, abril 2016).

Aun cuando en el código de convivencia del PEI 2011-2012, se hace referencia al uso del uniforme en general, sin detallar las prendas que lo componen -excepto por el de cultura física y una bufanda institucional-, contiene un acápite de uniformes en el que se especifica que "los estudiantes deben presentarse con la vestimenta de su cultura". Aquí se asume que se refiere a los estudiantes indígenas, puesto que para el caso de ser mestizo, se detalla otro uniforme.

Es decir que el uniforme de la cultura, está dentro de la categoría uniforme; y el uso correcto se supone exclusivo de los indígenas y se considera una muestra de respeto a la etnia y a la institución (PEI 2011-2012). Por un lado, dentro del uniforme se manifiesta el portar "vestimenta de su cultura" (PEI 2011-2012) sin detallar las prendas a usar —están sobreentendidas-. Por el otro, al referirse al uniforme para mestizos, se detallan las prendas y el color. Finalmente, el uso de lo que se define como uniforme de la cultura, resulta posiblemente más flexible que el uniforme mestizo.

Por otra parte, la intervención del Estado en el cumplimiento del artículo constitucional, que refiere a impulsar el uso de la vestimenta de los pueblos y nacionalidades del Ecuador, llega a materializarse en la propuesta del Plan Decenal de Educación 2016-2025 $5^{46}$. Aquí, 
se incluye la confección del "uniforme con pertinencia cultural" ${ }^{47}$ para el fortalecimiento de la educación inicial y la participación de actores de la economía popular y solidaria en la política. Y dentro de las acciones estratégicas de la política este Plan está orientado a "garantizar y fortalecer la oferta de Educación Intercultural Bilingüe en todos los niveles del sistema educativo, con énfasis en territorios en los que la población sea mayoritariamente de una nacionalidad ancestral" y se aborda la dotación de recursos ${ }^{48}$ educativos con pertinencia cultural y, dentro de ellos, la vestimenta.

Entonces, el reconocimiento que confiere el Estado a los pueblos indígenas a través de la indumentaria, llega al punto de realizar la donación de los uniformes para los estudiantes de las Unidades del Milenio, uniformes que pretenden ser vestimenta de su cultura o uniforme de la cultura. Sin embargo, la realidad es otra.

En la UEM Chibuleo, el Estado dona la indumentaria chibuleo como uniforme, pero no considera las particularidades de los estudiantes de las diferentes comunidades, como lo expresa uno de mis informantes clave: "como son indígenas dan la misma blusa a todos, como querer estandarizar a todos [...], a la hora de mandar estandarizan a todos, es como los cuadernos, como los libros, para todos hacen lo mismo" (Entrevista con A. Guapizaca, Chibuleo San Francisco, noviembre de 2016). Surge una contradicción entre la norma constitucional y su implementación ya que, por una parte, se impulsa el uso indumentario identificatorio de los diversos pueblos y, por la otra, se dona un uniforme que estandariza al indígena, es decir, se promueve una uniformización estatal de un indígena genérico a través la indumentaria (Foucault, 2015).

Las estudiantes mujeres, en particular, no portan la indumentaria donada, según datos etnográficos recopilados. Este fenómeno ocurre debido a que las prendas, presentan materiales con texturas distintas a los utilizados de manera cotidiana en las comunidades chibuleo, con una tipología de bordados de las blusas que no corresponden a los de este pueblo. Incluso algunas prendas no cuentan con acabados, como los bordados en los filos de las bayetas y anacos.

Dentro de la EIB, los profesores bilingües tienen un rol destacado en tanto constituyen modelos a seguir como educadores, y más aún como indígenas. En la UEM Chibuleo, si bien el uso de la vestimenta se norma para los estudiantes, los profesores de procedencia indígena que trabajan en la institución, no tienen ninguna norma que indique el uso de la vestimenta, más allá de la especificación en el código de convivencia que exige "asistir con una presentación adecuada y ser ejemplo de elegancia, probidad, disciplina y trabajo" (PEI 2013-2014). A través de mis estudios etnográficos, identifico que esta presencia adecuada está relacionada con el uso de la vestimenta de la cultura.

Este tipo de vestimenta, portada en la UEM Chibuleo, se encuentra naturalizada, como lo indica el Rector de esta institución: "hay cosas que más bien no se la hace desde la constitución, desde las normas, sino más bien desde los hechos ¿no? [...] en la vida, en la práctica" (Entrevista con A. Guapizaca, Chibuleo San Francisco, abril 2016). De ahí que la forma en que usan la vestimenta los profesores, más aún las mujeres, y las transformaciones que se derivan de estos usos al adaptarse al contexto educativo, se reflejan en la forma de vestir de los estudiantes. 
El uso de la vestimenta de procedencia étnica o "vestido étnico" (Eicher, 2000, p. 64; Hansen, 2004, p. 387) — que de acuerdo a mis investigaciones etnográficas las profesoras y representantes destacados chibuleo denominan como vestimenta de la cultura-, representa un esfuerzo constante por mostrar su identidad en el ámbito educativo.

Como se expuso previamente, insertarse al ámbito educativo portando su indumentaria propia - antes de los levantamientos indígenas de 1990, la introducción de la educación bilingüe y las reformas constitucionales-, significaba exponerse a burlas por parte de los no indígenas. Si bien luego de estos eventos se norma en las instituciones educativas - no superiores - portar vestimenta étnica, el grupo de mujeres que en el presente son educadores indígenas, padecieron dichas burlas al insertarse en instituciones educativas no indígenas. Asimismo, para evitar este maltrato y como consecuencia del contacto interétnico, dejaron de usar - de manera parcial o en una transformación total-su vestimenta, adquiriendo incluso ciertas prendas no indígenas, como sacos o chompas.

Es, en este sentido, que uno de mis informantes expone que "hay un problema en los profesores bilingües indígenas ¿no? que lamentablemente no tuvieron la formación de identidad [...] la universidad es universidad común para todos, entonces al final... al final terminas siendo uno más, entonces... tú estás reproduciendo eso" (Entrevista con A. Guapizaca, Chibuleo San Francisco, abril 2016). Puede entenderse, entonces, que las profesoras en su vida cotidiana utilicen ciertas prendas no indígenas y transformen algunas prendas indígenas; y que luego, al regresar a su comunidad, en su rol de educadoras, con una identidad resignificada y con título profesional, regresen también al uso total de su vestimenta, si bien con ciertas transformaciones.

Lo expuesto genera un punto de tensión en la indumentaria portada por las profesoras indígenas; por una parte, en su calidad de estudiantes universitarias adquirieron ciertas prácticas vestimentarias no indígenas; por la otra, como profesionales y educadoras, son un modelo a seguir, por lo que portan la vestimenta de la cultura.

Se establece, entonces, que la vestimenta de la cultura de las profesoras de las UEM Chibuleo, es el resultado de las transformaciones de la vestimenta propia y de las prácticas vestimentarias adquiridas por las profesionales, en sus procesos educativos no bilingües (Ver Figura 2). Transformaciones que, más allá de la morfología indumentaria como función estética del objeto de Diseño, trascienden a la función simbólica de este objeto. Más aún, evidencian la identidad resignificada del pueblo, al mismo tiempo que el capital cultural adquirido es mostrado y reproducido al interior de la institución educativa chibuleo.

La vestimenta de la cultura que portan las profesoras, da cuenta de un vínculo más fuerte con la identidad del pueblo, que la vestimenta portada por los estudiantes indígenas, que está más ligada a procesos de normalización y políticas estatales. La vestimenta de la cultura refiere a procesos de internalización (Roach y Eicher, 1992) del pueblo en una etnicidad privada que se hace pública (Weaver, 1984), más allá de la normalización (Foucault, 2015) y políticas impuestas por el Estado-Nación. En este punto, aclaro que de ninguna manera desmerezco, la intervención clave del Estado-Nación en el impulso al uso de la vestimenta que identifica a los pueblos indígenas, y que aporta en la revitalización de la vestimenta y de la etnia misma. 
A continuación, explico la formación de las cooperativas de ahorro y crédito, instituciones financieras chibuleo donde las mujeres portan uniforme propio. Estos establecimientos, constituyen otro de los hitos que permiten explicar la relación dialéctica indumentaria-identidad.

\subsubsection{Uniforme propio en las cooperativas de ahorro y crédito chibuleo}

La importancia de estudiar el uniforme propio portado por las mujeres de las cooperativas de ahorro y crédito, radica en que este da cuenta de la identidad chibuleo resignificada a raíz de la participación de la mujer en un trabajo por fuera de las actividades agrícolas y el aumento de capital económico de los chibuleo.

Los chibuleo, como expuse en el capítulo 1, son un caso paradigmático del proceso de diversificación económica vivenciado en la provincia de Tungurahua, que decantó en las cooperativas de ahorro y crédito. En este proceso, la vestimenta propia ha desempeñado un rol de diferenciador étnico, que acompaña a las mujeres en sus labores de campo, de comercio y, dentro de éste, de intermediación. Posteriormente a que las mujeres ocuparan el espacio público en las calles de las ciudades, la indumentaria pública se transformó en el uniforme utilizado en estas cooperativas. El comercio incide directamente en la generación de instituciones financieras chibuleo, como lo indica Tupac Caluña, quien ocupa un cargo público en el ámbito educativo:

... la gente de acá de Chibuleo es de naturaleza comerciante, hacen negocio, ha salido fuera de la provincia, por eso la generación de las instituciones financieras ¿por qué? porque aquí nace [...] porque nuestros abuelos fueron comerciantes, negociantes de ajo cebolla entonces después con el otro mercado se ha abierto a la población. (Entrevista con T. Caluña, Chibuleo San Francisco, enero 2016)

Las ganancias económicas, generadas a partir del comercio y la intermediación, les permitieron acumular capital y abrieron posibilidades de inversión. Los chibuleo, o al menos algunos de ellos, decidieron invertir su capital en la generación de cooperativas de ahorro y crédito desde la década de 1990 (Carrión, 2011), y continuar invirtiendo en la profesionalización de sus hijos, en su capital cultural (Bourdieu, 2001, 2012), rompiendo con ello, relativamente, las dificultades de acceso financiero de su etnia (Ospina, y otros, 2011b). En palabras de Bourdieu (2001), se puede decir que el capital económico chibuleo creció con las entidades financieras, y también derivó en el aumento del capital cultural con la profesionalización, que pudo reconvertirse nuevamente en capital económico.

El dificultoso acceso financiero de los chibuleo, no es particular de esta etnia, pero sí la forma en que enfrentaron estas dificultades con sus recursos disponibles. Carrión (2011) indica que fue apenas en la última década, que los indígenas comenzaron a ser considerados sujetos de crédito por las entidades financieras blanco-mestizas, como lo confirma un informante clave chibuleo: 
En el sector rural pocas personas tenían acceso a los créditos ¿si? ... ¿por qué? porque requerían escritura, garantes y bueno hay algunas financieras que lo confiaron pero la mayoría no, entonces a raíz de eso [...] nace en el centro de la ciudad y abarca ya con más confianza a toda población indígena y más que todo sector rural... no con trámites largos no con muchos papeleos sino simplemente da la confianza, entonces ¿ cómo surgió? por la confianza. (Entrevista con T. Caluña, Chibuleo San Francisco, enero 2016)

Es decir, que la identidad se consideró un indicador de solvencia económica. Las barreras financieras que existían para los indígenas, han disminuido a partir de la generación de entidades donde son ellos mismos quienes otorgan créditos, como es el caso de los chibuleo. Las cooperativas de ahorro y crédito chibuleo, surgen a partir del capital acumulado en los bancos comunales que mujeres indígenas supieron emprender, como una de sus actividades de diversificación económica y, como todos los proyectos de diversificación que inician las mujeres, al consolidarse empiezan a ser dirigidos por hombres (Carrión, 2011). Asimismo, las políticas gubernamentales de la década de 1990 permitieron la asociación $y$, con ello, incentivaron la generación de entidades financieras, como lo indica un dirigente político chibuleo respecto a la razón por la cual surgen las cooperativas de ahorro y crédito: "el Estado... facilitó toda esta parte del derecho a asociarse ¿no? tonces por ahí encuentro de amigos, de compañeros de conocidos de pronto se idean de hacer una actividad tal o cual" (Entrevista con A. Punina, Ambato, enero 2016).

Los efectos producidos por la apertura de las cooperativas de ahorro y crédito son notorios entre los chibuleo. Se evidencia una marcada diferenciación social y económica entre los beneficiarios directos - socios capitalistas - , y el resto de la población, que se beneficia de manera indirecta o no lo hace en absoluto. Asimismo, estas cooperativas, como la más grande de la provincia, Mushuc Runa ${ }^{49}$, han generado puestos de trabajo para los indígenas (Ospina et al., 2011b).

El nuevo contexto de trabajo para los indígenas, generó un abandono parcial o total de sus actividades tradicionales. Un nuevo "clima social", como lo denomina Ospina (2011b), generador de "nuevas aspiraciones y necesidades [...]: estudiar, endeudarse, invertir, pero también consumir o poseer símbolos de estatus” (p. 174). Estos símbolos de estatus son representados a través del uniforme propio en las cooperativas.

En mis estudios etnográficos, los informantes clave reconocen a tres cooperativas de ahorro y crédito lideradas por chibuleos, como las de mayor importancia, razón por la cual los estudios indumentarios que refieren a dichas entidades financieras. Ellos son: la cooperativa de ahorro y crédito Mushuc Runa, reconocida oficialmente con acuerdo del Ministerio de Bienestar Social No 1820 el 17 de diciembre de 1997; la cooperativa de ahorro y crédito Chibuleo creada el 17 de enero de 2003; y la cooperativa de ahorro y crédito Kullki Wasi creada mediante acuerdo ministerial $N^{\circ} 6582$ del 23 de enero de 2003.

Las entidades financieras han traído consigo el uso vestimentario indígena, que fortalece la identidad chibuleo y posiciona su imagen pública. El uniforme propio, como se refieren mis informantes a la indumentaria normada que usan en estas instituciones, acompaña el nuevo 
rol en el que se desempeñan las mujeres y evidencia la resignificación identitaria chibuleo. Según indica el informante Tupac Caluña, la exigencia de utilizar vestimenta indígena en las instituciones, equivale a tener "indígenas bien vestidos", refiriendo con esta expresión a la utilización de vestimenta propia. La importancia de portar esta indumentaria, reside en la posibilidad de identificarse en un marco de equidad étnica y respeto, entre iguales que visten diferente: "nosotros hacia los mestizos el respeto ¿no? y los mestizos hacia nosotros así el respeto” (Entrevista con T. Caluña, Chibuleo San Francisco, enero 2016).

La utilización normada de la indumentaria en las instituciones financieras, decanta en un proceso de transformación de la silueta. La vestimenta propia de silueta volumétrica utilizada en el campo se reduce hasta una silueta insinuante (Saltzman, 2004) ${ }^{50}$, que se adapta a las condiciones del ámbito laboral.

El uniforme propio de las instituciones financieras tiene normativas para cada día de la semana, lo que va disciplinando los cuerpos (Foucault, 2015) de las mujeres chibuleo. Estas normativas incluyen tipologías de blusas, colores de los bordados en los filos de anacos, bayetas y lishtas, en concordancia con los colores de los chumbis tejidos. Incluye también a indumentaria no indígena, como calzado tipo salón de tacón medio y alto, medias de nailon, y otras prendas que las mujeres usan con identificativos de la institución, como sacos, chompas y chalecos.

A través de lo expuesto en el presente capítulo, puedo señalar que la relación dialéctica indumentaria-identidad da cuenta, por un lado, de haber ganado respeto, lo que se traduce en el acceso a derechos. Por otro lado, ese acceso a derechos fue de la mano de un creciente capital cultural y económico chibuleo. Dicho capital cultural, se forjó a partir de la inversión de los chibuleo en los estudios para lograr la profesionalización de sus hijos, y de la implementación de la educación bilingüe en instituciones educativas indígenas. El capital económico, consecuencia del capital acumulado por los chibuleo en sus actividades de comercio y diversificación económica - en las que la mujer cumple un rol destacado-, fue invertido en la creación de cooperativas de ahorro y crédito dirigidas por hombres de este pueblo.

En todos estos ámbitos, la indumentaria es un diacrítico que refuerza y marca la pertenencia étnica en diferentes momentos. Esta representación de los chibuleo a través de la vestimenta, pone de relieve su función simbólica como objeto de Diseño. Vestimenta que al ser usada por las mujeres, las identifica al interior del grupo y las diferencia de los otros en la trama cultural. Se produce entonces un espacio de interacción, denominado interfaz (Fernández, 2015b; Bonsiepe, 1998), representado en el artefacto vestimentario de diseño, tal como desarrollo en el último capítulo.

En el siguiente capítulo, se exploran las construcciones identitarias de las mujeres; los usos $\mathrm{y}$ transformaciones de la vestimenta en los roles que asume en los diferentes contextos de su vida cotidiana. 


\section{Capítulo 3: Usos y transformaciones vestimentarias de la mujer chibuleo}

El presente capítulo explora los usos de la indumentaria, desde los distintos roles que asumen las mujeres chibuleo en su cotidianidad, como vehículos transmisores de sus rasgos identitarios. Para ello, en los siguientes apartados identifico, por una parte, los tres roles que surgieron de mi trabajo etnográfico, acerca de las mujeres chibuleo y que ellas distinguen con categorías nativas específicas como: las mamas, las profesoras y las de las cooperativas. A su vez, estas categorías, al interior del grupo de mujeres, se corresponde con un tipo de vestimenta y un uso específico, que ellas identifican en términos de: vestimenta propia, vestimenta de la cultura y uniforme propio, respectivamente.

\subsection{Construcciones identitarias de la mujer chibuleo. Usos indumentarios coti- dianos}

La mujer chibuleo, tal como se ha puesto de manifiesto a lo largo de la tesis, ha sido clave en la consolidación de la identidad étnica de su grupo. Su activismo en los levantamientos indígenas de 1990; su destacada intervención en la diversificación económica, y su desempeño en instituciones educativas y financieras, son elementos que desbordan en contribuciones útiles para evidenciar su protagonismo en los procesos de reivindicación de derechos.

Durante los años de trabajo etnográfico en las comunidades chibuleo, pude notar diferencias entre las mujeres, manifiestas a través del uso de distintas indumentarias. Lo antedicho, tal como Gómez (2016) sostiene en el estudio de las mujeres tobas del Chaco argentino, muestra "tres modelos de feminidad que representan tres formas de 'ser mujer" (p. 222). Así, en mis investigaciones, identifico tres formas de ser mujer chibuleo que constituyen construcciones identitarias, cimentadas en una continua negociación entre la etnicidad privada y la pública (Weaver, 1984). Estas categorías - las mamas, las profesoras, y las de las cooperativas-, conllevan ciertos habitus (Bourdieu, 2012), entre los que destacan características indumentarias propias.

Las mujeres chibuleo, a diferencia de otros pueblos de la provincia de Tungurahua ${ }^{51}$, portan la vestimenta propia en su cotidianidad, para desarrollar sus actividades productivas y profesionales. Las mamas, las profesoras y las de las cooperativas, se colocan la indumentaria con ciertas particularidades prácticas y estéticas, que les permiten desenvolverse en su vida laboral, características que trascienden al plano simbólico cuando aportan a la construcción de arquetipos indumentarios, como explico en el siguiente capítulo.

A continuación, doy cuenta de las actividades que desempeñan las mamas, las profesoras y las mujeres de las cooperativas, en concomitancia con sus usos indumentarios cotidianos. 


\subsubsection{Las mamas}

Ante la pregunta realizada en el marco del trabajo etnográfico, respecto a qué significa ser una mama, una de mis informantes clave, ofrece una respuesta categórica: "es más por el respeto que se tiene [...] es el respeto" (Entrevista con M. Lligalo, Chibuleo San Francisco, noviembre de 2016). Ser mama implica ser una mujer de avanzada edad, que por su forma de vida es respetada al interior de la comunidad, y que lo expresa, entre otras cosas, mediante el uso de la vestimenta propia (Ver Figura 2).

Esta indumentaria es reconocida como aquella que, habiendo pasado de generación en generación, fue portada por las mujeres durante los levantamientos de 1990, y continúa siendo utilizada en la actualidad. La vestimenta propia comprende anacos, chumbis, rebozos, lishta, camisa bordada, sombrero, tupu, wallkas y orejeras, además de buzos, sacos, calzado tipo mocasín o botas, y medias.

$\mathrm{Al}$ interior de las mamas, los chibuleo distinguen dos subcategorías. La primera de ellas incluye a las mujeres de una edad aproximada entre 70 y 80 años, nacidas en el campo y que participaron activamente en los levantamientos de la década de 1990. En el presente, lejos de ser activistas políticas, se dedican al cuidado de su familia, del campo y de los animales, como Juana Til y Andrea Pacari, ambas esposas de taytas chibuleo ${ }^{52}$.

La segunda subcategoría se compone de mujeres entre los 45 y 55 años, reconocidas como mamas por la comunidad, con base en dos razones. La primera responde a que su forma de vida -observada entre 2014 y 2016 - , es similar a las mamas del primer grupo. La segunda radica en que han contribuido al desarrollo del pueblo, desde cargos comunitarios. $\mathrm{Al}$ igual que las mujeres de la primera subcategoría, también nacieron en el campo, crecieron en el período de los levantamientos indígenas y la revitalización étnica, y desarrollan actividades locales como líderes, que generan respeto al interior de la comunidad. En este grupo identifico a Tránsito Manobanda, presidenta de la UNOPUCH, y a Juana Pandashina, esposa de uno de los hijos de taytas chibuleo.

Para la presente investigación, si bien me centro en las mamas del primer grupo, también me referiré a las mamas del segundo grupo, cuando sus intervenciones aporten al esclarecimiento de los usos y transformaciones de la vestimenta propia. En los siguientes párrafos, doy cuenta de la rutina o forma de vida de las mamas en conjunto con sus usos indumentarios.

En una jornada normal, las mamas se levantan muy temprano en la mañana para atender a su familia en la preparación del desayuno. Las actividades siguientes varían entre alimentar a sus animales y trabajar en el campo, como lo manifiesta la mama Andrea Pacari:

... levantamos ya cocinamos... comimos ya asegurar animalitos amarrar a chulla borreguito... ya vamos a asegurar, así vamos asegurando animalitos vuelta viendo que trabajar o estando ka trabajar ya vamos a trabajar... [...] en la tierra nomás nosotros sabemos ir a sembrar... sembramos papitas, habitas o así potreritos... hacimos siempre trabajando, trabajando. (Entrevista con A. Pacari, Chibuleo San Francisco, diciembre 2016) 
Mis insistentes preguntas respecto a cuál era la vestimenta utilizada para tales labores cotidianas y, en específico, para trabajar en el campo, finalmente dieron frutos. Aunque sin extenderse en explicaciones, Andre Pacari respondió: "ya viejito puesto, pero de esto mismo [...] Cuando vamos a sembrar... en la tierra con en el polvo, ya siempre como andamos así... trabajar casi siempre [...] se ensucia" (Entrevista con A. Pacari, Chibuleo San Francisco, diciembre 2016).

En esta circunstancia, la mama se refirió al estado de sus prendas y a las razones por las que portaba ropa vieja para trabajar, pero no a su composición. La descripción de la indumentaria que ella portaba quedó, sin embargo, registrada en mis notas de campo, que introduzco a continuación.

La mama porta un rebozo negro que hace las veces de sobretodo para la parte superior, cuya longitud llega hasta la cadera, acompañado de la lishta blanca a rayas. Ambas prendas, utilizadas para pachallir — cubrir la espalda-, se sujetan en el centro con un tupu de plata. En la parte interna superior porta una camisa blanca bordada - en colores verde, magenta y azul violáceo- con cuello redondo y una abertura vertical en el centro frente. Debajo de esta prenda lleva un buzo - no indígena- rojo que cubre su cuello y sobre esta misma porta un saco - no indígena- de color violeta que llega a estar en contacto con la lishta. Dos anacos negros envuelven su cuerpo desde la cintura hasta cubrir la rodilla, cada uno sujeto con un chumbi. En la envoltura de esta prenda, se observan varios pliegues en la parte delantera que aumentan el volumen de su silueta. El rostro de AP es enmarcado por un sombrero blanco y la marga accha - mechón de cabello cuyo largo alcanza hasta el final de la oreja-. Sus pies están cubiertos por botas bajas de color café - mestizas - que llegan hasta el final de la pantorrilla. (Notas de Campo, entrevista con A. Pacari, Chibuleo San Francisco, diciembre 2016)

Continuando con el tema de las labores desempeñadas por las mamas, además del trabajo en el campo - cuidado de animales y de sus cultivos-, tienen a su cargo todas las preparaciones culinarias y las actividades domésticas. No obstante, antes de la preparación de la última comida, las mamas aseguran a sus animales. Para finalizar el día, luego de servir los alimentos a su familia, se dirigen a descansar. Para esta última actividad del día, el descanso nocturno, utilizan pijama desde hace más de 35 años.

Tanto Juana Til como Andrea Pacari, pertenecen el primer grupo de mamas, y portan sombrero sobre la marga accha, rebozos, chumbis, anacos del mismo largo - desde la cintura hasta cubrir la rodilla-, entre las prendas y accesorios que identifiqué como vestimenta indígena. Asimismo, ambas portan sacos, buzos, calzado tipo mocasín y botas no indígenas. Las diferencias encontradas, al interior de este grupo de mamas, radican en el número de anacos y el color de los rebozos que usa una y otra. Juana, de 81 años de edad, se coloca cuatro anacos, uno de color azul y los otros tres de color negro; y dos rebozos azules - uno elaborado en lana de borrego-. Por su parte, Andrea, de 73 años de edad, porta solo dos anacos y un rebozo negros, complementados con una lishta. 
En cambio Tránsito Manobanda, que entre 2009 y 2016 ejerció la presidencia de la UNOPUCH, y pertenece al segundo grupo de mamas, debió intercalar estas actividades públicas con las tareas domésticas. Según sostuvo esta informante clave: "siempre para salir a otras cosas las ropitas que tenemos ya un poquito más limpio más buenas así para salir, siempre para los trabajos usamos así más viejitos, de ahí las ropas no son diferentes que tenemos nosotros" (Entrevista con T. Manobanda, Chibuleo San Francisco. Diciembre 2016). Entonces, al igual que en el primer grupo de mamas, la vestimenta utilizada de este segundo grupo, no se distingue por su tipología, sino que se vincula al estado de las prendas portadas: desgastadas para el trabajo en el campo, y nuevas y limpias para otras actividades.

Además, pude advertir dos fenómenos. Por una parte, todas las mamas chibuleo, sin excepción, portan anacos, chumbis, rebozos, lishta, camisas, sombreros, tupu, wallkas y orejeras junto con buzos y sacos - suéteres- no indígenas (Ver Figura 2). Probablemente porque estas últimas prendas han sido apropiadas (Bonfil Batalla, 1991) como parte de la indumentaria chibuleo, como lo evidencia el hecho de que ninguna intentó quitárselas para ser fotografiadas. Por la otra, el segundo grupo de las mamas, que en ocasiones porta chompas - prenda no indígena - para trabajar en el campo, sólo permiten ser fotografiadas una vez que se deshacen de esta prenda.

\subsubsection{Las profesoras}

Las profesoras son mujeres chibuleo, con edades que oscilan entre los 30 y los 50 años, hijas de chibuleo, que han accedido a la educación superior y trabajan en las unidades educativas del milenio. El grupo de las profesoras evidencia el aumento del capital cultural chibuleo, tanto por los títulos profesionales adquiridos, como por el trabajo desempeñado en instituciones educativas.

Las profesoras definen a la indumentaria que portan como vestimenta de la cultura, constituida por: anaco, chumbi, bayeta o lishta en su reemplazo, blusa, sombrero blanco - en días específicos-, tupu, collares y aretes. Además del uso de saco, calzado tipo salón de tacón alto o medio con medias de nailon, y una chompa con un identificativo del Ministerio de Educación, prenda de la que se deshacen para ser fotografiadas (Ver Figura 2).

La imagen que reflejan las mujeres con la vestimenta de la cultura, se convierte en un modelo a seguir por parte de sus estudiantes. Estas mujeres, además de desempeñar sus actividades educativas, atienden a su familia y desarrollan algunas labores en el campo. En este grupo se incluye Martha Lligalo, de 43 años; María Melchora Pilamunga, de 38 años; y Rita Baltazar, de 47 años, las tres docentes de la UEM Chibuleo.

En la mañana, las profesoras atienden a su familia en la primera comida del día y se dirigen a impartir clases. En efecto, María Melchora describe la vestimenta utilizada en su jornada laboral como profesora: "la bayeta, el tupo, las wallkas, el anaco, las blusas", además de mencionar a la lishta (Entrevista con M. Pilamunga, Chibuleo San Francisco, noviembre 2016). Por la tarde, las profesoras se ocupan de trabajar en el campo, para lo cual tienen que estar preparadas. Como menciona Rita Baltazar: "tenemos que estar bien fajados para poder cargar o sea nosotros no somos como de la ciudad nosotros no somos débiles, nosotros somos 
duros y fuertes" (Entrevista con R. Baltazar, Chibuleo San Francisco, noviembre 2016). Esta actividad se relaciona con la forma de ceñir el chumbi. Con ello indica que tanto las actividades realizadas en el campo, como en el hogar, requieren portar el anaco hasta las rodillas. Mientras que, para acudir a la institución educativa, se coloca un anaco de una dimensión mayor, que le cubre hasta los tobillos. Algo similar menciona Martha Lligalo, aun cuando según indica- su padre no le ha dado su parte de terreno para trabajar por no estar casada, detrás de su casa tiene un pequeño terreno "para la hierba de los cuyes nomás" (Entrevista con M. Lligalo, Chibuleo San Francisco, noviembre 2016). Esta mujer trabaja con el azadón para sacar abono para los animales, es decir que efectivamente trabaja en el campo y cuida animales. Aunque este tipo de actividades no son las únicas que desempeña en la tarde, también es trabajadora externa de una cooperativa de ahorro y crédito.

En todos los casos, las labores que las profesoras realizan en la tarde se orientan a la agricultura, al cuidado de animales y al hogar. Para desarrollar estas actividades, portan vestimenta propia desgastada, a diferencia de la que ocupan en la UEM Chibuleo, o también utilizan ropa no indígena como pantalones. Estos usos indumentarios se deben, tal como sostienen mis informantes, tanto al costo de la indumentaria indígena, como a la necesidad de conservarla para acudir al trabajo en las instituciones, como a la búsqueda de comodidad. Por la noche, las profesoras utilizan el pijama, que es una prenda no indígena. A partir de lo expuesto, puedo advertir que aun cuando las mujeres no consideran que la vestimenta de la cultura sea un uniforme con el que acuden a trabajar en la unidad educativa, al salir de esta institución cambian la indumentaria por otra. Este hecho, da cuenta de una ocasión de uso específico de la vestimenta de la cultura, que se ciñe exclusivamente al ámbito de las instituciones educativas.

La coexistencia entre la vestimenta de la cultura y la indumentaria no indígena, es un hecho evidente entre las chibuleo. Los costos de la primera, junto con el clima de la comunidad y la poca practicidad de la indumentaria propia para ciertas actividades del grupo de las profesoras, obligan al uso de la segunda.

Las identidades son móviles, y como tales, están en constante proceso de transformación (Abramoff, 2001; Barth, 1976; Beckett, 1998; Bonfil Batalla, 1991; Jackson, 1995). Este carácter dinámico de la identidad explica procesos similares a los reseñados hasta aquí, como el hecho que se sirvan de la función de utilidad o práctica que puede ofrecerles cierta vestimenta no indígena. Sin embargo, las mujeres chibuleo se distinguen porque mantienen la mayor parte de las prendas indígenas en la cotidianidad de su trabajo profesional, especialmente las profesoras y las de las cooperativas.

\subsubsection{Las de las cooperativas}

Las de las cooperativas, son mujeres chibuleo que tienen edades entre los 20 y los 40 años, y trabajan en las instituciones financieras. Estas mujeres cuentan con educación secundaria o bachillerato y están en proceso de culminar - o han culminado- su formación en educación superior. Al interior de las cooperativas ocupan los cargos de jefas de departamentos; atención al cliente; caja; archivo y bodega; e información. 
En estas instituciones, portan lo que ellas categorizan como uniforme propio, que se identifica como una categoría nativa y es incorporado en estos términos para el análisis. Así, a los fines de esta tesis, se entiende al uniforme propio, como el conjunto de prendas y accesorios cuyo uso está normado en cada institución. Estas prendas y accesorios son: anaco, chumbi, blusa, bayeta o lishta, tupu, sombrero, collares, aretes, zapatos de tacón alto o medio con medias de nailon (Ver Figura 2).

Los usos normados, refieren al establecimiento de determinadas prendas y accesorios para cada día de la semana, variando en elementos como la tipología de la blusa, el color de los filos de los bordados del anaco, la bayeta y el chumbi, que deben coincidir con los colores del bordado en las blusas y el tejido del chumbi. Tanto el uso de la lishta como del sombrero, responden a uno o dos días específicos de la semana. Además, las mujeres de las cooperativas utilizan prendas no indígenas con identificativos institucionales, como sacos, chalecos y chompas.

Las mujeres de las cooperativas evidencian el capital económico acumulado por la etnia, en tanto representan a las cooperativas de ahorro y crédito forjadas por los chibuleos. En este grupo entrevisté a Cecilia Tiche, de 34 años, y Josefina Walo, de 36 años, de la cooperativa de ahorro y crédito Mushuc Runa; Manuela Llambo de 37 años, y Kuri Caluña, de 30 años, de la cooperativa de ahorro y crédito Chibuleo; María Mungabusí, de 37 años, y Elena Tiche, de 32 años, de la cooperativa de ahorro y crédito Kullki Wasi. Estas informantes trabajan en las tres instituciones chibuleo más destacadas, en las que me fundamento para dar cuenta de este proceso.

Las de las cooperativas, en su mayoría, residen en Chibuleo, y se trasladan diariamente a la ciudad para trabajar en el ámbito institucional financiero, portando el uniforme propio. Las mujeres de las cooperativas, vinculan explícitamente el hecho de trabajar en estas instituciones, con la necesidad de superación y de mejorarse a sí mismas, a través del abandono de la labor física en el campo y el hogar -impulsado por sus padres- y su reemplazo por un trabajo de carácter administrativo en las ciudades. El uniforme propio que portan constituye una variación de la vestimenta propia, que se adapta al contexto de las instituciones financieras.

Este grupo de mujeres, antes de ingresar a trabajar en las cooperativas, utilizaban la vestimenta propia. Así lo exponen informantes de las tres cooperativas mencionadas anteriormente. De Mushuc Runa, Cecilia Tiche sostiene: "yo siempre he utilizado mi vestimenta de chibuleo todos los días desde que nací" (Entrevista con C. Tiche, Ambato, diciembre de 2016) y Josefina Walo expresa "desde niña ya se ha crecido con anaco" (Entrevista con J. Walo, Ambato, diciembre 2016). De la cooperativa Kullki Wasi, mis informantes expresan algo similar. En palabras de María Mungabusí: "desde chiquita yo he vivido en la comunidad y desde chiquita me han vestido así con anaco" (Entrevista con M. Mungabusí, Ambato, diciembre 2016). En todas las intervenciones pude advertir que las mujeres fueron socializadas en el uso de la vestimenta propia - particularmente del anaco- desde niñas, influenciadas principalmente por sus padres. Cuando las mujeres ingresan a trabajar en las cooperativas, la vestimenta propia sufre algunas adaptaciones que se encuentran normadas por las instituciones, proceso que da emergencia al uniforme propio.

Según datos que surgen del trabajo de campo, la vestimenta propia es adaptada para su uso en las instituciones financieras, convirtiéndose en un uniforme propio. Su uso está 
reglamentado para cada día de la semana, estipulando asimismo las particularidades de uso de la vestimenta no indígena.

Las mujeres de las cooperativas cumplen un horario de oficina, iniciando sus tareas entre las siete y ocho de la mañana, y finalizando pasadas las seis de la tarde. En la mañana, luego del desayuno en sus residencias en las comunidades chibuleo, se dirigen a la ciudad de Ambato para iniciar el trabajo en las cooperativas, previo a dejar a sus hijos en centros educativos, ya sea en Chibuleo o en la ciudad de Ambato.

$\mathrm{Al}$ interior de las cooperativas, las mujeres ocupan diferentes puestos de trabajo, con posibilidades de ascenso, como en el caso de Manuela Llambo, que relata haber "pasado por diferentes áreas, "por ejemplo, yo empecé con atención a cajas, atención a clientes, jefatura de cajas, inversiones" (Entrevista con M. Llambo, Ambato, diciembre 2016). O también lideran departamentos desde su inicio, como en el caso de Cecilia Tiche, cuya tesis condujo a la creación del departamento de talento humano (Entrevista con C. Tiche, Ambato, diciembre 2016). Independientemente del puesto de trabajo que ocupan, las mujeres portan un único uniforme propio al interior de cada institución. Estos uniformes tienen diferencias leves entre las distintas instituciones de ahorro y crédito.

En Mushuc Runa, la indumentaria indígena utilizada a diario, según mencionan mis informantes y se constata en mis observaciones, son: anaco negro, bayeta negra o lishta en su lugar, y faja o chumbi. De acuerdo al reglamento, para cada día de la semana se colocan el sombrero, una tipología de blusa bordada específica y los collares (wallkas). Dentro de las prendas no indígenas portadas en la institución están los sacos con "modelo chaquetas", que cumple, según Cecilia Tiche, dos funciones: cubrirse del frío e identificarlas con el nombre de la cooperativa, para diferenciarlas de otras instituciones (Entrevista con C. Tiche, Ambato, diciembre 2016). Esta intervención expone la utilización de identificativos institucionales ${ }^{53}$ en las prendas no indígenas portadas por las chibuleo.

En la cooperativa de ahorro y crédito Chibuleo, el uniforme propio también comprende indumentaria indígena y no indígena. Respecto al uso de las blusas, una interlocutora menciona que "la cooperativa tiene cinco modelos, como son cinco días que trabajamos, cinco modelos de camisa" (Entrevista con M. Llambo, Ambato. Diciembre 2016). Estos usos normados, en particular de las blusas con diferentes diseños para cada día de la semana, son características propias del universo del vestuario formal no indígena, dentro del segmento protocolario (Jaramillo, 2010).

Dentro de las particularidades no indígenas que se insertan en la indumentaria propia, se incluyen los chumbis o fajas, con el logo de la cooperativa. Es decir, en esta indumentaria indígena, también se aplican los identificativos institucionales.

En definitiva, las prendas indígenas utilizadas en esta cooperativa son la bayeta, el anaco, el chumbi o faja, las blusas, las wallkas y el sombrero. Asimismo, se utilizan alpargatas calzado que de acuerdo a los taytas chibuleo, es de procedencia indígena pero no originario de chibuleo-. Dentro de la indumentaria no indígena, se encuentra el uso de la chompa, zapatos de taco y aretes. Todos cuentan con identificativos institucionales, tanto en la vestimenta indígena como no indígena, que se articulan dando origen al uniforme propio. En la cooperativa de ahorro y crédito Kullki Wasi, la indumentaria portada para trabajar, al igual que en las otras dos instituciones financieras expuestas anteriormente, es el uniforme 
propio. La indumentaria portada por Elena Tiche en el momento de la entrevista — día jueves - incluye anaco negro, chumbi, blusa blanca con bordados - en colores: azul, violeta, magenta y verde-, bayeta sujeta en el hombro con un $t u p u$, collar, aretes y zapatos negros de tacón.

Con estas intervenciones puedo señalar una vez más la convivencia de la vestimenta indígena con la no indígena, que constituye la categoría nativa de uniforme propio. La indumentaria que conforma esta última tipología indumentaria de las mujeres en Kullki Wasi se compone de los siguientes elementos: anaco negro, blusa blanca, faja o chumbi, bayeta, cinta - para envolver el cabello_, collar rojo — wallkas -, lishta y sombrero. Estos últimos cuatro objetos vestimentarios indígenas son utilizados sólo en días específicos, mientras que los cuatro primeros son de uso diario - lunes a viernes-. Asimismo, las mujeres de esta cooperativa portan chaleco, buzo, zapatos de tacón, con características que identifican a los uniformes institucionales.

Los usos normados del uniforme propio en las instituciones financieras se relacionan con un doble proceso de marcación: por un lado, las identifica como parte del pueblo chibuleo y, al mismo tiempo, señala su pertenencia a una institución determinada. Estos usos combinan indumentaria indígena con no indígena, en cuyo caso también tienen identificativos institucionales. Éstos pueden estar tejidos en los chumbis, como en el caso de la cooperativa Kullki Wasi, o bordados en las prendas no indígenas adoptadas, como sacos, chalecos y chompas en el caso de las tres instituciones.

El uso de prendas no indígenas, se debe tanto a la identificación de la institución, es decir, a la diferenciación simbólica de la indumentaria a las que hace referencia Jones (2005) y se encuentra dentro de las funciones simbólicas y estéticas que describen Fernández (2015a) para los objetos indumentarios y Lobäch (1981) para los industriales. Pero también responde a la utilidad del uso de la ropa, dentro de la función de utilidad o práctica, en tanto estas prendas sirven para protegerse del frío.

Terminada la jornada laboral en las cooperativas de ahorro y crédito, las mujeres de este grupo, para salir a la calle, emplean prendas indumentarias que pueden ser parte o no del uniforme institucional. El factor climático, obliga a la utilización de prendas no indígenas para proteger el cuerpo de las mujeres del frío. Portar únicamente la bayeta o la lishta, y la blusa, en la parte superior del cuerpo, no permite mantener la temperatura corporal. Es posible que este hecho se relacione con el tipo de material utilizado para la confección de las prendas y con la reducción de dimensiones de la bayeta y la lishta en las instituciones. En horas de la noche, las mujeres de las cooperativas se reúnen con sus familias para la última comida del día, además de realizar labores domésticas. Para estas actividades, las mujeres reemplazan el uniforme por vestimenta más cómoda del repertorio no indígena. Al respecto, Manuela Llambo menciona que "anaco sí ya no pongo" (Entrevista con M. Llambo, Ambato, diciembre 2016). Para dormir, todas mis interlocutoras coinciden en el uso de pijama. En cuanto a las actividades desarrolladas en los fines de semana, éstas varían entre trabajar en el campo, realizar tareas del hogar y pasear con su familia. Como da cuenta la intervención de Manuela Llambo: "por ejemplo en la mañana lo primero que hacemos es desayunar, luego nos vamos a la hierba para los conejos, de ahí sí nos ponemos a lavar, de ahí si a limpiar la casa” (Entrevista con M. Llambo, Ambato, diciembre 2016). Así también María Munga- 
busí lo expresa: "el fin de semana a veces paseamos, salimos con mis hijos" (Entrevista con M. Mungabusí, Ambato, diciembre 2016). Los usos indumentarios de los fines de semana difieren del uniforme propio, y más bien se acerca a la tipología vestimentaria no indígena. Es decir que, el no portar el uniforme propio ni tampoco prendas indígenas chibuleo, tanto para desarrollar las tareas del hogar entre semana, como los fines de semana, responde a la comodidad que ofrece la vestimenta no indígena, dentro de la función de utilidad o práctica, de los universos de vestuario sportwear, jeanswear y casual - pantalones- (Jaramillo, 2010). Mientras que el uso cotidiano del uniforme propio, de lunes a viernes en las cooperativas, se debe tanto a normativas institucionales como a un proceso de internalización por parte de quienes la portan, que persigue el objetivo de mostrar tanto la pertenencia al pueblo como la pertenencia institucional.

En definitiva, los usos indumentarios en las tres construcciones identitarias de las mujeres analizadas, muestran una articulación dialéctica entre la indumentaria y la identidad tanto al interior del grupo, como con respecto a otros grupos étnicos. Asimismo cada arquetipo tiene sus particularidades de acuerdo al contexto en el que portan vestimenta propia, vestimenta de la cultura o uniforme propio $^{54}$. En efecto, por la noche y en los fines de semana, estos atuendos son reemplazados por vestimenta no indígena en el caso de las profesoras y las de las cooperativas, o también pueden alternar su uso con la vestimenta propia los fines de semana. En el caso de las mamas, sólo algunas duermen con prendas de la vestimenta propia, y durante los fines de semana mantienen dicho uso. Estas similitudes y diferencias se exponen en el siguiente cuadro comparativo. 


\begin{tabular}{|c|c|c|c|}
\hline \multicolumn{2}{|c|}{$\begin{array}{c}\text { Mamas } \\
\text { Vestimenta propia }\end{array}$} & \multirow{2}{*}{$\begin{array}{l}\text { Las profesoras. } \\
\text { Vestimenta de la } \\
\text { cultura }\end{array}$} & \multirow{2}{*}{$\begin{array}{l}\text { Las mujeres de las } \\
\text { cooperativas. } \\
\text { Uniforme propio }\end{array}$} \\
\hline Grupo 1 & Grupo 2 & & \\
\hline $\begin{array}{l}\text {-De dos a cuatro anacos } \\
\text { azules o negros, que } \\
\text { llegan al alto de las } \\
\text { rodillas. }\end{array}$ & $\begin{array}{l}\text {-De uno a dos anacos } \\
\text { negros que llegan al alto } \\
\text { de las rodillas. }\end{array}$ & $\begin{array}{l}\text {-Un anaco negro que llega a } \\
\text { la altura de los tobillos. }\end{array}$ & $\begin{array}{l}\text {-Un anaco negro que llega a } \\
\text { la altura de los tobillos. }\end{array}$ \\
\hline -Varios chumbis. & -De uno a dos chumbis. & -Un chumbi. & -Un chumbi. \\
\hline $\begin{array}{l}\text {-Dos rebozos con } \\
\text { dimensiones que llegan } \\
\text { al alto de la cadera, en } \\
\text { colores negro y azul. }\end{array}$ & $\begin{array}{l}\text {-Un rebozo negro con } \\
\text { dimensiones que llegan } \\
\text { al alto de la cadera. }\end{array}$ & $\begin{array}{l}\text {-Una bayeta negra con } \\
\text { dimensiones que llegan al alto } \\
\text { de la cintura. }\end{array}$ & $\begin{array}{l}\text {-Una bayeta negra con } \\
\text { dimensiones que llegan al alto } \\
\text { de la cintura. }\end{array}$ \\
\hline $\begin{array}{l}\text {-Una lishta blanca a } \\
\text { rayas. }\end{array}$ & $\begin{array}{l}\text {-Una lishta blanca a } \\
\text { rayas -uso ocasional-. }\end{array}$ & $\begin{array}{l}\text {-Una lishta blanca a rayas } \\
\text {-uso ocasional en lugar de la } \\
\text { bayeta-. }\end{array}$ & $\begin{array}{l}\text {-Una lishta blanca a rayas } \\
\text {-uso normado en lugar de la } \\
\text { bayeta-. }\end{array}$ \\
\hline $\begin{array}{l}\text {-Una camisa blanca } \\
\text { bordada, con cuello } \\
\text { redondo y una abertura } \\
\text { vertical en el centro } \\
\text { frente - escote lágrima-, } \\
\text { y manga corta. }\end{array}$ & $\begin{array}{l}\text {-Una camisa blanca } \\
\text { bordada, con cuello } \\
\text { redondo y una abertura } \\
\text { vertical en el centro } \\
\text { frente - escote lágrima-, } \\
\text { o con diferentes escotes, } \\
\text { y manga corta. }\end{array}$ & $\begin{array}{l}\text {-Una blusa blanca bordada, } \\
\text { con diferentes tipos de escote } \\
\text { y largos de manga. }\end{array}$ & $\begin{array}{l}\text {-Una blusa blanca bordada, } \\
\text { con diferentes tipos de escote } \\
\text { y largos de manga, de acuerdo } \\
\text { al día de la semana. }\end{array}$ \\
\hline -Sombrero blanco. & -Sombrero blanco. & $\begin{array}{l}\text {-Sombrero blanco -de uso } \\
\text { ocasional-. }\end{array}$ & $\begin{array}{l}\text {-Sombrero blanco -uso } \\
\text { normado para uno o dos días } \\
\text { específicos-. }\end{array}$ \\
\hline $\begin{array}{l}\text {-Uno o dos tupus de } \\
\text { plata. }\end{array}$ & -Un tupu de plata. & $\begin{array}{l}\text {-Un tupu de plata o un } \\
\text { prendedor en reemplazo. }\end{array}$ & $\begin{array}{l}\text {-Un tupu de plata o un } \\
\text { prendedor en reemplazo }\end{array}$ \\
\hline $\begin{array}{l}\text {-Wallkas y orejeras de } \\
\text { coral o en material } \\
\text { plástico que simula el } \\
\text { coral. }\end{array}$ & $\begin{array}{l}\text {-Wallkas y orejeras en } \\
\text { material plástico que } \\
\text { simula el coral. O } \\
\text { collares y aretes en el } \\
\text { mismo material. }\end{array}$ & $\begin{array}{l}\text {-Collares y aretes en material } \\
\text { plástico que simula el coral de } \\
\text { las wallkas y orejeras. }\end{array}$ & $\begin{array}{l}\text {-Collares y aretes en material } \\
\text { plástico que simula el coral de } \\
\text { las wallkas y orejeras. }\end{array}$ \\
\hline $\begin{array}{l}\text {-Uno a dos buzos. De } \\
\text { uno a dos sacos. }\end{array}$ & $\begin{array}{l}\text {-Uno o ningún buzo. Un } \\
\text { saco. }\end{array}$ & $\begin{array}{l}\text {-Uno o ningún saco. Una } \\
\text { chompa con identificativo del } \\
\text { Ministerio de Educación. }\end{array}$ & $\begin{array}{l}\text {-Prendas con identificativos } \\
\text { institucionales, que se portan } \\
\text { una a la vez: saco, chaleco y } \\
\text { chompa -no indígenas-. }\end{array}$ \\
\hline $\begin{array}{l}\text {-Calzado tipo mocasín o } \\
\text { botas, sin o con medias } \\
\text { tejidas de lana o } \\
\text { acrílico. }\end{array}$ & $\begin{array}{l}\text {-Calzado tipo mocasín } \\
\text { sin medias, o botas con } \\
\text { medias tejidas de lana o } \\
\text { acrílico. }\end{array}$ & $\begin{array}{l}\text {-Calzado tipo salón de tacón } \\
\text { medio o alto, con medias } \\
\text { nailon. }\end{array}$ & $\begin{array}{l}\text {-Calzado tipo salón de tacón } \\
\text { medio o alto, con medias } \\
\text { nailon. También usan } \\
\text { alpargatas en días específicos. }\end{array}$ \\
\hline Silueta volumétrica & Silueta volumétrica & Silueta insinuante & Silueta insinuante \\
\hline
\end{tabular}

Tabla 1. Cuadro comparativo de las tipologías vestimentarias que portan los grupos de mujeres chibuleo. Fuente: elaboración propia

En este apartado expuse cómo están compuestas las distintas categorías vestimentarias, los usos específicos de las mismas y el modo en que se entretejen con las construcciones identitarias de los diversos grupos de mujeres chibuleo 


\subsection{Transformaciones vestimentarias de la mujer chibuleo}

Indagar los cambios y continuidades de la indumentaria de la mujer chibuleo, - columna vertebral de mi investigación doctoral-, me ha llevado a transitar por la historia de lucha y reivindicación de los derechos indígenas, la conquista de la educación bilingüe y la diversificación económica conducente a la generación de instituciones propias, como las entidades educativas y financieras. En estos procesos, la intervención estatal, a través de sus políticas, en aras de fortalecer la identidad de los pueblos y nacionalidades indígenas, fue un elemento clave ya que, como analicé previamente, dichas políticas estuvieron orientadas a darle impulso al uso indumentario de los diferentes grupos étnicos.

\subsubsection{El anaco y el chumbi no se negocian, se transforman}

En las comunidades chibuleo, la indumentaria étnica persiste debido a la insistencia de los taytas; el ejemplo de las mamas; la internalización de las mujeres del pueblo; la uniformización vestimentaria en las instituciones y las políticas constitucionales. Dentro de estas prendas, el anaco y el chumbi son irreemplazables para las mujeres chibuleo.

El anaco y el chumbi no se negocian. Hay una resistencia, siguiendo a Bonfil Batalla (1991), de las mujeres andinas a reemplazarlas por otra. Este arraigamiento es más marcado en las mujeres que en los hombres. De allí que, el anaco y el chumbi, constituyan los diacríticos identitarios más visibles de su cultura

En este sentido, el anaco portado como prenda andina cumple funciones más allá del uso práctico. En efecto, el anaco es un identificador identitario y un elemento de diferenciación social, y de igual manera opera el uso del chumbi. Si bien la continuidad del uso de las mujeres andinas del anaco y al chumbi mantiene estas prendas dentro de la indumentaria cotidiana chibuleo, ambas han estado expuestas a transformaciones, de las que doy cuenta a continuación.

\subsubsection{El anaco}

El anaco andino utilizado por las mujeres chibuleo, que cubre la parte inferior de su cuerpo, responde a características — forma, color, materiales - similares a las de otros pueblos ecuatorianos y de la región andina. Las transformaciones más destacadas del anaco, están relacionadas con sus variantes longitudinales, sistemas de oclusión, cantidad de anacos portados y cambios de material. Además, se puede advertir el uso del color en la prenda y la combinación de hilos de color sobre esta en el filo inferior.

El largo del anaco varió de una falda envolvente con una longitud que cubre las rodillas de las mujeres, en la época de los levantamientos indígenas de la década de 1990 - y cuyo largo aún conserva el grupo de las mamas-, a una falda que llega al tobillo utilizada por las profesoras y las mujeres de las cooperativas. Aun cuando las mamas chibuleo mantienen esta prenda, el tiempo y el contexto en los que las portadoras de la indumentaria se desenvuelven, ocasionan transformaciones que sólo pueden ser entendidas a través del diálogo con sus protagonistas. 
Se puede afirmar que las transformaciones de la indumentaria chibuleo más próximas a la década de 1990, refieren a los usos del largo del anaco. Este cambio se corresponde con la generación siguiente de las mamas, es decir por sus hijas; puntualmente con una de ellas, Martha Lligalo, que pertenece al grupo de las profesoras. Tupac Caluña menciona a Martha Lligalo y un accidente como génesis el aumento de la longitud del anaco. Destacó además, que por usar un largo diferente al habitual — desde la cintura hasta cubrir el tobillo-, modificación que implementó junto con su hermana - quien, al parecer, se solidarizó en este cambio-, fue motivo de fuertes críticas en el pueblo (Entrevista con T. Caluña, Chibuleo San Francisco, enero, 2016).

La madre de Martha Lligalo, Andrea Pacari, corrobora lo antedicho, detallando que fue su hija quien por primera vez usó un largo de anaco diferente, a causa de un accidente que marcó su pierna. Con estos antecedentes recurrí a una entrevista con Martha, mi interlocutora, quien recuerda el evento de esta manera:

Bueno cuando yo estaba en segundo curso mi anaco era normal como los mayores mi anaco era alto, entonces un día [...] la puerta de la casa de mi mami era con bloques y vidrios, [...] entonces el carro... entró mal jalando todo la pared de bloques entonces me caí, me cayó encima de mi pierna entonces me lastimó, me llevo casi la mitad de la pierna. (Entrevista con M. Lligalo, Chibuleo San Francisco, diciembre de 2016)

Este hecho ocurrió a fines de la década de 1980, época en la que Martha estudiaba en un colegio de Santa Rosa -zona rural cercana a Chibuleo San Francisco-, y para ese entonces, según indica la informante:

... todavía seguía con el anaco alto, pero me ponía medias de nailon claro cuando iba al colegio era medias blancas... Pero para ir a cualquier otro lugar, así de fiesta o en cualquier parte delante del público era feo que me vean con la cicatriz, entonces me puse medias de nailon. Entonces siempre estar con zapatos de taco, no se ponía con cualquier zapato las medias nailon no quedaba con cualquier zapato... siempre estaba con zapatos de taco no me gustaba y no tenía plata para comprarme muchos zapatos de taco. Entonces me daba vergüenza. Entonces empecé a bajar poquito el anaco... poquito mi mami dijo casi no se nota, después otra vez bajé otro poquito más y dijo mi mami dice casi ya no se nota... Entonces yo me seguía bajando más hasta el punto de que bajé hasta el tobillo. (Entrevista con M. Lligalo, Chibuleo San Francisco, diciembre de 2016)

Es decir que a partir del accidente de Martha Lligalo, y luego de que las opciones para cubrir su cicatriz — como el uso de medias nailon y zapatos de taco- se agotaran, debido a los altos costos que representaban su adquisición, comenzó el proceso de extensión del largo del anaco hasta el tobillo. Esta innovación que le permitía cubrir por completo la marca del accidente. Martha menciona que su prima, con quien acudía al colegio todos los días, en un acto de empatía también bajó su anaco (Entrevista con M. Lligalo, Chibuleo San Francisco, diciembre de 2016). Es decir que, si bien el largo del anaco inicia con Mar- 
tha, continúa con su hermana y su prima, también hijas de mamas, y posteriormente se extiende al resto de las integrantes de su generación y comunidad. Expuesta a las críticas de la comunidad, Martha Lligalo desarrolló modificaciones en su vestimenta propia. Cabe aclarar que Martha es hija de un tayta chibuleo, que tiene un estatus de líder reconocido en el pueblo, y estos cambios la convirtieron en un modelo a seguir por parte de las mujeres "jóvenes" - como mi interlocutora las denomina- de la comunidad. De manera sincrónica, fue objeto de crítica por parte de los "mayores" porque "hay que mantener la cultura" (Entrevista con M. Lligalo, Chibuleo San Francisco, diciembre de 2016).

Cabe incorporar al análisis del alargamiento de esta prenda, la posible incidencia del contacto intercultural, en particular al coincidir con el largo de anaco de las otavaleñas, que llega hasta los tobillos. Dicho contacto fue fruto de los estudios de mi informante en un colegio urbano. También es esta clave se pueden interpretar las resistencias de las generaciones anteriores ante este cambio y ante la posible pérdida o transformación de un diacrítico identitario que diferenciaba a los chibuleo de otros étnicos, en este caso puntual, de los otavalo. Estos procesos, dan cuenta de los intercambios indumentarios intraculturales ${ }^{55}$ que van más allá de la función de utilidad o práctica del anaco respecto a cubrir el cuerpo, y en este caso se implementaron a partir de la primacía de la función estética (Fernández, 2015a; Lobäch, 1981) del objeto vestimentario, para disimular imperfecciones del cuerpo (Jones, 2005).

Las mujeres jóvenes de la comunidad comienzan, entonces, a extender su anaco hasta media pantorrilla e incluso hasta el tobillo, pero no guiadas por las motivaciones que inicialmente llevaron a Martha Lligalo a hacerlo, sino por una necesidad de seguir algo diferente. En efecto, este cambio se consolida a través de la imitación (Simmel, 1938), pues como lo menciona Hansen, "el vestido étnico" también es dinámico y cambiante, como la moda, dadas "las cambiantes definiciones de preferencia local" (Hansen, 2004). De este modo, lo que inició como una estrategia individual para disimular un accidente - cubrir una cicatriz-, pasó a ser un instrumento de distinción (Jones, 2005).

Como sostuve anteriormente, la transformación del anaco chibuleo fue desaprobada por los taytas de la comunidad, empeñados en mantener la cultura sin modificaciones, inmóvil. Este hecho contradice lo que ocurría con la vestimenta de la mujer chibuleo. No sólo se estaba alargando el anaco por parte de las mujeres jóvenes de aquel entonces, que son quienes en el presente componen los grupos de las profesoras y de las cooperativas; sino que también cambiaban los materiales con los que se confecciona esta falda envolvente y el resto de las prendas de la indumentaria chibuleo.

Con esta extensión de la longitud del anaco se extiende también de manera vertical la silueta (Saltzman, 2004), una variación admitida dentro de la "no moda" expuesta por Fernández (2015a) y Saulquin para referirse al "vestido estable [...] que expresa la pertenencia cultural" (2010, p. 70). No sólo el largo del anaco ha variado, sino que esta prenda ha tenido que adaptarse también a condiciones que implican mayor comodidad para sus usuarias. Otras transformaciones que registro en esta prenda son las formas de oclusión o cierre que expone Barthes (2008) en las variantes de relación, así como también el textil utilizado - que explico dentro del apartado bayeta y lishta-, que están dentro de las funciones prácticas (Lobäch, 1981) de este objeto vestimentario, e inciden también en la morfología de la indumentaria. 
Además del largo, Martha, mientras cursó su instrucción secundaria, transformó su anaco, de una tela rectangular envuelta a la cintura con la que debía formar múltiples pliegues sostenidos por el o los chumbis, en una falda con pliegues preformados. Estos cambios fueron realizados con el fin de colocarse de manera más rápida la prenda, luego de su clase de educación física, a la que debía asistir con camiseta y pantalón corto - uniforme mestizo obligatorio- (Entrevista con M. Lligalo, Chibuleo San Francisco, diciembre de 2016). Como se observa en el ejemplo previo, Martha encontró la forma de que el anaco se viera igual en su forma externa, pero reduciendo el tiempo de colocación al reformarlo, cosiendo los pliegues y colocando una cremallera al costado. Con estas modificaciones, el tiempo empleado en vestirse se equiparaba al de sus compañeras, que utilizaban uniformes mestizos.

Estos sistemas de oclusión - o cierre - del anaco, son los que usan en la actualidad, tal como identifiqué en mi trabajo de campo, la mayoría de las profesoras y las mujeres de las cooperativas. Esta búsqueda por reducir el tiempo de colocación de la indumentaria para asistir a sus trabajos, también explica por qué las mujeres de los grupos mencionados se colocan un solo anaco. En efecto, la disminución del número de anacos constituye otro de los cambios en los usos de esta prenda chibuleo. Según Rowe (1998), la cantidad utilizada variaba entre cuatro y siete anacos puestos de manera simultánea. Este número se redujo a cuatro, en el caso de las mamas, y baja a uno o dos en las profesoras o las de las cooperativas.

La reducción del número de anacos ocurre por motivos ligados a la función de utilidad o práctica del objeto vestimentario, debido al peso que conlleva portar cuatro anacos envueltos y con pliegues. Además, los sistemas de oclusión que se adoptan, por una parte, reducen el tiempo de colocación, y por la otra limitan el uso de múltiples anacos, a solo uno. Asimismo, resulta poco práctico portar entre dos y cuatro anacos para desarrollar un trabajo en las instituciones, donde se tiende a estilizar la figura. Es decir, que la función de utilidad del anaco influye en la apariencia externa, incidiendo en la función estética, porque reduce el volumen de la silueta de la mujer chibuleo, que pasa de ser envolvente y volumétrica, a insinuante.

Si bien la vestimenta chibuleo forma parte de la categoría del vestido de la no moda (Fernández, 2015a; Saulquin, 2010) y la moda tiene origen occidental, en el contacto interétnico, ciertas particularidades de esta moda se han instaurado en la indumentaria chibuleo - sobre todo en las instituciones-, a través de adaptaciones. En efecto, por una parte admite adopciones de siluetas no indígenas que disminuyen el volumen del cuerpo y, por la otra, mantiene el uso del anaco en un proceso de resistencia (Bonfil Batalla, 1991). Estas adaptaciones y adopciones actualizan la silueta (Saltzman, 2004) de las mujeres dentro de la función estética del objeto vestimentario (Fernández, 2015a; Lobäch, 1981). Estos cambios se han realizado con la anuencia de la comunidad, en tanto el anaco es una marca indígena andina, que evidencia la identidad étnica de quien la porta y la distingue de los no indígenas. Otra de las prendas que, como expuse al inicio del apartado, no se negocian, es el chumbi, que sostiene al anaco, y constituye otra marca identitaria. Esta prenda también presenta transformaciones, como explico a continuación. 


\subsubsection{El chumbi}

Los chumbis - o faja, tal como a veces lo denominan mis informantes-, tiene la función práctica de cubrir la parte inferior del cuerpo al sujetar el anaco, y se suma a la función estética que está orientada a dar forma a las siluetas. Puntualmente consiste en aumentar el volumen del cuerpo en el caso de las mamas, o definir la cintura en el caso de las profesoras y las mujeres de las cooperativas.

Las transformaciones que refieren al chumbi, en los tres grupos de mujeres, se expresan en la cantidad de chumbis portados, el tipo de material utilizado para su confección y el tipo de figuras presentes en sus tejidos. Además, registro otra transformación del chumbi como son los sistemas de cierre, portados por las mujeres de las cooperativas.

El número de chumbis utilizados por las mujeres chibuleo depende, por un lado, del número de anacos portados: mientras más anacos se utilizan, mayor es el número de chumbis que deben ser envueltos, fajados y ceñidos. Por el otro, depende del tipo de trabajo que realice la mujer. Para el caso de las mamas, Juana Pandashina porta dos anacos con dos chumbis. Los argumentos de mis interlocutoras se orientan a las vicisitudes de las labores agrícolas y la necesidad de resistir la carga utilizando varios de ellos que dan soporte a la cadera. Es preciso recordar, respecto a este punto, que el número de chumbis utilizados por las mamas, así como los anacos — como expliqué en el apartado anterior-se ha reducido. Como Martha Lligalo sostenía: "antes yo le veía a mi mami [...] por dentro ponían dos anacos con una faja y más afuera ponían tres anacos más con dos tres fajas más” (Entrevista con M. Lligalo, Ambato, noviembre 2016). Así también lo indica Tránsito Manobanda: "adentro ponían dos anacos y encima 4 anacos, con 3, 4 fajas" (Entrevista con T. Manobanda, Chibuleo San Francisco, enero 2015). En definitiva, si bien en el caso de las mamas, los chumbis continúan utilizándose para fajar la cadera y soportar la carga dentro de las funciones de utilidad del objeto, en la actualidad ese número se ha reducido.

En el caso de las profesoras y las mujeres de las cooperativas, el chumbi cumple más una función estética que práctica. Consiste en el deseo de estas mujeres por ver su cuerpo esbelto, pero manteniendo la vestimenta propia. Para ello, se colocan solo un chumbi que envuelve al único anaco, estrechando y definiendo la cintura. Los cambios se registran, asimismo, en el tipo de material utilizado para su confección y las figuras que contiene, tal como explico a continuación.

A fines de la década de 1960, según Juana Pandashina lo recuerda, el chumbi era realizado con un material distinto al utilizado para la década de 2010: "el chumbi o sea faja chumbi [...] ahora mejor cuesta barato unos 3, 4 dólares pero antes con hilo purito sabíamos poner" (Entrevista con J. Pandeshina, Chibuleo San Francisco, diciembre 2016). "Hilo purito" refiere a que antes se tejía con lana, mientras que el chumbi que "cuesta barato" es confeccionado con hilo orlón de fibra acrílica.

Este argumento lo corrobora Agustín Punina al presentarme un chumbi que, según relata, las mujeres chibuleo portaban alrededor de 1970 y 1980. "Esta es la faja antigua que nuestras abuelas utilizaban [...] y... puro de lana también ¿no? la lana de borrego" (Entrevista con A. Punina, Chibuleo San Pedro, enero 2016). 
Además del cambio de material para realizar los chumbis, existe una transformación respecto a las figuras tejidas en el centro. Estos significados remiten a la función simbólica, puesto que el objeto indumentario es vinculado con las labores del campo y el cuidado de los animales. El cambio de tejido artesanal a industrial, según mis informantes, ha obstaculizado la continuidad de estos diseños en las prendas, es decir que, además del cambio de material, también ocurre un cambio en las formas tejidas en el chumbi, generado por la imposición del método industrial frente al artesanal. Aun cuando mis informantes mencionan el cambio de figuras de animales por otras, no indican qué figuras han ocupado su lugar. Sin embargo, a través de la observación participante, pude advertir que el chumbi usado de manera cotidiana posee figuras geométricas, en contraste con las figuras geometrizadas de animales utilizadas anteriormente.

Preciso aclarar en este punto que, si bien dentro del atuendo cotidiano portado por los tres grupos de mujeres chibuleo, los chumbis son de tejido industrial y figuras geométricas en el centro, para fiestas y ocasiones especiales, algunas mujeres utilizan fajas o chumbis "antiguos" (Entrevista con A. Punina, Chibuleo San Pedro, enero 2016), es decir, confeccionados artesanalmente y con dibujos de animales geometrizados tejidos en el centro.

La transformación del chumbi que refiere a los sistemas de oclusión, ocurre en el uso indumentario de las mujeres de las cooperativas; son adaptaciones del chumbi largo y envolvente que usan las mamas - con dos o más vueltas-, que ninguna de las interlocutoras menciona en las entrevistas. Al menos en dos de las tres cooperativas relevadas de manera etnográfica, pude advertir que el uso del chumbi largo y con un sistema de oclusión envolvente, se alterna con el uso de, al menos, dos sistemas de cierre adicionales.

Uno de estos sistemas es el cruce - en la parte de la espalda - de un cordón elástico que rodea botones dispuestos en hileras en ambos extremos del chumbi, que envuelve la cintura - en una sola vuelta-. El otro sistema identificado consiste en la utilización de broche; para ello, el chumbi es envuelto por sobre el anaco - en una sola vuelta-, hasta que se cruzan los dos extremos y se abrochan. En estos dos sistemas de oclusión, el chumbi es más corto que el habitual, en tanto rodea la cintura en una sola vuelta. Además, las variantes en el sistema de oclusión le brindan mayor flexibilidad y movilidad al cuerpo, en comparación al chumbi que se envuelve al menos dos veces alrededor de la cintura ${ }^{56}$.

En definitiva, las transformaciones del chumbi que se inscriben en el número de fajas, el cambio de material, el tipo de tejidos y de confección — de artesanal a industrial—; y el cambio en los sistemas de oclusión, inciden en las funciones de la prenda. El chumbi cumple con las tres funciones del objeto vestimentario, de utilidad, estética y simbólica; pero varía la relevancia de una función sobre las otras en relación con el grupo de mujeres que lo porta y la labor que desempeñan.

\subsubsection{Entre la lishta y la bayeta: el rebozo de las mamas}

Las mujeres chibuleo cubren con mantos rectangulares la parte superior de sus cuerpos, a los que sujetan con un tupu en el centro del pecho o sobre un hombro; estos mantos son la lishta, la bayeta y el rebozo. El uso terminológico de estas dos últimas prendas varía en 
función de sus dimensiones, tal como se expuso en el primer capítulo, pero también en relación con el grupo de mujeres que la portan. Bayeta y lishta son dos nombres comúnmente utilizados por las profesoras y las mujeres de las cooperativas, mientras que el uso del vocablo rebozo está reservado para el manto utilizado por las mamas.

En las comunidades chibuleo, el nombre de bayeta es utilizado para la prenda que cubre la espalda de las profesoras y de las mujeres de las cooperativas. El uso de la bayeta como prenda, surge a partir del nombre del material de los rebozos - tal como he expuesto en el capítulo 1-. La bayeta - como prenda- es, entonces, una derivación del rebozo, que además registra diferencias en sus dimensiones. Una de las profesoras aclara de una manera más específica estas diferencias: "una bayeta yo me pongo de $125[\mathrm{~cm}]$ de largo y ancho de $70[\mathrm{~cm}]$ y el rebozo que le digo es más ancho, es más grande, es un metro cincuenta por un metro así ha de ser, más también" (Entrevista con M. Lligalo, Chibuleo San Francisco, noviembre 2016).

Los rebozos de las mamas, que pueden ser de color negro o azul, tienen una longitud que llega al alto de la cadera. Por su parte, la longitud de la bayeta negra portada por las profesoras y las mujeres de las cooperativas llega a la cintura — función estética-, dimensión que puede ser equiparada a la de la fachalina (Jaramillo, 1990).

La transformación de rebozo a bayeta, también se evidencia en la función de utilidad o práctica que desempeña una y otra prenda. Al respecto, una mama indica "así ha sido siempre, pero así graaande rebozo hasta acá... ahora es chiquito [...]. Para cargar al guagua con rebozo aquí, así cargábamos nosotros" (Entrevista con A. Pacari, Chibuleo San Francisco, diciembre 2016). Esta intervención, por un lado, corrobora el cambio de dimensión y, por el otro, hace referencia a una de las funciones que el rebozo amplio cumplía, en la carga de los niños.

Las profesoras y las de las cooperativas, utilizan la bayeta más con fines estéticos que prácticos. Estas mujeres han dejado de utilizar la bayeta para cargar a los niños, puesto que en su trabajo como docentes, o dentro de las entidades financieras, no requieren hacer ningún tipo de esfuerzo físico, sino que ambos exigen un desempeño intelectual.

Es decir que la transformación de las dimensiones que convierte al rebozo en bayeta, es una adaptación de la prenda para dar respuesta a las necesidades estéticas y prácticas de las mujeres, en contextos laborales específicos.

Respecto a la lishta, se registran dos grandes transformaciones: la primera respecto a la adaptación de sus dimensiones, y la segunda respecto a la alteración en el uso, ambas relacionadas con las transformaciones de la bayeta. Las dimensiones de la lishta varían en concomitancia con el rebozo y la bayeta: las mamas utilizan la lishta de las dimensiones del rebozo, y las profesoras junto con las de las cooperativas, una lishta del tamaño de la bayeta. Este hecho, registrado a través de la observación participante, indica que la lishta ha adaptado sus dimensiones.

Para dar cuenta de la alteración en el uso que ocurren tanto en la lishta $a^{57}$ como en la bayeta, me sustento, por una parte, en datos bibliográficos andinos del Ecuador, que refieren a la fachalina y el rebozo - como sus similares-; y por la otra, en mis análisis etnográficos. Los estudios de Jaramillo (1990) indican que en Otavalo, además de usar la fachalina sobre los hombros "se observa [...] entre las mujeres una nueva forma de llevar esta prenda: pasa por debajo del brazo derecho, de manera que la fachalina cubra el pecho y la espalda, y se 
anuda sobre el hombro izquierdo" (p. 137). Es decir que existen dos maneras de llevar la fachalina en Otavalo: una de forma simétrica sobre los dos hombros, y otra que da como resultado una asimetría (Leborg, 2013), al portar la prenda sobre un solo hombro, transformación que evidencia una alteración en el uso.

Esta transformación de la fachalina usada en Otavalo, se hace también visible en la lishta y la bayeta de la mujer chibuleo, excepto por el anudado ya que, como he expuesto, ellas sujetan estas prendas con un tupu. La alteración en el uso de estas dos prendas chibuleo, también se observa en los estudios de Rowe (2011) respecto a los Andes ecuatorianos, donde el rebozo es a menudo usado con ambos extremos sobre el hombro izquierdo.

Entre las mujeres chibuleo se observan estas dos formas de llevar la lishta y la bayeta, al igual que entre las mujeres de Otavalo en particular, y las mujeres andinas del Ecuador en general. Estas dos formas - colocada sobre ambos hombros y sujetada a la altura del pecho, o colocada bajo un brazo y sujetada sobre uno de los hombros- alteran el uso original de la lishta y la bayeta.

En mis investigaciones etnográficas registro que en general son las mamas chibuleo quienes llevan puestas la lishta y el rebozo de la primera forma, sobre ambos hombros. Mientras que el resto de las mujeres chibuleo varía entre una y otra forma. Sin embargo, prefieren el uso por debajo de un brazo y sujetada sobre el hombro, ya que brinda mayor comodidad (Entrevista con M. Pilamunga, Chibuleo San Francisco, noviembre 2016).

Las profesoras y las mujeres de las cooperativas alternan este uso dependiendo del clima función práctica- $-\mathrm{y}$ también del contexto y de la manera en que desean ser vistas - función comunicativa-. Cuando el clima es frío, sujetan la lishta en el pecho porque de esa manera cubre mejor la espalda y los hombros. Sin embargo, cuando desempeñan tareas de tipo intelectual, donde el clima no es un factor determinante -o que resuelven utilizando prendas no indígenas que proporcionan abrigo como saco, chaleco o chompa-, se la colocan por debajo del brazo y sobre el hombro. Los motivos expuestos responden tanto a la apariencia, como a la comodidad, ya que permite mayor movilidad de sus dos brazos.

Existen otras transformaciones en el atuendo de las chibuleo relacionadas al uso de la bayeta, la lishta y el rebozo, como son el reemplazo — cambio-, el desuso, y/o la superposición de estas prendas. Este tipo de transformaciones son parciales y ocurren durante la jornada laboral de los distintos grupos de mujeres estudiadas. Todas estas transformaciones dan cuenta de otra: la combinación (Fernández, 2015a; Karasik, 2010; Theodossopoulos, 2012; Turner, 1991), en este caso, de prendas indígenas con otras no indígenas.

En el caso de algunas mamas, de manera ocasional, durante las labores cotidianas en el campo y en el interior de sus hogares, utilizan sacos sin rebozos ni lishtas. Aquí no puede decirse que existe un reemplazo de unas prendas por otras, en tanto los sacos han sido apropiados por las mamas - como expongo en el capítulo 4-. Entonces, puedo inferir que se trata más bien de un desuso parcial del rebozo y la lishta.

El cambio o reemplazo de la bayeta y/o la lishta por sacos, chompas o chalecos, se registra en el atuendo de las mujeres de las cooperativas. Por una parte, reemplazan la bayeta y la lishta, para el uso dentro de la institución, por sacos o chalecos, que forman parte del uniforme institucional. Además, reemplazan estas prendas por chompas, generalmente para salir del trabajo. En ambos casos, las razones que mis interlocutoras mencionan para realizar este cambio responden a la función práctica, particularmente debido a factores climáticos y vinculados con una mayor comodidad. 
En el grupo de las profesoras, antes que el reemplazo de la bayeta y/o la lishta por chompas o sacos, es más frecuente la superposición de unas prendas con otras. Las profesoras se colocan una chompa sobre la lishta y/o la bayeta en unos casos, o bien primero se colocan el saco, y encima la lishta y/o la bayeta. Mientras que las mujeres de las cooperativas, en ocasiones reemplazan tanto la bayeta como la lishta por chompas, sacos o chalecos, con identificativos institucionales. Prendas que pertenecen también al uniforme mestizo en las entidades financieras.

Hasta este punto se han analizado, por una parte, las adaptaciones y alteraciones del uso de la bayeta y la lishta como prendas individuales del atuendo de la mujer chibuleo. Por la otra, se evidenció el reemplazo, desuso y superposición de la lishta, la bayeta y el rebozo, transformaciones que ocurren en su interacción con prendas no indígenas. A continuación expongo las transformaciones de las camisas o blusas apropiadas por las chibuleo para su repertorio indumentario.

\subsubsection{Las camisas y las blusas}

Las camisas portadas por las mamas chibuleo desde antes de la década de 1990, son prendas adoptadas de la indumentaria no indígena, como consecuencia de un proceso de apropiación (Bonfil Batalla, 1991). Estas prendas experimentaron un sinnúmero de adaptaciones durante mi recorte temporal de estudio (1990-2016), hasta convertirse en las "camisas modernas" o "blusas", utilizadas por las profesoras y las de las cooperativas ${ }^{58}$. A partir de los datos etnográficos, sostengo que la apropiación de la camisa ocurrió antes del recorte histórico de esta tesis, con aportes tanto desde la indumentaria no indígena como desde la de otros pueblos andinos de Ecuador. Agustín Punina, menciona que "todo el modelo de la camisa, el diseño de la camisa, corte, todo esto ya vino diseñado desde las mujeres de pujilí [...] las mujeres chibuleo hoy se empoderan de toda esta vestimenta" (Entrevista con A. Punina, Chibuleo San Pedro, enero 2016). Es decir que, si bien la apropiación ocurre en el contacto interétnico, también encontré referencias de intercambios intraétnicos ${ }^{59}$. Dentro de la etnia chibuleo, fue entre las décadas de 1960 y 1970 que apareció el uso de la camisa - no indígena- entre las mujeres. Con el paso del tiempo, esta prenda reemplazaría totalmente al tupulli60 - prenda indígena-. Estos reemplazos se observan también en investigaciones realizadas respecto a otros pueblos andinos de Ecuador (Buitron, 1964; Jaramillo, 1990; Carretero et al., 2016; Maldonado, 2012; Rowe, 1998, 2011), y en particular de las comunidades chibuleo (Caluña et al., 2008; Rowe, 1998, 2011), que coinciden, además, con los datos obtenidos en mi trabajo etnográfico.

$\mathrm{Al}$ respecto, Tupac Caluña aporta datos de su familia, e indica, respecto de su abuela: "a ella nunca vi utilizar camisa, solo tupulli” (Entrevista con T. Caluña, Chibuleo San Francisco, enero 2016). Mientras que su madre, Juana Til — del grupo de las mamas-, desde que era pequeña y hasta su casamiento en la década de 1950, utilizó tupulli. Sin embargo, posteriormente a esa fecha Juana lo cambió por la camisa ${ }^{61}$, que utiliza hasta el presente con características y fines similares. 
Para fines de la década de 1980, e inicios de 1990 (Rowe, 1998; 2011), las características de la camisa eran las siguientes: manga corta, cuello de forma redondeada y una abertura que nace del centro del pecho - escote lágrima-. Estas características se conservan en la actualidad, entre el grupo de las mamas.

A estas particularidades se suma el aporte de Tupac Caluña, que menciona el uso de "bordados de platillos [...] y de estrellas" (Entrevista con T. Caluña, Chibuleo San Francisco, enero 2016). En efecto, durante una de las entrevistas, Tupac Caluña mostró una camisa que definió como "el único modelo de camisa que tenían antes" (Entrevista con T. Caluña, Chibuleo San Francisco, enero 2016) ${ }^{62}$. En las notas de campo, la describo detalladamente:

Una camisa de mangas cortas, de lino color blanco, de corte recto - en sentido vertical- y conformada de dos piezas en el frente y en la espalda - en sentido horizontal-. Las dos piezas inferiores, tanto la delantera como la trasera, llevan dos pinzas en cada pieza, mientras que las piezas superiores llevan bordados alrededor del cuello - pecho, espalda y hombros-, así como también en las mangas.

El cuello de la camisa es redondo con una abertura en el pecho y otra en la espalda. Isabel Capúz, esposa de Tupac, explica que algunas personas se ponían un botón o un imperdible en la abertura del frente para que no quedara suelto. Estas camisas eran todas iguales, con cambios en los bordados.

Para comprobarlo, Tupac e Isabel me muestran dos camisas con bordados distintos. Una con formas que ellos definen como platillo, consiste en hojas bordadas y con un borde de otro color alrededor, acompañado de rosas. La otra, con un bordado de estrellas de seis puntas y doce colores; cada punta está dividida en dos, en sentido vertical, con un color diferente. Los colores que utilizan en ambos bordados son azul, verde y violeta, o rosado intenso - magenta-. (Notas de campo, Chibuleo San Francisco, enero 2016)

De manera similar, Agustín Punina, durante una de las entrevistas, me mostró camisas con estas mismas características (Entrevista con A. Punina, Chibuleo San Pedro, enero 2016). Datos que son complementados por Martha Lligalo al mencionar que "era totalmente antigua, con unos botones hasta acá arriba” (Entrevista con M. Lligalo, Chibuleo San Francisco, noviembre 2016). En cuanto a las formas del bordado de las camisas, los datos obtenidos refieren a las denominadas estrellas y platillos con rosas, que podían combinarse entre sí. Estas formas, posteriormente, comenzaron a geometrizarse.

Hasta este punto expliqué la morfología de la camisa portada para fines de la década de 1980 e inicios de 1990, y que en 2016 continúa en uso por parte de las mamas. A continuación, expongo las razones que mis interlocutores adjudican para explicar la transformación de la camisa en blusa. Una de las razones por las que ocurre este cambio se produce para mejorar la comodidad en el uso de la prenda. Como menciona Isabel Capúz: 
... ponían un botoncito aquí para que no esté suelto así... algunas ponían un imperdible muy pequeñito especialmente para el cuello para coger así... ese era el único modelo ya no había más pero [...] como mi esposo dice ya la nueva generación... para mí especialmente es muy incómodo, por la comodidad también hay algunas mujeres que se ha cambiado también porque para mí es muy incómodo que esté aquí como... ahorcado [el cuello] o sea a mí especialmente no me gusta así. (Entrevista con T. Caluña, Chibuleo San Francisco, enero 2016)

Este dato es corroborado por Martha Lligalo, quien menciona que el escote del cuello se ha ampliado, para "que sea fácil para poderme sacar la blusa" (Entrevista con M. Lligalo, Chibuleo San Francisco, noviembre 2016). Ambos casos señalan que la transformación del escote, se produce a partir de la función de utilidad o práctica del objeto vestimentario, orientado a brindar una mayor comodidad a su usuaria. El escote de la blusa es más profundo que el de la camisa, por lo que el cuello tiene mayor movilidad y es más fácil quitársela. Pero existen otras razones a destacar, relacionadas con el contacto interétnico en instituciones educativas. Martha menciona su paso por el colegio Hispanoamérica, como uno de los motivos por los que comenzó a utilizar la blusa manga larga (Entrevista con M. Lligalo, Chibuleo San Francisco, noviembre 2016). Así también lo expresa Isabel Capúz:

... las mujeres que hemos estado trabajando [en las cooperativas], hemos estado estudiando [...] en la universidad, veo mujeres como usted que tienen unas blusitas muy escotadas... ya y yo digo ¡no! voy a hacer un bordado así pero que esté así escotado, con ese cuello que me gusta. (Entrevista con T. Caluña, Chibuleo San Francisco, enero 2016)

De acuerdo a lo expuesto, las transformaciones de la camisa a blusa, ocurren a partir de tres procesos: una necesidad práctica; el contacto interétnico de las chibuleo que asisten a instituciones educativas no indígenas; y el trabajo en entidades financieras indígenas.

A partir de la asistencia a instituciones educativas interétnicas, las chibuleo tendieron a desear "escotes como las blusas de las chicas de la ciudad" (Entrevista con M. Lligalo, Chibuleo San Francisco, noviembre 2016). Esto se profundiza a partir de las imágenes de las revistas de moda, dando como resultado la confección de blusas con bordados chibuleos. Estas articulaciones muestran una tendencia a utilizar la morfología de prendas no indígenas dentro de la función estética del objeto vestimentario.

En suma, el contacto interétnico en las instituciones educativas y financieras decanta en la transformación de la camisa en blusa. Esta última tipología es adoptada por las profesoras y las de las cooperativas, mientras que las mamas conservan las características de las camisas portadas durante los levantamientos indígenas de 1990. A continuación explico los procesos involucrados en este cambio.

Lo primero que debe señalarse es que las adaptaciones de estas prendas, ocurren de manera enfática desde la década del 2000 (Fernández, 2015a; Karasik, 2010; Theodossopoulos, 2012). La intervención de Isabel Capúz respalda lo antedicho, cuando sostiene que ha 
cambiado la camisa por blusa hace diez años atrás (Entrevista con T. Caluña, Chibuleo San Francisco, enero 2016), es decir alrededor de 2006.

Asimismo, Agustín Punina menciona que fue a partir "de 2005 en adelante... por ahí algunas [mujeres] empiezan a... diseñar las camisas que actualmente utilizan [...], empiezan ya a asomar estos diseños" (Entrevista con A. Punina, Chibuleo San Pedro, enero 2016) ${ }^{63}$. Estas fechas concuerdan con la época en la que las mujeres empiezan a trabajar en las cooperativas de ahorro y crédito indígena.

Esta cronología coincide con los procesos ligados a la promulgación en 2008 de la Constitución de la República del Ecuador. Aun cuando se pudiera situar este cambio diez años antes de los registros etnográficos, la Carta Magna de 1998, vigente hacia 2005 y 2006, contiene en uno de los incisos del artículo $19^{64}$, el impulso al uso de la vestimenta de los pueblos indígenas. De acuerdo a estos hechos, sumados a lo expuesto en el capítulo 1, infiero que las políticas estatales ligadas a la revitalización de la vestimenta de los pueblos y nacionalidades indígenas, influyeron en las transformaciones de las camisas a blusas.

La morfología de la blusa chibuleo, es una adaptación de los modelos de blusas no indígenas. Así lo explica Tupac Caluña:

... de acuerdo al tiempo y al estilo ¿no? lo adaptan [...] por ejemplo de las blusas ya no es como antes solo manga corta, sino también tiene manga larga con diferentes... modelos [...], diferentes diseños, porque más antes era solamente hasta acá con unas cositas manga, manga y acá abotonadito [al cuello]. Entonces ahora hacen diferentes modelos diferentes diseños y el bordado de infinidad de colores. (Entrevista con T. Caluña, Chibuleo San Francisco, enero 2016)

Este fragmento de la entrevista con Tupac Caluña evidencia que las transformaciones de las prendas se desarrollan a partir de la longitud de las mangas, los modelos de las blusas - corpiño-y las formas de escotes y bordados. El escote es una variante que diferencia a la camisa - utilizada por las mamas-, de la blusa - portada por los otros dos grupos de mujeres-, como lo exponen mis interlocutoras. "El cuello acá eso era completamente cerrado antes no había ni para mostrar los pechitos o nada, era cerrado" (Entrevista con ET, Ambato. diciembre 2016); "el escote si no era con escote era hasta acá arriba pero después empezamos a poner” (Entrevista con M. Ligalo, Chibuleo San Francisco. diciembre 2016). Estas intervenciones muestran que el escote de la blusa se profundiza en referencia a la camisa. Martha Lligalo explica que una de sus compañeras - no indígenas - en el colegio, fue quien le sugirió que hiciera esta adaptación a inicios de la década de 1990, adaptación que para esta época no formaba parte de las características indumentarias cotidianas de la mujer chibuleo.

El escote pronunciado no fue aceptado por los taytas chibuleo. Martha recuerda que "nos habló diciendo que estamos exhibiendo mucho, que las mujeres indígenas no deben exhibirse tanto" (Entrevista con M. Lligalo, Chibuleo San Francisco, diciembre 2016). Intervención que se complementa con lo expuesto por una de las mamas: "ahora en este tiempo salen así [...] ahora... ambas hijas viven poniendo así por los hombros... pecho" (Entrevista con A. Pacari, Chibuleo San Francisco, diciembre 2016). A partir de lo expuesto, se expone la 
desaprobación del escote por ciertas generaciones, $\mathrm{y}$ - a pesar de ello- su instalación, en la actualidad, por parte de las profesoras y de las mamas del grupo de las más jóvenes.

Con respecto a las transformaciones longitudinales de la manga, en 1990, las mamas y el resto de la comunidad utilizaba la manga corta. Martha afirma que "las blusas no eran así [indica la blusa de manga larga que porta], las blusas eran de mangas cortas y bordados" (Entrevista con M. Lligalo, Chibuleo San Francisco, noviembre 2016). Estos datos son corroborados durante entrevistas, tanto con mujeres del grupo de las profesoras, como del grupo de las cooperativas.

Sin embargo, Martha explica que "la manga larga siempre existía desde mucho más antes, sino que no sé... a alguien se le ocurrió cortar hasta acá arriba ¿no? y después volvimos a poner manga larga" (Entrevista con M. Lligalo, Chibuleo San Francisco, diciembre 2016). Esta intervención concuerda con los estudios de Rowe (2011) respecto a uno de sus hallazgos que es que el estilo más antiguo de blusa anterior a 1988, que era de manga larga. En definitiva, previo a 1990, se registró el uso de la manga larga; en la época de los levantamientos se utilizaba la manga corta; y luego hubo una reincorporación de la manga larga, en conjunción con la manga tres cuartos y la manga corta, tal como pude observar durante mi trabajo de campo. Sin embargo, esta última longitud se presenta con menor frecuencia en el caso de las blusas de las profesoras y las de las cooperativas.

Las transformaciones de la blusa, tanto en el escote como en los tipos de manga, también se evidencian en las prendas que Tupac Caluña e Isabel Capúz muestran durante una de las entrevistas. Blusas de corte recto y línea princesa con canesú, con escotes redondeado, en V, cuadrado, en U y barca. Mangas tipo flauta, montada, saddle - variante de la manga ranglan-; de longitudes corta, media, tres cuartos y larga. La explicación de estas variantes nuevamente remite a las adaptaciones que las mujeres chibuleo hacen a partir de la observación de las formas de las blusas no indígenas, en establecimientos educativos e instituciones financieras.

Otra adaptación de la camisa a blusa, ocurre en el corpiño, o básico de cuerpo ${ }^{65}$. Respecto a este elemento, las descripciones de mis interlocutoras son escasas, por lo que debí apelar a la observación. El cambio consistió en pasar de la camisa amplia y corte recto, que aporta una silueta volumétrica utilizada por las mamas, a la blusa que se ajusta al cuerpo con una silueta adherente y/o insinuante (Saltzman, 2004) en las prendas de los otros dos grupos. Asimismo, los materiales de confección de las camisas y las blusas son diferentes. María Mungabusí indica que "las blusas que ahora hacemos más [...] transparentes" (Entrevista con M. Mungabusí, Ambato, diciembre 2016). Es decir, las telas utilizadas varían de poliéster y lino, hasta materiales que producen un efecto traslúcido. En las intervenciones anteriores se advierte también que la realización del bordado, tanto de las camisas como de las blusas, continúa siendo de forma manual. Afirmación que se apoya en otras intervenciones de mis interlocutoras. Andrea Pacari menciona "ahora sí, casi todo mundo bordamos" (Entrevista con A. Pacari, Chibuleo San Francisco, diciembre 2016), en tanto es una costumbre transmitida de madres a las hijas desde una edad temprana. Esta costumbre pone en evidencia un proceso de resistencia, a partir de una prenda que ha sido apropiada de los no indígenas e innovada (Bonfil Batalla, 1991) por los chibuleo a través del bordado a mano. 
Estos bordados de las camisas y de las blusas, si bien varían en sus formas, mantienen la representación histórica de los elementos de la naturaleza. Las formas en que han variado se relacionan con un proceso de la geometrización de estos elementos de la naturaleza. Un tayta menciona "el bordado de la camisa tiene las flores de ocas, de papas, todo lo que contienen las flores del campo" (Entrevista con J. J. Lligalo, Chibuleo San Francisco, abril 2016). Las profesoras, corroboran estos datos al indicar que el bordado representa "todo lo que es la agricultura" (Entrevista con M. Lligalo, Chibuleo San Francisco, noviembre 2016); "la naturaleza que nosotros estamos viviendo" (Entrevista con R. Baltazar, Chibuleo San Francisco, noviembre 2016). Las mujeres de las cooperativas coinciden en la existencia de este vínculo entre los bordados y los elementos de la naturaleza circundante. Asimismo, a partir de la variación de los tipos de escote pronunciado, ocurrió otra transformación, en este caso, respecto a la disposición de los bordados en la blusa: "anteriormente nos poníamos en la mitad del pecho digamos, pero ahora en cambio es para que se note la blusa o sea el bordado" (Entrevista con K. Caluña, Ambato, diciembre 2016). En efecto, los bordados se colocan en el centro del cuello - pecho según Kuri Caluña- de las camisas, y en las blusas están dispuestos en el contorno del escote pronunciado. Tanto la adaptación de formas como la alteración del uso que se registra en los bordados de las blusas, son observados en las prendas portadas por las profesoras y las mujeres de las cooperativas.

En este punto, destaco otras intervenciones que dan cuenta de las transformaciones de la blusa en su conjunto. Cecilia Tiche afirma que "ahora tenemos variedades de blusas en diferentes modelos, en diferentes telas, desde las más sencillas a las más caras, entonces son innovaciones que se han dado y eso nos hace más que todo ver más bonitas que más antes" (Entrevista con C. Tiche, Ambato, diciembre 2016). Complementa Martha Lligalo al mencionar que "muchas de las blusas que yo he diseñado, han copiado las chicas, por eso me saben decir: ¡Dios mío! vos que nomás [...] haces, entonces ha habido muchos cambios" (Entrevista con M. Lligalo, Chibuleo San Francisco, noviembre 2016). Estas intervenciones, además de indicar que existe una amplia variedad de blusas, dan cuenta de las innovaciones que desarrollaron en las blusas las chibuleo, y en su autorrepresentación como diseñadoras. En este caso, serían diseñadoras difusas según la terminología empleada por Manzini (2015), en tanto utilizan su capacidad natural para diseñar ${ }^{66}$.

A partir de lo analizado en este apartado, sostengo que la blusa es la prenda que registra más transformaciones dentro de la vestimenta de la cultura portada por las profesoras y el uniforme propio utilizado por las mujeres de las cooperativas.

\subsubsection{Sombreros que se esfuman}

El sombrero utilizado por comunidades andinas, es también uno de los accesorios de los chibuleo (Caluña et al., 2008; Rowe, 1998, 2011), portado por hombres y mujeres sin distinción de forma. Este sombrero blanco, hecho de lana de fieltro, de copa redonda amarrado con un hilo azul y borde elevado hacia arriba, protege la cabeza del sol dentro de sus funciones de utilidad o funciones prácticas. Así lo indica Andrea Pacari: "no poniendo en el sol, ya se quema la cabecita” (Entrevista con A. Pacari, Chibuleo San Francisco, diciembre 2016). 
Además de la utilidad mencionada, el sombrero distingue a los chibuleo de los otros indígenas, y de los no indígenas. Mis interlocutores mencionan que han optado por portar indumentaria similar a las comunidades indígenas aledañas a Chibuleo ${ }^{67}$, excepto por el tipo de sombrero. Martha Lligalo subraya con respecto a los parecidos que los "tamboloma, pilahuin y los de Apatuc, los angahuana se han vestido como nosotros" (Entrevista con M. Lligalo, Chibuleo San Francisco, noviembre 2016 ${ }^{68}$. No obstante, identifica su diferencia identitaria a partir de dos diacríticos: "somos reconocidos como los ponchos rojos, los sombreros blancos" (Entrevista con M. Lligalo, Chibuleo San Francisco, noviembre 2016) ${ }^{69}$.

El sombrero chibuleo no registra transformaciones en su forma, color y textura, entre 1990 y 2016; con lo cual infiero que su uso responde a un proceso de resistencia (Bonfil Batalla, 1991). Sin embargo, este accesorio ha transitado procesos de desuso cotidiano por parte de las profesoras y las mujeres de las cooperativas, y también de readopción, como se expone en los siguientes párrafos.

El uso cotidiano del sombrero chibuleo muestra continuidad y transformaciones, desde la época de los levantamientos indígenas de 1990, hasta la actualidad. En el caso de las mamas, a partir de mis observaciones etnográficas, la utilización de este accesorio sucede diariamente, independientemente del clima. Así lo corrobora el tayta Juan José Lligalo: "así como está mi esposa, así han ido no han cambiado... no han dejado el sombrero... no han dejado nada, ellas han ido así a la lucha" (Entrevista con J. J. Lligalo, Chibuleo San Francisco, abril 2016). Esta intervención, además de evidenciar el uso del sombrero por las mamas en la década de 1990, también advierte el uso de este accesorio en 2016, con las mismas características de uso cotidiano (Notas de campo, Chibuleo San Francisco, abril de 2016).

Entre el grupo de las profesoras y las mujeres de las cooperativas, aun cuando el sombrero es un elemento que identifica su comunidad de procedencia, su utilización fluctuó dentro del período de estudio entre el desuso, registrado a fines de la década de 1980 e inicios de 1990, y su readopción desde el 2010 en adelante, a partir de normativas institucionales que implementan su uso.

El desuso del sombrero para las actividades diarias, coincide con la época en que entraban en contacto diario las chibuleo con los no indígenas, cuando cursaban sus estudios en las instituciones educativas de la ciudad. El uso de este accesorio generaba maltrato, o las burlas de parte de los no indígenas, como sostienen mis informantes:

El sombrero yo dejé también por el colegio mismo, porque mucho me molestaban, golpeaban en el sombrero entonces a veces dolía, a veces quitaban el sombrero era una prenda más fácil para que ellos [mestizos] quiten y se burlen ¿no? entonces por eso he dejado el sombrero. (Entrevista con M. Lligalo, Chibuleo San Francisco, noviembre 2016)

Si bien como mencioné antes, para el grupo de las mamas el sombrero cumple una función de utilidad o práctica, al proteger sus cabezas del sol durante las tareas agrícolas; para el grupo de las profesoras y las mujeres de las cooperativas, este accesorio no sólo no aporta en utilidad al desempeñarse al interior de las instituciones, sino que incluso resulta incómodo. Uno de los motivos es el peso del sombrero. Asimismo, al acudir a impartir 
clases en la UEM Chibuleo, Martha Lligalo indica que "a veces estoy con el cabello mojado $[\ldots]$ y el sombrero cuando se moja es como que quedara sucio, entonces no se pone" (Entrevista con M. Lligalo, Chibuleo San Francisco, noviembre 2016).

A partir de lo antedicho, se advierte que el desuso del sombrero por parte del grupo de las profesoras y las mujeres de las cooperativas, responde tanto al maltrato de parte de los no indígenas, como a la incomodidad de las mujeres que lo utilizan en las instituciones. Respecto al proceso de readopción del sombrero chibuleo, debemos comenzar aclarando que no es un hecho aislado. Pueblos como los collas de Argentina (Karasik, 2010), los kayapó de Brasil (Turner, 1991) y los emberá de Panamá (Theodossopoulos, 2012), han experimentado la readopción de prendas indígenas en desuso.

En el caso de los chibuleo, la readopción del sombrero para días específicos de la semana al interior de las instituciones, es impulsada por los profesores indígenas de las entidades educativas, y por quienes dirigen las instituciones financieras. Este proceso se encuentra influenciado, al mismo tiempo, por las enseñanzas de taytas y mamas dentro de su ámbito familiar y comunitario, así como también por las políticas de fortalecimiento de la identidad de los pueblos y nacionalidades indígenas del Ecuador impulsadas por el Estado.

Para corroborar lo antedicho expongo las intervenciones de mis interlocutores. En el ámbito educativo, una de las profesoras de la UEM Chibuleo relata que:

... los jóvenes piensan, pensaban muy distinto, pensaban dejar no más así el poncho, el sombrero, o sea aculturizarse se llama ¿no? dejar su ropa y poner otra ropa ¿no? Pero la comunidad en sí, los líderes, hemos, han parado durísimo, los docentes también nosotros. Por eso estamos en inicial 1 para rescatar eso mismo [...], nosotros aquí como docentes desde pequeñito a ver su poncho..., ahí está mire, solo el sombrero no puede comprar [a veces] porque cuesta caro cuesta 120 dólares porque no todos disponen de dinero. (Entrevista con M.M. Pilamunga, Chibuleo San Francisco, noviembre 2016)

La informante destaca la labor de los líderes comunitarios y los profesores en la readopción del sombrero. Así también uno de los dirigentes políticos chibuleo menciona:

... del tema de la vestimenta, ya un poquito los profesores kichwas en este caso el compañero José Lligalo un poquito ha ido... ha estado constantemente en esto por lo menos con los niños [...]. Bueno, también ha habido esta cuestión, esta cuestión económica también ¿no?, por ejemplo el sombrero del pueblo chibuleo hoy por hoy está costando 150 a 200 dólares. (Entrevista con A. Punina, Ambato, enero 2015)

En estos fragmentos de entrevista, destacan al menos dos factores. Por una parte, el impulso a la readopción del sombrero promovido desde las instituciones educativas bilingües y los líderes comunitarios. Por la otra, el elevado costo del sombrero termina dificultando el proceso de readopción. 
El grupo de las profesoras que promueven la utilización del sombrero en las instituciones educativas, readoptan este accesorio para sí mismas. En coincidencia con la normativa educativa que sostiene que en los establecimientos educativos, como la UEM Chibuleo, los estudiantes deben llevarlo los días lunes "para identificarlos de dónde es" (Entrevista con M. Lligalo, Chibuleo San Francisco, noviembre 2016). Este uso obligatorio es acogido también por las profesoras. Martha Lligalo sostiene: "últimamente sí hemos recuperado bastante al sombrero, así me he puesto, a veces más que todo en la fiesta se pone el sombrero, entonces acá [UEM Chibuleo] sí también lo traigo" (Entrevista con M. Lligalo, Chibuleo San Francisco, noviembre 2016). La misma informante que explica los motivos del desuso del sombrero, refiere a su readopción en contextos festivos y en los establecimientos educativos.

El uso vestimentario normado en las cooperativas, también estimula la readopción del sombrero al interior de la institución, y se transforma en un ejemplo a seguir por la comunidad. Al respecto, la mama Tránsito Manobanda expone que:

[En los] últimos años las cooperativas que han venido, ellas han fortalecido nuestras vestimentas, más antes mejor ya estábamos perdiendo [...] hasta el sombrero [...] Siquiera un día a la semana, siquiera el día lunes ellos están... con la vestimenta propia ya ellos... han fortalecido mejor para nosotros. (Entrevista con T. Manobanda, Chibuleo San Francisco, enero 2015)

Es decir, que las instituciones financieras promueven que sus trabajadoras porten sombrero al menos un día a la semana, al igual que la UEM Chibuleo. De allí que la readopción del sombrero, en el grupo de las profesoras y las mujeres de las cooperativas, sea intermitente y no se sostenga tanto en sus actividades de la vida cotidiana.

A partir de lo expuesto en este acápite, di cuenta, en primer lugar, del destacado rol que asume el sombrero para identificar a los chibuleo y diferenciarlos de otros pueblos indígenas cercanos. Motivo por el cual portar el sombrero incluso llega a la obligatoriedad, tanto en las instituciones educativas bilingües, como en las financieras chibuleo que norman su uso al menos un día a la semana.

En segundo lugar, identifiqué un doble proceso respecto al uso del sombrero. Si, por un lado, este accesorio cayó en desuso a fines de la década de 1980 e inicios de 1990, por grupo de las actuales profesoras y las mujeres de las cooperativas, cuando estudiaban en instituciones no indígenas - con base en su poca practicidad y las burlas recibidas-, se produce desde el 2010 en adelante, un movimiento de readopción del sombrero. Este proceso se encuentra atravesado, tanto por la incidencia de la transmisión de las prácticas vestimentarias de los taytas y las mamas a las nuevas generaciones, como por la intervención de las autoridades y profesoras indígenas en las instituciones educativas; el uso normado promovido por quienes dirigen las instituciones financieras; y el impulso del uso de la vestimenta propia, de parte de las autoridades estatales. 


\subsubsection{El tupu}

El tupu chibuleo, o prendedor, que sujeta las prendas superiores - lishta y bayeta o rebozo- de la mujer chibuleo, ha mantenido esta función práctica hasta la actualidad en los tres grupos de mujeres chibuleo. Las intervenciones de mis informantes alimentan esta lectura $^{70}$ en coincidencia con la bibliografía referida a otros pueblos andinos (Buitrón, 1964; Caluña et al, 2008; Carretero et al., 2016; Jaramillo, 1990), que corrobora la misma función. Sin embargo, pude advertir otra utilidad del tupu en el grupo de las mamas:

... para sostener para que no caiga, pero al mismo tiempo es para defensa $[\ldots]$ Porque más antes, en una pelea algo, con esto se defendían. [...] Mi madre contaba que a un señor hace muuucho tiempo ¿no? habían matado solo con el tupu [...]. Es arma blanca, sino lo que es por la cultura mismo se mantiene. (Entrevista con T. Caluña, Chibuleo San Francisco, enero 2016)

Esto también lo corrobora Kuri Caluña: "es para nuestra defensa, para la defensa de nuestros nombres, de nuestros antepasados, de aquí cualquier cosa que nos diga, cogía esto y... se ponía a pelear" (Entrevista con K. Caluña, Ambato, diciembre 2016). Es decir, que el tupu, constituía también un arma de defensa de las mujeres chibuleo.

Cabe aclarar que el uso del $t u p u$, más allá de la forma y de la función utilitaria que fueron conservadas, tuvo un período de desuso y fue reemplazado por imperdibles a fines de la década de 1980. Promediando la primera década del 2000, este accesorio, al igual que el sombrero, experimentó un proceso de readopción. En este sentido Martha Lligalo da cuenta, por un lado, del desuso del accesorio, pero también nota que se viene produciendo, desde los últimos quince años, un proceso de readopción: "últimamente hemos estado recuperando" (Entrevista con M. Lligalo, Chibuleo San Francisco, noviembre 2016). Estas intervenciones echan luz respecto de un proceso de readopción del $t u p u$, que incluso comienza a ser fabricado nuevamente.

Es importante destacar que en el desuso del tupu, influyó el alto costo que representaba adquirirlo (Rowe 1998, Carretero et al., 2016). En coincidencia con lo que Tránsito Manobanda sostiene al respecto: "nuestros abuelos parece que ellos no tenían [dinero] así... simplemente para guardar creo que vendían a algunos otavaleños [...] cada tupu valía unos 50 dólares" (Entrevista con T. Manobanda, Chibuleo San Francisco, diciembre 2016). De este modo, las mujeres chibuleo que conservaron los tupus, continuaron su uso, en particular las mamas.

El número de tupus, que llegaba a dos o tres sobre la misma prenda hasta 1980 (Rowe, 1998), se redujo a uno en el uso cotidiano. Este tupu se utiliza para sujetar más de un tipo de chal al mismo tiempo, como la lishta y los rebozos en el caso de las mamas, o la lishta y la bayeta en el caso de las profesoras y de las mujeres de las cooperativas. Mis informantes dan cuenta de este hecho al mencionar que, en la década de 1990, algunas mujeres sujetaban sus rebozos hasta con dos tupus, mientras que, al momento de los registros etnográficos, se colocan sólo un tupu. Más aún, en la actualidad se registró un uso alternado con 
un prendedor no indígena, según lo indiquen las normas de las instituciones en que se desempeñan laboralmente; o según su preferencia o capacidad económica, ya que, en caso de poder permitírselo, pueden adquirir los tupus de plata.

Entonces, puedo afirmar que, si bien los tupus no dejaron de ser portados por la totalidad de las mujeres chibuleo, a partir de la primera década del 2000, la readopción de este accesorio se extendió al resto de las mujeres, en particular a las profesoras y las de las cooperativas. Según mis registros, la readopción del tupu, al igual que toda la indumentaria chibuleo, es concomitante con el surgimiento de las instituciones financieras dirigidas por indígenas. Cecilia Tiche, describe este momento como sigue:

... ya inicia a digamos a rescatar la vestimenta en sí, porque anteriormente ya la gente estábamos perdiendo ya la vestimenta [...] Por ejemplo, en el caso de cuando nos íbamos a la universidad, así ya no se utilizaba la bayeta que siempre nosotros utilizamos con el tupo que es de plata, que nos sirve como imperdible para unirles las puntas de las bayetas y usar como chalina. (Entrevista con C. Tiche, Ambato, diciembre 2016)

Es decir, el uso del tupu de plata junto con la bayeta, que dejan de usar las mujeres que acuden a las instituciones de educación superior en los 1990, es readoptado a partir de mediados de la primera década del 2000, con la generación de las cooperativas de ahorro y crédito, y con el impulso al uso de la vestimenta chibuleo. El uso alternado entre el tupu y el prendedor no indígena - que lo reemplaza-, es más evidente en los grupos de las profesoras y las mujeres de las cooperativas. Una de mis informantes de las instituciones financieras da cuenta de ello: "sí, utilizamos el tupo, sino que ahora por el trabajo los días jueves utilizamos el prendedor color dorado, por eso nomás...sino tupo" (Entrevista con K. Caluña, Ambato, diciembre 2016). Es decir, que el uso del prendedor no indígena en lugar del tupu, responde al cumplimiento de las normativas institucionales. A ello se suma que, en todos los grupos investigados, esta alternancia ocurre debido al alto precio del tupu y, por esto, a la necesidad de conservarlo en buen estado.

Otra transformación del tupu, es la alteración en el uso que ocurre en concomitancia con las prendas que sujeta, es decir la lishta, la bayeta y el rebozo - como se explicó en acápites anteriores-. Junto con la variación del lugar en el que se sostienen estas prendas, también existe una alteración del sitio en el que se coloca el tupu, ya sea en el centro del pecho o sobre un hombro.

\subsubsection{Wallkas y orejeras}

Las wallkas portadas por las chibuleo son accesorios hechos de coral rojo, que se colocan alrededor del cuello y presentan múltiples hileras circulares o vueltas. Las orejeras tienen características similares a las wallkas, con ciertas diferencias, tales como el menor número de vueltas, y que en el filo inferior llevan una jiga. Ambos accesorios han estado expuestos a transformaciones. 
La adaptación de la longitud de estos accesorios, la adopción de formas no indígenas y el cambio de material, son algunos de los cambios identificados en las wallkas y las orejeras que se detallan en los siguientes párrafos.

La longitud de estos accesorios se ha reducido. Así lo sostiene uno de mis informantes: "en sí el estilo de las orejeras que lo decimos... las washkas de pronto ahora solo ponen uñita, más antes era... larguísimas" (Entrevista con T. Caluña, Chibuleo San Francisco, enero 2016). Tupac Caluña, junto con su esposa Isabel Capúz, muestran durante la entrevista que estos accesorios, tenían una dimensión hasta por debajo de la cintura de la mujer como largo máximo. Así lo expone también María Melchora Pilamunga, respecto a las wallkas: "antes era por acá mire [...] hasta el vientre, hasta el filo de la faja ya, pero ahora mire cómo cargo yo" (Entrevista con M. Pilamunga, Chibuleo San Francisco, noviembre 2016). La dimensión del accesorio al que refiere mi interlocutora y que porta durante la entrevista, se ajusta al contorno del cuello.

Respecto a las orejeras, además de la adaptación en la longitud que se evidencia en el grupo de las mamas, identifiqué en las profesoras y en las de las cooperativas, la adopción de formas de aretes no indígenas, que requieren perforación. Así cuenta una mama, que sus hijas de 30 y 18 años han sustituido las orejeras por aretes "así chiquitos, no más hasta aquí, ellas ya no ponen como nosotros, así con hilo no" (Entrevista con J. Pandashina, Chibuleo San Francisco, diciembre 2016). Estas transformaciones de las orejeras responden a su función de utilidad, como explico a continuación.

Las razones de la adopción de las formas de los aretes no indígenas, en lugar de las dos vueltas - circuitos - de las orejeras, son expuestas por mis informantes. Martha Lligalo menciona lo ocurrido mientras portaba orejeras a finales de la década de 1980:

... las orejeras largas que nos ponían... yo también hasta el colegio, tercer curso [1988] ponía, entonces en una de esas [...] se me engancha en la estaca de la oveja... se me engancha y me sale así, esta oreja se cortó así [...] desde ahí mi mami me empezó a poner los aretes pequeñitos. (Entrevista con M. Lligalo, Chibuleo San Francisco, diciembre de 2016)

Este fragmento de entrevista no sólo expone la escasa practicidad de la longitud de las orejeras, sino que incluso muestra que puede lastimar a la portadora. Martha también argumenta que este cambio se vincula con "la necesidad mismo de ir a la ciudad [...] porque era más fácil ponerme las orejeras pequeñas” (Entrevista con M. Lligalo, Chibuleo San Francisco, noviembre 2016). Otra de las informantes del grupo de las profesoras, también hace referencia a la dificultad de portar las orejeras largas:

... lo tengo de reliquia ahí todo colgado. Para mí es un estorbo, como trabajo aquí [UEM Chibuleo], cargado por aquí... me estorba pues es muy largo. [...] por ejemplo en momentos de cultura física [...]. Por eso me he cambiado yo. (Entrevista con M. Pilamunga, Chibuleo San Francisco, noviembre 2016) 
Las orejeras largas son consideradas, por las mujeres, como poco prácticas, tanto para acudir al trabajo en instituciones educativas como para transportarse a la ciudad; más imprácticas aún, en el desarrollo de actividades físicas. Asimismo, en las instituciones financieras se portan aretes - de formas y dimensiones no indígenas-, en lugar de las orejeras largas, por el peso. Según explica la informante María Mungabusí: “a veces todo el día pasar con todo ese peso no pues, pero sí ya hemos acogido los aretitos pequeños asi”" (Entrevista con M. Mungabusí, Ambato, diciembre 2016).

Entonces, identifico al menos dos razones para la adopción de las formas de los aretes no indígenas y la consecuente reducción de longitud de las orejeras. Por un lado, la incomodidad y el peso de estos accesorios dan cuenta de las transformaciones de éstos a partir de su función práctica, en contextos diferentes al trabajo rural. Por el otro, también responde al contacto interétnico.

En el caso de las wallkas, las transformaciones se producen, por una parte, en el grupo de las mamas, respecto a la longitud y el número de vueltas - circuitos-, que podían llegar a ser hasta 40 en la década de 1990 (Entrevista con T. Caluña, Chibuleo San Francisco, enero 2016). Según infiero a partir de lo ocurrido con las orejeras, la larga extensión de las wallkas, sumado al número de vueltas, lo han convertido en un accesorio pesado y poco práctico para su uso en la cotidianidad. De allí que, actualmente, predominen adaptaciones que reducen el largo de las wallkas hasta llegar, como máximo, a la altura de la cintura, y el número de vueltas hasta quince.

Por otro lado, en las categorías de las profesoras y las mujeres de las cooperativas, identifiqué adopciones de la forma de los collares no indígenas en las wallkas. Así lo describe Agustín Punina: "ahora ya no utilizan así... por ejemplo ahorita mija... ya no utiliza de esta manera. Utilizan las vueltas, pero en gradas". (Entrevista con A. Punina, Chibuleo San Francisco, enero 2016). Es decir, que la forma de las wallkas se ha transformado, pasando de confeccionar vueltas - circuitos- completas, a simularlas con hileras dispuestas en gradación en la parte delantera (Jones, 2005; Leborg, 2013). Esta es tan sólo una de las adopciones de las formas de los collares no indígenas, que transformaron las wallkas.

Hasta este punto, se expuso cómo en el grupo de las mamas, las orejeras y las wallkas han modificado el largo y el número de vueltas, reduciéndolos — adaptación-; mientras que en los grupos de las profesoras y en las mujeres de las cooperativas, se adoptan las formas de los collares y aretes no indígenas.

Además de las adaptaciones y adopciones que ocurren en las wallkas y orejeras, se produjo un cambio del material en el que se elaboraban estos accesorios, de un material natural - spondylus o coral-, a uno plástico. Si bien este cambio ya era notorio en un período anterior a la década de 1990, como lo evidencian los estudios de Rowe (1998), es importante dar cuenta de este proceso, por la relevancia que le atribuyen mis interlocutores en el período de estudio.

En efecto, para la década de 1990, mencionan que la longitud y el material en que eran producidos estos accesorios, simbolizaban un mayor poder adquisitivo. Si las orejeras eran más largas de lo habitual, y las wallkas de coral puro, entones quien las portaba contaba con mayor capital económico. Al respecto, Tupac Caluña sostiene que: 
... eso significaba la riqueza ¿no? la riqueza, el poderío que tenían ciertas mujeres, pero solo de coral, coral puro. [...] El costo, entonces ahora... ya las mujeres que lo hacen ya lo diseñan con... en los aretes ya ponen los corales hacen los diseños, diferentes diseños algunos que tienen... otros casos que no tiene mucho... lo compran de plástico, son diseños similares. (Entrevista con T. Caluña, Chibuleo San Francisco, enero 2016)

Con esta intervención, identifico que el indicador de riqueza ${ }^{71}$ de los accesorios se vincula tanto a la longitud como al material de elaboración. La utilización de plástico ${ }^{72}$, aunque simule los diseños en coral, expresa un menor poder adquisitivo. En términos de Bourdieu (2012), este hecho da cuenta de la distinción de clases, en este caso, al interior del grupo étnico. La diferencia se identifica entre las mujeres con mayor poder adquisitivo, que portan los accesorios de material costoso y original, y las mujeres que usan una copia barata y sintética. Interesa en este punto echar luz acerca de que las mujeres chibuleo también elaboran los accesorios y, según indica Tupac Caluña, los diseñan. Éste es un caso de diseño difuso (Manzini, 2015) — al igual que en el caso de las blusas_, por parte de las mujeres chibuleo.

Para la época de mis registros etnográficos, el uso del coral en las wallkas y orejeras continúa siendo un indicador de riqueza, que se visibiliza en el uso de los accesorios de coral durante las fiestas, frente a la utilización del plástico en la vida cotidiana. Como lo expresan mis informantes:

Tupac Caluña: Ya la gente dice ah... ese es plástico, las mujeres saben que es plástico, mientras que hay otras que ya tienen así bastante [...] el que tiene dinero puede comprar [coral].

Isabel Capúz: Por ejemplo, en estas fiestas. Están llenos de corales hasta 15 sogas.

TC: Obviamente no son de ellas... hasta van a alquilar... piden a las familiares entonces.

IC: En estos tiempos actualmente así hablando así ahora ya... no tienen toda la familia como antes tenían coral, ni para comprar ya no hay. Hay algunas familias nomás, específicamente algunas... que tienen coral. (Entrevista con T. Caluña; I. Capúz, Chibuleo San Francisco, enero 2016)

Mis informantes hacen referencia a la fiesta de los Reyes Magos, que se desarrolló el mismo día de la entrevista. Asimismo, dan cuenta de la importancia de portar accesorios de coral y del número de vueltas para evidenciar riqueza. La necesidad de cubrir esta función simbólica lleva incluso a pedir prestadas las orejeras y wallkas a familiares, o también a alquilarlas. Entonces el uso de los accesorios de coral se reserva para ocasiones especiales, mientras que en su cotidianidad, la mayoría de las mujeres chibuleo, y en particular las profesoras y las mujeres de las cooperativas, portan estos accesorios elaborados en un material artificial que simula el coral. 
En definitiva, en la categoría de las mamas, estos accesorios presentan adaptaciones que reducen su longitud y número de vueltas, en las wallkas y orejeras. Por su parte, en el grupo de las profesoras y las de las cooperativas, se registran adopciones de las formas de aretes y collares no indígenas. Asimismo, tanto las wallkas como las orejeras mantienen el color rojo del coral, y en el uso cotidiano son elaborados en un material sintético que es más liviano y de menor costo. El uso de los accesorios elaborados con coral natural es reservado para ocasiones especiales y festivas. En los tres grupos de mujeres, se identificaron transformaciones de los accesorios - walkas y orejeras- y de su ocasión de uso en relación con su función estética y práctica (Fernández, 2015a; Lobäch, 1981).

En este apartado he podido evidenciar que las transformaciones de diseño en los objetos vestimentarios se desarrollan a partir de las funciones de utilidad/práctica y estética, en consonancia con las construcciones identitarias de las mujeres chibuleo que los portan, es decir, con su función simbólica. Transformaciones que ocurren en la misma vestimenta indígena por el devenir histórico, así como también por adopciones de indumentaria no indígena, y particularidades que identifican a instituciones específicas. En este sentido, considero que se establecen modificaciones y adopciones vestimentarias como resultado de la dinámica interétnica. Lo antedicho echa luz respecto a la forma en que el Diseño, aporta en la construcción de la identidad de las mujeres chibuleo.

En este punto, es posible advertir que las tres funciones del objeto vestimentario, pasan a formar parte del artefacto del Diseño, cuando la indumentaria es usada por las mujeres chibuleo en un contexto determinado. En este sentido, abordo a la interfaz como la función comunicativa, que incluye la función estética y simbólica; y a la prótesis, como la función práctica y simbólica del artefacto del diseño.

\section{Capítulo 4: El diseño indumentario chibuleo}

El presente capítulo tiene el propósito de analizar el Diseño del artefacto vestimentario de la mujer chibuleo, como diacrítico identitario y evidencia de su resignificación dialéctica. Para ello, en los siguientes apartados, se reconstruyen, en primera instancia, las tipologías de la indumentaria al interior del grupo indígena.

En segundo lugar, se estudian los arquetipos indumentarios, que emergen de las construcciones identitarias de los tres grupos de mujeres identificados, y las siluetas vestimentarias, en un análisis que también considera sus transformaciones históricas.

Finalmente, se analiza a la indumentaria chibuleo como artefacto de diseño, explorando la manera en que esta se ha constituido en diacrítico identitario de su pueblo.

\subsection{Transformaciones de la indumentaria y procesos interétnicos-}

Las transformaciones identificadas en la indumentaria de la mujer chibuleo, dan cuenta de los procesos de resistencia, apropiación e innovación en "la dinámica cultural de las 
relaciones interétnicas" (Bonfil Batalla, 1991, p.185) al interior del grupo. Estas transformaciones pueden analizarse desde el campo del Diseño, a partir de la alteración de los usos y el traslado o subversión de la ocasión de uso (Fernández, 2015a, 2016a); o desde la Antropología, mediante los términos de adopción, cambio y readopción (Karasik, 2010; Theodossopoulos, 2012; Turner, 1991). Las transformaciones registradas tanto desde el Diseño como desde la Antropología son la adaptación (Fernández, 2015a, 2016a; Karasik, 2010; Theodossopoulos, 2012) y la combinación (Fernández, 2015a, 2016a; Karasik, 2010; Theodossopoulos, 2012; Turner, 1991).

Previo al abordaje de dichas transformaciones, aclaro que, tal como sostuve anteriormente, también existe continuidad en el uso de algunas prendas y accesorios chibuleo. La continuidad indumentaria, entendida como un proceso de resistencia al interior del grupo indígena está definida por el uso de las mismas prendas y accesorios durante un período prolongado de tiempo. Las prendas que reflejan continuidad del uso vestimentario chibuleo son el anaco, el chumbi y el rebozo - que se transforma en bayeta-, en los tres grupos de mujeres identificados.

Asimismo, la continuidad se refleja en el uso persistente del sombrero, wallkas y orejeras, que portan las mamas en su cotidianidad. El uso de estos dos últimos accesorios se generalizó para las profesoras y las mujeres de las cooperativas, pero no en su vida cotidiana, sino en contextos de fiestas y rituales propios de la comunidad, como expuse en el capítulo anterior. Aun cuando estas prendas y accesorios chibuleo conservan su forma, se ha transformado el material de confección, el color y el volumen.

Las mujeres chibuleo son cocreadoras ${ }^{73}$ de la vestimenta, ya que durante la experiencia de uso la transforman. Estas transformaciones pueden darse a partir de la adopción de vestimenta no indígena - o de alguna de sus particularidades-, al repertorio indígena, en prendas como la camisa, la blusa, el saco, el buzo, y la chompa, además de complementos como medias y calzado. En particular la camisa es adoptada por las mamas, y la blusa por el grupo de las profesoras y las mujeres de las cooperativas. El proceso de apropiación, sucede cuando un grupo es capaz de producir o reproducir los elementos ajenos adoptados, y estos pasan a ser propios (Bonfil Batalla, 1991); este es el caso de las camisas y las blusas. Este proceso se identificó en la camisa y la blusa no indígenas, cuyas diversas tipologías y color - blanco-, han sido apropiadas y reproducidas por los chibuleo, al incorporar bordados que representan elementos de la Pachamama, y entran en un proceso de innovación. Es decir que estas prendas son producto de la apropiación y la innovación, dentro de la dinámica interétnica.

Con respecto al saco, aun cuando lo usan los tres grupos de mujeres chibuleo, es portado cotidianamente por las mamas, quienes además permiten ser fotografiadas sin intentar quitarse esta prenda. Algo similar ocurre con las mujeres de las cooperativas, que mantienen el saco para ser fotografiadas, siempre que sea el que forma parte del uniforme. En el caso de las profesoras, estas prefieren deshacerse de esta prenda.

En cuanto al buzo, que es colocado por debajo de la camisa, es una adopción cotidiana únicamente del grupo de las mamas, y ha pasado a formar parte de su atuendo, mientras que los otros dos grupos de mujeres no lo han incluido en su repertorio. 
La chompa es otra prenda adoptada, pero en este caso por las profesoras y las mujeres de las cooperativas. Sin embargo, es preciso aclarar que para ser fotografiados, estos grupos se quitan la chompa, lo que implica una adopción parcial; no llega a una completa apropiación. Los motivos de esta adopción responden a cuestiones climáticas, y a que su uso se encuentra permitido dentro de las instituciones en las que se desempeñan. El mismo caso ocurre con el chaleco, adoptado solamente por las mujeres de las cooperativas.

En cuanto a las medias y calzado no indígena, ambos son adoptados por los tres grupos de mujeres, dependiendo del trabajo que realizan en su vida cotidiana. Las mamas adoptan medias tejidas junto con calzado tipo mocasín o botas; los otros dos grupos de mujeres portan medias nailon con calzado tipo salón, con tacón medio o alto; y en días específicos utilizan alpargatas, calzado indígena, que las mujeres chibuleo adoptan de otro pueblo dentro de la misma etnia.

Además, entre la indumentaria no indígena adoptada al repertorio chibuleo, se encuentran las formas y tipologías de los collares y aretes no indígenas. Estas adopciones morfológicas de las wallkas y orejeras indígenas, se presentan en la vestimenta de las profesoras y las mujeres de las cooperativas.

Por otra parte, pude identificar modalidades de cambio indumentario, que ubico dentro del proceso de apropiación; ya que para cambiar las prendas y accesorios, o sus materiales y la manera de construcción, primero debe ser adoptada por el grupo étnico. Así, el cambio puede implicar una interrelación entre la resistencia y la apropiación (Bonfil Batalla, 1991), como es el caso del uso de una indumentaria indígena que persiste, pero cuyos materiales o su manufactura se modifican.

La camisa es la prenda que expresa el cambio entre las chibuleo, ésta no sólo ha sido adoptada en un proceso de apropiación, sino que además se usa en reemplazo del tupulli. El tupulli, que según mis registros etnográficos comienza a ser abandonado en la década de 1960, para inicios de la década de 1990, era de uso infrecuente.

Alrededor de este mismo período de tiempo, ocurrió el cambio de materiales en la indumentaria chibuleo de prendas como el chumbi, el rebozo y la lishta. Estas prendas cambiaron de fibra de lana y confección manual, a fibra acrílica de manufactura industrial, en los atuendos de las mamas, las profesoras y las mujeres de las cooperativas.

Asimismo, he dado cuenta del remplazo de los corales utilizados para la confección de wallkas y orejeras, por materiales plásticos que simulan el color, forma y textura de los originales. El uso del coral implica la posesión de un poder adquisitivo que casi ninguna mujer posee, y las pocas que tienen accesorios confeccionados en este material natural, los han heredado de algún familiar, y los utilizan sólo durante las festividades del pueblo. Tanto los materiales de las prendas, como de los accesorios chibuleo, cambiaron de naturales a artificiales. Las prendas también experimentaron el cambio en el tipo de manufactura — de confección manual a industrial-, mientras que los accesorios hasta la actualidad son elaborados manualmente.

Si bien los cambios datan de antes del período de estudio de la presente tesis, se incorporan al análisis debido a la importancia que le otorgan taytas, dirigentes, mamas, y también algunas profesoras y mujeres de las cooperativas. Puntualmente, dentro del recorte histórico de la investigación (1990-2016), se observan transformaciones en los materiales y tipologías de las blusas. Randa, charme y seda, son materiales utilizados en las blusas de 
las profesoras y de las mujeres de las cooperativas, desplazando al lino, material con el que se confeccionaba la camisa de las mamas, desde 1990 hasta el presente.

Así también, el tipo de camisa de escote lágrima, manga corta y silueta rectangular utilizado aun por las mamas, es reemplazado por blusas con diversidad de escotes, mangas y silueta insinuante en los otros dos grupos de mujeres. Es decir, que el atuendo de las mamas conserva la forma y el material de la camisa de 1990; mientras que los cambios se evidencian en las blusas de las profesoras y las mujeres de las cooperativas.

Asimismo, dentro del período de estudio, pude dar cuenta del reemplazo paulatino e intermitente de la bayeta por el saco, así como del reemplazo del tupu por prendedores, ambos casos visibles en la indumentaria de las profesoras y las mujeres de las cooperativas. $\mathrm{Si}$ bien observo estos cambios en una fase de estudio acotada, es preciso mencionar que ellos han ocurrido paulatina y gradualmente, en un período de tiempo prolongado, e incluso continúan generándose.

Otro cambio surge de la combinación entre prendas y accesorios indígenas, y aquellas prendas no indígenas que han sido apropiadas e innovadas. Entre la vestimenta de procedencia indígena están algunas prendas como el anaco, bayeta, rebozo, lishta y chumbi; y accesorios como las orejeras, las wallkas, el sombrero y el tupu. Entre la vestimenta de procedencia no indígena, está la camisa y la blusa - que luego de ser apropiadas, los chibuleo las consideran propias-, el saco, el buzo, la chompa y el chaleco; dentro de los accesorios, los collares, los aretes, los prendedores, las medias y el calzado.

En relación con lo antedicho, es preciso distinguir las combinaciones cotidianas de las combinaciones intermitentes. La combinación cotidiana se evidencia en la vestimenta de las mamas, que articula anaco, rebozo, lishta, chumbi, orejeras, wallkas, sombrero y tupu de procedencia indígena; con buzo, saco, medias tejidas y calzado de tipo mocasín, o botas de procedencia no indígena. El tupu, en ocasiones, es reemplazado por un imperdible.

En la vestimenta de las profesoras, las combinaciones ocurren entre anaco, bayeta, lishta, chumbi y sombrero, de procedencia indígena; y saco, chompa, collares, aretes, medias nailon y calzado tipo salón — con tacón medio o alto-, de procedencia no indígena. Otra combinación ocurre entre el tupu indígena y los prendedores no indígenas, que cumplen la misma función práctica de sujetar la bayeta y la lishta. Sin embargo, su uso es generalmente alternado, lo que implica que cuando se porta uno, no se usa el otro. Respecto al sombrero, es preciso aclarar que no se porta de manera cotidiana, sino que su uso está reservado para uno o dos días a la semana.

La combinación de indumentaria indígena y no indígena, en el atuendo de las mujeres de las cooperativas, es similar al de las profesoras, con la diferencia de que las variaciones en la forma y el color de las prendas no indígenas, responde a las normas internas de la institución. Otras modificaciones que se realizan a la vestimenta propia son las adaptaciones, como las transformaciones de las dimensiones de la bayeta, la lishta y el anaco, en la indumentaria de las profesoras y las mujeres de las cooperativas. En cuanto al al rebozo, la lishta y el anaco de las mamas, las modificaciones pueden ser leídas como un proceso de resistencia a fin de continuar su uso, mejorando su función práctica en nuevos contextos y desempeños urbanos. La bayeta y la lishta presentan reducción de longitud, mientras que el anaco aumenta su dimensión longitudinal y se reduce en sentido horizontal. Además, disminuyen la cantidad de bayetas y anacos portados. En efecto, el grupo de las mamas 
pasó a usar entre uno y dos rebozos, y entre dos y cuatro anacos; los otros dos grupos utilizan una bayeta y un anaco. Otra adaptación que implica resistencia se muestra en la reducción de las dimensiones de las orejeras y las wallkas, además de la disminución del número de vueltas en este último accesorio.

En la blusa apropiada por las profesoras y las mujeres de las cooperativas, se presentan adaptaciones tipológicas en escotes, mangas y siluetas (Travers-Spencer y Zaman, 2008). Pueden considerarse también una adaptación, en este caso dentro el proceso de innovación, los bordados que se incorporan, con las hombreras, al corpiño de la blusa. Las formas de los bordados se adaptan, de figuras orgánicas, a formas cada vez más geometrizadas o geométricas de elementos que refireren a la Pachamama; en especial de la flor de la papa. Así también, las formas de animales que se tejen en el centro del chumbi, se han adaptado, a través de un proceso de geometrización similar.

En cuanto a la readopción (Karasik, 2010; Theodossopoulos, 2012; Turner, 1991), en tanto incorporación de la indumentaria indígena que durante un tiempo este grupo étnico ha dejado de usar, los chibuleo la presentan en la lishta, el sombrero y el tupu, en los atuendos portados, principalmente, por las profesoras y las mujeres de las cooperativas. Readopciones que también pueden ser leídas como parte del proceso de resistencia, en términos de Bonfil Batalla (1991).

En el caso de la lishta, se readopta en un material distinto a la fibra de lana y su manufactura manual. Esta prenda de envoltura, portada por los tres grupos de mujeres, cambia a una fibra acrílica que se confecciona a nivel industrial. Sin embargo, existen ciertas diferencias en el uso de un grupo y de los otros dos. Parte de las diferencias consiste en la dimensión de la lishta, en el caso de las mamas continúa llegando hasta la cadera, mientras que en las profesoras y las mujeres de las cooperativas esta prenda tiene adaptaciones, puesto que su dimensión se ha reducido, cubriendo desde la parte superior del cuerpo hasta la cintura. La readopción del sombrero y el tupu, ocurre en la indumentaria portada por las profesoras y las mujeres de las cooperativas, pero de manera intermitente. En cuanto al primero, se utiliza sólo ciertos días de la semana laboral de acuerdo al consenso de las profesoras en el caso de las instituciones educativas, y a la normativa interna a las que están sujetas las mujeres de las cooperativas en las instituciones financieras. Es decier, se utiliza uno o dos días a la semana, y los días restantes se suprime su uso. Con respecto al uso del tupu, éste también es utilizado algunos días y los restantes es reemplazado por prendedores, en tanto es un accesorio imprescindible para sujetar la lishta y la bayeta, lo que no ocurre con el sombrero, ya que no tiene reemplazo.

En el caso de las mamas, tanto el sombrero como el tupu han sido de uso continuo; este hecho es más notorio en el sombrero utilizado en la cotidianidad, mientras que el tupu ha tenido un uso intermitente ya que, como se dijo, se porta de manera alternada con imperdibles o prendedores. Las razones que pude identificar responden a que el material del tupu — plata - tiene un costo elevado, por lo que muchas mamas deciden no usarlos en su cotidianidad.

La alteración de uso (Fernández, 2015a) de la indumentaria chibuleo sobre el cuerpo de las mujeres, la identifiqué en prendas que han sostenido una continuidad en el tiempo. Este tipo de transformación se evidencia en las formas de colocación de la bayeta y la lishta, 
que pasaron de colocarse en forma simétrica sobre la espalda y prenderse en el centro del pecho, a portarse de forma asimétrica y prenderse sobre un hombro. Estas alteraciones ocurren en la indumentaria de las profesoras y las mujeres de las cooperativas, mientras las mamas conservan el modo de uso con sujeción en el frente.

El traslado o subversión de la ocasión de uso indumentario (Fernández, 2015a), se evidencia en las prendas que, siendo originariamente utilizadas para el trabajo en el campo, son también portadas para trabajar en instituciones educativas y financieras. Estas prendas son el anaco y el chumbi, usados por los tres grupos de mujeres, además del rebozo, portado por las mamas, y la bayeta, portada por los otros dos grupos.

El anaco envuelto con el chumbi, de acuerdo a los datos etnográficos obtenidos, es utilizado por las mamas para fortalecer la cadera al momento de realizar las labores del campo como cargar y arar. Lo mismo sucede con el rebozo, que muchas veces, además de la función utilitaria de abrigo, es empleado por las mamas para cargar hierba o alimentos cosechados sobre sus espaldas. Estas prendas forman parte de la indumentaria de las mamas, y del atuendo de las profesoras y las mujeres de las cooperativas. En estos últimos dos grupos las prendas fueron adaptadas para el desarrollo de otras actividades. Por lo antes expuesto, identifico que el anaco, el chumbi, el rebozo o la bayeta, aun cuando son utilizados por los tres grupos de mujeres para trabajar, los ámbitos de trabajo y el contexto son distintos, lo que implica un traslado dentro de la ocasión de uso.

De lo analizado hasta acá, se concluye que las transformaciones de la vestimenta de la mujer chibuleo, evidencian procesos de resistencia, apropiación e innovación al interior del grupo étnico. Asimismo, estos se combinan en el entramado interétnico como parte de su construcción identitaria.

Los elementos vestimentarios, catalogados dentro de la innovación, están vinculados tanto con la resistencia como con la apropiación. Respecto a la interrelación entre resistencia e innovación, el uso del anaco en las cooperativas de ahorro y crédito, por una parte, implica resistencia y continuidad de un elemento cultural propio. Pero por la otra, al reducirse la cantidad de anacos y pliegues, así como el cambio en las formas de cierre, pasando de envoltura a cremallera con botones y pliegues preformados, como el que utilizan algunas mujeres, implica un proceso de innovación.

Asimismo, el portar chumbi muestra, por un lado, el proceso de resistencia; y por el otro, el cambio de las formas de oclusión de envoltura - a elementos como broches o tiras elásticas-, involucra la innovación.

La conexión entre apropiación e innovación, se expresa a través de las camisas y las blusas blancas apropiadas, en tanto las mujeres bordan sobre éstas elementos representativos de la naturaleza - en particular la flor y las hojas de la papa-. Además, están las formas de los collares y aretes no indígenas, que las mujeres confeccionan con colores y materiales que imitan los corales utilizados en las wallkas y orejeras.

El análisis de las transformaciones de la vestimenta al interior del grupo, constituye un aporte al análisis de la construcción de la identidad indígena desde el Diseño de Indumentaria, explicitando asimismo la forma en que se constituyen los arquetipos vestimentarios que explico a continuación. 


\subsection{Arquetipos indumentarios chibuleo}

Los arquetipos son "modelos ideales" (Maffesoli, 2009) construidos en base a las imágenes de las mujeres chibuleo, que en nuestro caso se generan a partir de la indumentaria. En el devenir histórico de los grupos étnicos, al "reorganizar la jerarquía de sus valores de acuerdo con su imaginario social” (Saulquin, 2010, p.115), configuran características vestimentarias que dan origen a construcciones arquetípicas. En este sentido, los hitos históricos, sociales y políticos transformaron la identidad chibuleo, y con ella, su indumentaria. En la actualidad, los chibuleo distinguen tres grupos de mujeres al interior del grupo étnico (las mamas, las profesoras y las mujeres de las cooperativas), con sus respectivos arquetipos indumentarios.

En efecto estos grupos de mujeres se fueron cincelando en diferentes etapas de la lucha por la reivindicación de los derechos indígenas, y la apertura histórica de nuevos roles sociales. En estos escenarios, las mujeres portan su indumentaria étnica, con características comunes y diferencias dentro de cada grupo tal como se detallará a continuación.

\subsubsection{El arquetipo indumentario de las mamas}

Entre los años 1990 y 2016, son escasas las transformaciones vestimentarias que se registran en el arquetipo vestimentario de las mamas (Ver Figura 2). Estas transformaciones giran principalmente alrededor de la disminución del número de anacos, chumbis y rebozos portados. En efecto, la parte superior del cuerpo de las mamas está cubierta por uno o dos rebozos de color negro o azul, que se sujetan en el centro del pecho con un tupu de plata. Los rebozos, en su mayoría son tejidos con fibras acrílicas, aunque algunas mamas portan uno de estos rebozos tejido en lana. Portan además una lishta, considerada por las mamas también como un rebozo, pero de color blanco, con rayas verticales. Una particularidad de los rebozos -incluida la lishta - de las mamas, es su dimensión, que inicia en los hombros y termina en el alto de la cadera. Estas tres prendas tienen bordados en zigzag en sus filos, simulando la forma de las montañas, en colores magenta, azul y plateado.

Debajo de los rebozos portan una camisa blanca, de silueta rectangular, cuello redondo con una abertura vertical en el centro al frente - es decir, de escote lágrima-, y manga corta con plises a la altura de los hombros. En la camisa se incluyen las hombreras, con bordados a mano, que se colocan alrededor del cuello por sobre los hombros, además de detalles bordados en las mangas. Los bordados son representaciones de la flor y las hojas de la papa, realizados en colores verde, magenta, azul y/o azul violáceo.

Para la parte inferior, las mamas utilizan entre dos y cuatro anacos, todos de color negro o combinados con uno azul, que envuelven su cuerpo desde la cintura hasta cubrir las rodillas, sujetados con chumbis envueltos en la cintura y la cadera. Las mamas forman varios pliegues principalmente en la parte delantera de los anacos, con lo que logran aumentar significativamente el volumen de su silueta. Además, los filos de los anacos están bordados con la misma forma y colores que los rebozos. 
Los chumbis tienen en el centro - shungo- motivos geometrizados de animales - en tejidos artesanales-, y con más frecuencia figuras geométricas —en el caso de tejidos industriales-, en diversas combinaciones de color, que varían entre azul, azul violáceo, magenta y verde. Sin embargo, el color blanco en los extremos de los chumbi, es un elemento constante.

Dentro de los accesorios está el sombrero blanco de ala corta y vuelta, con copa pequeña, que lleva un hilo azul alrededor, accesorio que enmarca el rostro de las mujeres junto con la marga accha - un mechón de cabello cuyo largo alcanza hasta el final de las orejas-. Otros accesorios son las orejeras, que se suspenden de las orejas con hilos, y cuya dimensión sobrepasa la altura del busto hasta llegar a la cintura; y las wallkas, que se suspenden del cuello con dimensiones que llegan también a la cintura. Ambos accesorios elaborados en coral o un material artificial que lo imita; y el tupu de plata que sujeta los rebozos.

Además de estas prendas y accesorios, el intenso frío y el terreno áspero - antes de tierra y ahora pavimento con residuos de las construcciones de casas chibuleo-, ha hecho que las mamas adopten prendas no indígenas. Así, entre los rebozos y la camisa se colocan un saco de manga larga con botonadura delantera (que generalmente no abrochan, dejando ver la camisa), en colores magenta, rojo, azul violáceo o gradaciones de azul. Entre la camisa y el cuerpo, portan uno o dos buzos de manga larga con cuello alto que sobrepasan el escote de la blusa y cubren la mayor parte del cuello, en los mismos colores que los sacos. Asimismo, adoptan calzado tipo mocasín.

Todas las características mencionadas configuran la silueta de las mamas, que en su conjunto extiende el volumen corporal de estas mujeres en sentido horizontal, lo que corresponde a la tipología de silueta volumétrica en los términos de Saltzman (2004). Esta silueta, sumada a la trama de significación interpretada en la construcción identitaria de la vestimenta propia, conforman el arquetipo indumentario de las mamas. Si bien en el presente estas mujeres trabajan en el campo, son un modelo a seguir porque representan la lucha por la reivindicación de los derechos de la etnia y la exigencia de respeto (Ver Figura 2).

\subsubsection{El arquetipo indumentario de las profesoras}

El arquetipo vestimentario de las profesoras, es denominado por los chibuleo como vestimenta de la cultura, y al ser portado por las profesoras, se entretejen los derechos reivindicados en el marco de la educación y el incremento del capital cultural alcanzado por los chibuleo. El conjunto de prendas que conforma el arquetipo indumentario de las profesoras en el presente, se conforma de prendas y accesorios indígenas que continúan en uso y otras adoptadas del repertorio indumentario no indígena (Ver Figura 2).

Esta nueva silueta indumentaria de las profesoras, es menos voluminosa que la silueta de las mamas, como expongo en los párrafos siguientes. La parte superior del cuerpo es cubierta por una bayeta de color negro, o una lishta blanca con rayas de color magenta o azul. Estas prendas pueden estar colocadas de manera simétrica sobre la espalda hacia el centro del pecho; o asimétrica, por debajo de un brazo y sobre uno de los hombros; para sujetarlas se utiliza un tupu, o prendedores sobre uno de los hombros. 
La blusa blanca, debajo de la bayeta, es confeccionada en diferentes tipos de telas combinadas - randas, transparencias y lino-, y se presentan en diferentes modelos, con escotes redondeados o en $\mathrm{V}$, con bordados alrededor del cuello, y mangas montada o flauta (Travers-Spencer y Zaman, 2008) entre las más comunes, cuyo largo varía; unas por encima de los codos y otras que llegan a la muñeca. También incluye el anaco negro, desde la cintura hasta la altura de los tobillos, con un chumbi envuelto que ayuda a formar entre cuatro y cinco pliegues. El chumbi es de color blanco en los extremos, con figuras geométricas o de animales geometrizados en el centro y figuras geométricas en los extremos en colores magenta y tonos de azul - principalmente- que se entretejen con color blanco.

En cuanto a los accesorios, usan aretes y un collar, ambos confeccionados en materiales plásticos que imitan el coral. Los aretes son largos, y llegan hasta el final del cuello, mientras que los collares lo envuelven con un mínimo de tres vueltas en gradación desde el inicio del cuello hasta el inicio del busto. Asimismo, utilizan el sombrero blanco, uno o —-máximo- dos días a la semana, y portan zapatos tipo salón, de tacón alto o medio, con medias nailon, que son adoptados del repertorio no indígena.

Las características vestimentarias mencionadas dan forma a la silueta de las profesoras, que extienden la dimensión corporal de la mujer en sentido vertical - sobre todo la dimensión longitudinal del anaco y el uso de zapatos de tacón- y delinea el cuerpo, conformando una silueta insinuante (Saltzman, 2004). Las profesoras y su arquetipo indumentario constituyen un modelo tanto para las estudiantes como para el resto de mujeres de la comunidad, en tanto evidencia del capital cultural adquirido gracias a la conquista de los derechos educativos (Ver Figura 2).

\subsubsection{El arquetipo indumentario de las mujeres de las cooperativas}

El arquetipo vestimentario de las mujeres de las cooperativas, emerge con el surgimiento de las instituciones financieras. Las mujeres de las cooperativas portan, en términos nativos, uniforme propio que constituye un símbolo de elegancia o distinción, por lo que su uso se extiende no sólo a las mujeres del pueblo, sino también a las de otros pueblos de la ciudad de Ambato. El uniforme propio de las mujeres de las cooperativas tiene una doble identificación. Por una parte, muestra la pertenencia al pueblo chibuleo; y por la otra, mediante los identificativos institucionales, denota la pertenencia a una entidad financiera específica. Al interior de cada institución se norman las características de las prendas y accesorios que deben portarse cada día de la semana. La silueta de las mujeres de las cooperativas es menos voluminosa que en el caso de las mamas y se asemeja a la silueta de las profesoras, como expongo a continuación.

La parte superior del cuerpo es envuelta por una bayeta negra durante la mayor cantidad de días de la semana, o por la lishta blanca con rayas uno o dos días, según establece cada institución. Estas prendas, que rodean el torso de las mujeres, se colocan de manera asimétrica por debajo de un brazo, se cruzan por encima del hombro contrario y se sujetan con un tupu o un prendedor. La bayeta y la lishta llegan, como máximo, hasta la cintura y debajo de estas prendas se colocan las blusas. 
Las blusas blancas son las prendas que experimentan mayor variación de acuerdo al día de uso. Los materiales e insumos empleados en la confección de estas prendas, el diseño de su corpiño, la tipología del escote y la manga, sumado a la forma de los bordados en colores azul, azul violáceo, magenta y verde, caracterizan de manera diaria las blusas en el ámbito de las cooperativas.

Este grupo de mujeres utiliza sólo un anaco negro con pliegues para cubrir la parte inferior del cuerpo, prenda que se coloca en la cintura y cuya longitud llega hasta los tobillos. Los anacos con pliegues utilizados en las entidades financieras son preformados - en su mayoría-, es decir, que si bien el anaco sobre el cuerpo de las mujeres de las cooperativas tiene la misma apariencia del anaco envuelto de las mamas, en realidad tiene pliegues cosidos al anaco, y cuenta con un sistema de cierre con cremallera y botones como una falda no indígena. Estas adaptaciones del anaco ofrecen mayor rapidez y agilidad a la mujer al momento de vestirse.

Un chumbi - o faja - envuelve el anaco en la cintura, puede dar alrededor de dos vueltas al anaco o también, de acuerdo al día de la semana, presentar sistemas de cierre diferentes, como broches y cordones elásticos con entrecruzado, que en lugar de aumentar el volumen en la cintura, contribuyen a disminuirlo visualmente.

El chumbi, en color blanco en los extremos y entretejido con otros colores en el centro, tiene figuras geométricas en colores similares a los usados en los filos de la bayeta o de la lishta y el anaco, según el día de la semana; así también los bordados de las blusas. Existe otra particularidad en los chumbis de algunas cooperativas: en el centro del tejido se coloca un identificativo que corresponde a la cooperativa.

Los colores utilizados en los bordes de las bayetas, lishtas y anacos, así como en los bordados de las blusas, le otorgan uniformidad al atuendo. Si bien los colores que se utilizan para tal efecto son el azul, el azul violáceo, magenta y verde - principalmente-, uno de estos colores predomina de acuerdo con el día de la semana.

Respecto al uso de accesorios indígenas, se norma el portar sombrero un día específico de la semana, el uso del tupu de plata para sujetar la lishta o la bayeta, y el uso de aretes y collares, en materiales y colores que simulan el coral y el oro de las orejeras y wallkas de las mamas.

En las cooperativas, además del uso de la indumentaria chibuleo, se permite portar prendas y accesorios no indígenas, sobre todo cuando la temperatura climática desciende. Estas prendas son: sacos, chompas y chalecos, en colores que guardan relación a los colores institucionales. Se registran sacos de color verde y chompas azules en la cooperativa Kullki Wasi, y sacos y chalecos rojos en la cooperativa Chibuleo.

El color y estilo del calzado varía de acuerdo al día, si bien se establecen generalidades, como el uso de calzado tipo salón de tacón medio y alto, en colores negro y café principalmente, acompañado de manera cotidiana con medias nailon. Asimismo, se norma el uso de alpargatas para un día de la semana.

Sin bien el uniforme a portar en cada día de la semana se encuentra normado, incluye todos los días el anaco, el chumbi, la blusa y, dependiendo del día, la bayeta o lishta. Las particularidades indumentarias mencionadas dan forma a la silueta de las mujeres de las cooperativas, que al igual que la silueta de las profesoras, extienden la dimensión corporal en sentido vertical y delinean la figura, lo que en términos de Saltzman (2004) corresponde a la silueta insinuante. 
El uniforme propio que portan las mujeres de las cooperativas configura otro arquetipo indumentario, que da cuenta tanto del aumento del capital económico como del capital cultural (Ver Figura 2).

En definitiva, los tres arquetipos vestimentarios analizados, delinean dos tipos de siluetas distintas; una volumétrica (las mamas), que extiende la dimensión corporal de la mujer en sentido horizontal. La otra insinuante (portada por las profesoras y las mujeres de las cooperativas), que extiende la dimensión corporal en sentido vertical al delinear la figura, de acuerdo a la cantidad y longitud de las prendas portadas, así como del tipo de tacón en el calzado utilizado.

A través de este apartado, he podido dar cuenta de la existencia de arquetipos vestimentarios dentro de la etnia, lo que constituye un campo de estudio original, dado que los arquetipos que han sido abordados por autores como Entwistle (2002), Lipovetsky (2013), Maffesoli (2009) y Saulquin (2010), son mayoritariamente occidentales.

Estos arquetipos evidencian la forma del cuerpo vestido de las mujeres, y el entramado histórico-social y político de los pueblos y, en esta clave, se teje la indumentaria como artefacto del Diseño y diacrítico identitario

\subsection{El artefacto indumentario de diseño}

El artefacto vestimentario de Diseño, es un objeto comunicativo de la vida cotidiana que tiene la capacidad de transformar la imagen de quien lo porta, a partir de la trama social que lo envuelve. En el artefacto de Diseño interactúan dos elementos que se complementan: la interfaz y la prótesis (Fernández, 2015a, 2016b; Krippendorff, 2006; Manzini, 2015; Juez, 2002; Broncano, 2009).

\subsubsection{El artefacto indumentario como interfaz y como prótesis}

Como vengo sosteniendo, la vestimenta de la mujer como diacrítico es una marca de su identidad, proceso que se puede reconstruir a partir de la lucha por la reivindicación de los derechos indígenas como los levantamientos, el reconocimiento constitucional de la etnia y las instituciones chibuleo que surgen producto de las dos anteriores. El uso de la indumentaria sobre los cuerpos sociales (Douglas, 1978; Fernández, 2016a) de las mujeres chibuleo en estos procesos identitarios, decantan en los tres arquetipos indumentarios o modelos chibuleo, expuestos en el capítulo anterior.

A partir del análisis de estos arquetipos puedo dar cuenta de los espacios de interacción entre cuerpo, indumentaria y contexto en el momento del uso (Fernández, 2016b) ${ }^{74}$, así como de las interfaces que integran los artefactos de Diseño a la vida cotidiana, y comunican -intención - la identidad del pueblo en un sentido general.

Cada arquetipo comunica algo diferente. El arquetipo indumentario de las mamas comunica la lucha por el reconocimiento de los derechos de la etnia en el marco del respeto; el arquetipo indumentario de las profesoras, comunica el aumento del capital cultural; y el 
arquetipo indumentario de las mujeres de las cooperativas, comunica el incremento del capital económico.

Asimismo, la interfaz de los arquetipos vestimentarios de las profesoras y las mujeres de las cooperativas comunica, en términos de mis informantes, la elegancia de la mujer indígena. Con ello se refieren las chibuleo a los cánones estéticos consensuados por ellas con respecto a valoraciones estéticas positivas. Esta interfaz se materializa en las siluetas vestimentarias insinuantes de las mujeres que portan calzado de tacón medio y alto — no indígenas-, como prótesis que extiende las dimensiones del cuerpo de las mujeres en sentido vertical, y presentan una imagen distinguida y actualizada (Saltzman, 2004).

Desde otro ángulo, las siluetas que definen el contorno de la indumentaria chibuleo, pueden ser analizadas en tanto prótesis ampliativas (Broncano, 2009). En efecto, a partir de la silueta volumétrica de las mamas se crean otras siluetas insinuantes que conforman los arquetipos de las profesoras y las mujeres de las cooperativas, en función del contexto en el que se desenvuelven. Las siluetas volumétricas e insinuantes, amplían o extienden las capacidades materiales y culturales del cuerpo, por lo que la vestimenta chibuleo, en un sentido específico, es una "prótesis cultural materializada" (Fernández, 2016, p. 10) del artefacto del Diseño que se manifiesta en los distintos arquetipos.

Por una parte, la silueta volumétrica en el arquetipo de las mamas, que amplía el cuerpo en sentido horizontal y se observa desde los levantamientos de 1990, se preserva hasta el período en que finaliza el trabajo etnográfico. Sin embargo, el volumen ha disminuido en concomitancia con el número de anacos y rebozos portados por las mamas. En este caso, la indumentaria chibuleo del arquetipo de las mamas, ha constituido y continúa siendo una prótesis material, en tanto la vestimenta amplía las capacidades de la mujer para soportar la carga en la labor de campo y el cuidado de animales.

Esta función práctica también se mostró importante para transportar a los niños hacia las ciudades durante el período de los levantamientos indígenas. Por un lado, los anacos sujetos con varios chumbis dan firmeza y fuerza en la cadera; y por el otro, los rebozos amplios - que sobrepasan el alto de cadera - permiten envolver los productos del campo para transportarlos y, como se mencionó, también a los niños.

Como prótesis cultural, en esta vestimenta se entreteje la vida cotidiana de las mujeres dedicadas al campo, los animales y el hogar en todo el período de estudio: desde sus memorias de participación en los levantamientos de la década de 1990, en los que su cuerpo vestido con silueta volumétrica ocupó el espacio público de la zona urbana para exigir respeto, hasta el presente. En este sentido, la silueta de las mamas es la prótesis cultural materializada de la lucha por la reivindicación por los derechos indígenas.

Por otro lado, la indumentaria chibuleo de los arquetipos de las profesoras y las mujeres de las cooperativas de silueta insinuante, es una prótesis material que lejos de potenciar una actividad física, potencia el movimiento del cuerpo en el marco urbano y administrativo al permitir mayor movilidad y comodidad. En otras palabras, se relaciona con el fortalecimiento de otro tipo de trabajo, más ligado con lo intelectual de las mujeres en las instituciones. La extensión longitudinal del anaco hasta los tobillos, la disminución del largo de la bayeta y la lishta, que deja entrever el chumbi que marca la cintura, las blusas ceñidas al cuerpo y el uso de tacón, extienden la dimensión del cuerpo en sentido vertical, 
y dan la apariencia de un cuerpo más delgado y alto. Es decir, una silueta vinculada con la imagen de la mujer que desarrolla un trabajo intelectual — proyectado en las instituciones no indígenas-, antes que la imagen de la mujer indígena vinculada con el trabajo físico en el campo. Como prótesis cultural, en la indumentaria de las profesoras y las mujeres de las cooperativas se teje la trama tanto de su participación en la educación bilingüe y superior, como en la formación de financieras indígenas.

Con lo expuesto en los párrafos anteriores, puedo señalar que la indumentaria chibuleo es una prótesis cultural materializada, que da cuenta tanto de las extensiones físicas - carga- como intelectuales, en los procesos de modificación del cuerpo a través de la vestimenta. Como también puede leerse en esta indumentaria, la trama cultural que se entreteje en las construcciones identitarias chibuleo y en los procesos interétnicos. Habida cuenta de lo sostenido hasta aquí, puedo afirmar que la indumentaria de la mujer chibuleo, sus transformaciones y continuidades, dan cuenta de la dinámica interétnica y de las distintas significaciones que ha adquirido la identidad de este pueblo en su devenir histórico, social y político. Estas significaciones se materializan en los arquetipos vestimentarios indígenas identificados en la presente investigación. En este sentido, el diseño del artefacto vestimentario en los arquetipos de la mujer chibuleo, se posiciona como un diacrítico de la resignificación dialéctica indumentaria-identidad.

\section{Conclusiones}

En esta tesis abordé los usos y transformaciones de la indumentaria de la mujer chibuleo entre 1990 y 2016. A partir del análisis de las transformaciones de la indumentaria acaecidas en este proceso, identifiqué y analicé tres tipologías vestimentarias. A su vez y como parte del análisis, relacioné dichas tipologías con tres momentos histórico-sociales y políticos. Estos hitos fueron los levantamientos indígenas de 1990, con el consecuente reconocimiento constitucional de los derechos de la etnia, y luego la creación de instituciones educativas bilingües, en específico la Unidad Educativa del Milenio Chibuleo, y las cooperativas de ahorro y crédito.

Del estudio de la indumentaria en relación con estos procesos, se puso en relevancia la utilización y conceptualización de la vestimenta, como diacrítico marcador de la identidad chibuleo en relación con otros grupos y al interior del mismo. Lo antedicho se delineó claramente con respecto al primer hito histórico identificado, los levantamientos indígenas de 1990. En este contexto, el portar lo que a la luz del análisis devino en la categoría nativa "vestimenta propia", constituía un símbolo de pertenencia chibuleo en el marco de la lucha por el reconocimiento de derechos específicos.

Asimismo, este uso de la vestimenta propia, cuyas características han sido estudiadas exhaustivamente en el desarrollo de la tesis, se correspondió con un grupo específico de mujeres chibuleo, las mamas. Estas mujeres, que rondan los 70 y 80 años de edad, principalmente dedicadas a actividades agrícolas y residentes de la zona rural, portan este tipo de vestimenta, transmitiendo la importancia de su uso a las nuevas generaciones, en términos de "la lucha por el respeto" que protagonizaron durante los levantamientos, y como un 
símbolo del orgullo étnico identitario. También porta este arquetipo un subgrupo dentro de las mamas, más jóvenes - entre 45 y 55 años- que no sólo trabajan en el campo sino que desempeñan actividades de liderazgo político dentro de sus comunidades.

La vestimenta, en tanto artefacto y ocasión de uso, también tuvo otro cambio importante a partir del reconocimiento de derechos a nivel constitucional. A partir de allí, se crearon instituciones específicas, tales como las UEM, que son escuelas bilingües, y las cooperativas de ahorro y crédito. De la mano de estas instituciones, surgen otras dos tipologías vestimentarias, que en términos nativos son la "vestimenta de la cultura", para las unidades educativas; y el "uniforme propio" en el caso de las cooperativas. En ambas instituciones se encuentra normado el acudir a trabajar con indumentaria que responda a la procedencia étnica.

La vestimenta de la cultura, es utilizada principalmente por un grupo específico de mujeres, que son las profesoras, de una edad estimada entre los 30 y 50 años. Tal como se desarrolló, está tipología tiene continuidades y diferencias con respecto a las otras dos tipologías identificadas. Cabe aclarar que en el caso de la UEM Chibuleo no se especifica en documentos las prendas y accesorios a portar por las profesoras; antes bien, estos usos responden a un consenso entre las mujeres de este grupo con taytas, mamas chibuleo y las autoridades de la institución.

Por último, las mujeres de las cooperativas, responde al capital económico acumulado por los chibuleo desde los '70, con sus actividades de diversificación económica, capital que reinvierten en este tipo de instituciones financieras a partir de la década de los 90. El grupo de mujeres denominadas en esta tesis como "las de las cooperativas", trabajan en las instituciones financieras, tienen entre 20 y 40 años de edad, y portan la tercera tipología identificada que es el "uniforme propio".

Este uniforme propio responde a una normativa que especifica las prendas y accesorios que deben ser portados para cada día de la semana. Adicionalmente a esta indumentaria, este grupo de mujeres adopta sacos, chompas y chalecos con identificativos institucionales, que en rigor están normados para el uniforme de los no indígenas que trabajan en este tipo de instituciones.

En definitiva, este proceso histórico, cuyo hilo conductor fue el respeto adquirido por los chibuleo en la lucha y reivindicación de los derechos de su etnia, en el presente está íntimamente relacionado con el uso y transformaciones vestimentarias de los grupos de las mujeres identificadas como las mamas, las profesoras y las mujeres de las cooperativas. Indagar etnográficamente estos usos y transformaciones echó luz acerca de dos cuestiones. Por un lado, reveló que los chibuleo hacen uso de la vestimenta como un diacrítico, tanto en la esfera privada como pública. Así lo evidencié, tanto en el caso de las mamas que portan vestimenta propia y se dedican al trabajo en el campo y en un menor número al liderazgo político, cuyo uso indumentario se fortaleció desde 1990 hasta la actualidad. Como, en los grupos de las profesoras que usan vestimenta de la cultura, y las mujeres de las cooperativas que portan uniforme propio, desempeñándose en las instituciones educativas y financieras respectivamente, cuyos usos indumentarios también constituyen un diacrítico identitario, tanto al interior de la etnia como con respecto a otros grupos.

Por otro lado, este abordaje etnográfico puso de manifiesto las transformaciones vestimentarias de Diseño ocurridas en los grupos de mujeres identificados, como una materialización de las transformaciones sociales y políticas de la etnia. Asimismo, evidenció la 
interrelación indisociable de las funciones comunicativas — estética y simbólica-, con las funciones de utilidad o prácticas en las transformaciones indumentarias. Modificaciones que ocurren en el devenir histórico de los chibuleo, que establecen vínculos vestimentarios interétnicos y dan respuesta a los nuevos contextos de uso normados de la vestimenta en las instituciones.

Las transformaciones de la vestimenta pueden resumirse en la combinación de prendas indígenas como el anaco, el chumbi, la lishta, el rebozo - mamas -, la bayeta — profesoras y mujeres de las cooperativas- y accesorios, como sombrero, tupu, wallkas y orejeras, con prendas y accesorios no indígenas. Entre estas últimas están la camisa, sacos, buzos, medias tejidas en lana o acrílico y calzado tipo mocasín o botas, adoptados por el grupo de las mamas; blusa, chompa, saco, medias de nailon y zapatos de tipo salón con tacón medio o alto, adoptados tanto por el grupo de las profesoras como por el de las cooperativas. Además de chalecos adoptados sólo por el último grupo.

También identifiqué el cambio o reemplazo del tupulli por la camisa de manga corta, escote lágrima y silueta rectangular en el grupo de las mamas; y la transformación de la camisa en blusa de silueta insinuante y su diversidad tipológica en escotes y mangas en los otros dos grupos. Asimismo, el cambio de material de lino en las camisas, a una variedad de materiales como randa, charme y seda en las blusas. Observé también, en los grupos de las profesoras y las mujeres de las cooperativas, el reemplazo intermitente de la bayeta por el saco, y del tupu por el prendedor.

Se reconstruyó, además, el proceso de adaptación, como una transformación que da cuenta, por un lado, de la reducción del número de prendas del mismo tipo, como anacos, chumbis y rebozos - en la indumentaria de las mamas-, al uso de una prenda de cada tipo - en el caso de la vestimenta de las mujeres que trabajan en las instituciones-.

También se identificaron la modificación en las dimensiones verticales de las prendas, reducción en el caso de la bayeta y la lishta, y aumento en el caso del anaco. Así como se transformó la forma de los bordados en las blusas, que geometrizan los elementos de la naturaleza como flores y hojas, o bien incluyen directamente figuras geométricas. Ambas adaptaciones ocurren en los atuendos de las profesoras y las de las cooperativas, con respecto al atuendo de las mamas.

Respecto a la readopción de prendas y accesorios, se observa en el caso de la lishta en los tres grupos de mujeres identificados; el sombrero y el tupu en el caso de las mujeres que trabajan en las instituciones, cuyos usos en días específicos de la semana dependen de la normativa de estos lugares.

La alteración de usos, se consignó en los tipos de colocación de la bayeta y la lishta por las mujeres de las instituciones. El cambio consistió en pasar de cubrir la espalda y prenderse con el tupu en el centro del pecho - dando la apariencia de simetría-, a ponerse las prendas por debajo de un brazo y sujetarse con el tupu sobre un hombro en forma asimétrica. El traslado o subversión de la ocasión de uso, se evidencia en el pasaje de la utilización de varios anacos hasta la rodilla con chumbis que se envuelven y ajustan en la cintura y cadera - para cargar durante la labor en el campo-; a un anaco hasta los tobillos con un chumbi que rodea y ciñe la cintura para definir la figura de las mujeres en las instituciones. La interrelación de las transformaciones vestimentarias mencionadas, reveló el cambio de silueta que se dibuja sobre los cuerpos de las mujeres. El pasaje fue, de una silueta volumé- 
trica en la vestimenta propia de las mamas, definida particularmente por el aumento de la dimensión del cuerpo de estas mujeres en sentido horizontal - a través del uso de varias prendas del mismo tipo como anacos, chumbis y rebozos-, a una silueta insinuante. Esta silueta es identificada, tanto en la vestimenta de la cultura de las profesoras, como en el uniforme propio del grupo de las mujeres de las cooperativas, debido a que el conjunto de prendas portadas - una de cada tipo- delinean los cuerpos de estas mujeres, y aumentan su dimensión en sentido vertical, tanto por la extensión del largo del anaco hasta los tobillos como por el uso de zapatos de tacón.

Las mamas, las profesoras y las mujeres de las cooperativas, junto con las siluetas que se dibujan sobre sus cuerpos, y las tipologías de prendas y accesorios utilizados con características particulares para cada grupo, son modelos a seguir por otras mujeres del pueblo. En este sentido, la vestimenta propia, la vestimenta de la cultura y el uniforme propio, con sus significados, se convierten en arquetipos indumentarios, que representan la lucha por el reconocimiento de los derechos de la etnia, en el caso del primer tipo de vestimenta; y los derechos conseguidos y reivindicados diariamente en los otros dos tipos.

Los usos y transformaciones de la vestimenta propia, la vestimenta de la cultura y el uniforme propio, portada por los tres grupos de mujeres chibuleo identificados, dan cuenta de la relación dialéctica indumentaria-identidad, y de la indumentaria como artefacto del diseño. Este artefacto, que es la vestimenta usada por las mamas, las profesoras y las mujeres de las cooperativas, se constituye en el diacrítico de la identidad chibuleo, en constante proceso de resignificación. Las transformaciones apuntan, por un lado, a las modificaciones de la silueta de las mujeres y a la ampliación de las capacidades físicas de sus cuerpos, en función de los roles que las mujeres desempeñan en el campo y en las instituciones. Por el otro, la vestimenta como objeto comunicativo de la vida cotidiana, se fue transformando para expresar contextualmente una identidad de pertenencia y de diferencia, variable en función del momento histórico y el grupo de mujeres que lo porta.

Los resultados de la investigación, constituyen un aporte para cubrir el hiato conceptual entre los estudios de Diseño de Indumentaria, y los que se dedican al análisis de la identidad de grupos étnicos; y están dirigidos a la comunidad científica que desarrolla investigaciones sobre Diseño en específico, además de ser de interés para antropólogos y otros profesionales que estudian al vestido desde las diferentes disciplinas de las ciencias sociales.

Además, esta tesis es una contribución a la escasez de estudios bibliográficos sobre los chibuleo, la indumentaria portada en particular y la vestimenta andina en general. La metodología propuesta, y el cruce disciplinar entre el Diseño y la Antropología, constituye, en consecuencia, un antecedente para desarrollar estudios similares.

Más aún, con la presente investigación saldo, por una parte, el desafío propuesto por Roach y Eicher (1992) respecto a la necesidad de profundizar los estudios que vinculen la teoría del vestido con la comunicación de identidad. En efecto, a través del caso de la indumentaria chibuleo, analicé la construcción de la identidad del pueblo, leída a partir de transformaciones tanto sociales y políticas, como vestimentarias.

Asimismo, analicé las significaciones y resignificaciones comunicadas por la vestimenta como artefacto del Diseño, tomando la consideración de Fernández (2016a) respecto a que las funciones del vestido requieren un estudio "amplio y pormenorizado en el contexto de la teoría del diseño" (2016a, p. 251) y, en tal sentido, analicé los usos y transfor- 
maciones de la indumentaria chibuleo en interrelación con sus funciones, en el devenir histórico, social y político de la etnia.

En síntesis, con esta investigación se ha enfatizado el estudio de la indumentaria indígena como lugar de las construcciones identitarias, que para el caso de las mujeres chibuleo, dio a luz tres arquetipos vestimentarios. Si bien Fernández (2015a, 2016a, 2018) teoriza al vestido como artefacto del diseño, principalmente desde las concepciones de Occidente, a través del estudio de la indumentaria de la mujer chibuleo, doy cuenta que también es posible analizar la indumentaria como artefacto del diseño desde los pueblos indígenas.

La temática abordada, lejos de concluir en esta tesis, abre nuevos interrogantes para futuras investigaciones, que continúen indagando en la indumentaria de los diferentes grupos étnicos desde el Diseño, y su relevancia en relación a los procesos de construcción identitaria de estos pueblos.

\section{Notas:}

1. Fuente: Censo de población y vivienda (2010). Instituto Nacional de Estadística y Censos (INEC). Datos procesados por el INEC y la Comisión Nacional de Estadísticas para los Pueblos Indígenas, Afroecuatoriano y Montubio (CONEPIA), respecto a las preguntas de autoidentificación de nacionalidad y pertenencia a pueblos específicos. No obstante, dejo expuesto que de acuerdo a los datos del CODENPE y las cifras manejadas en medios de comunicación gubernamentales como radio y televisión, la población del pueblo Chibuleo asciende a 12.000 personas. Cifra que también registra los estudios de Stark (1985). García (2013), por su parte, sostiene que el pueblo Chibuleo "cuenta con una población cercana a los 6.000 habitantes" (p. 505).

2. Fuente: Censo de población y vivienda 2010. Instituto Nacional de Estadística y Censos (INEC). La población total de la parroquia rural de Juan Benigno Vela es de 7.456 personas, con una proporción indígena de $64.87 \%$, es decir 4.087 personas.

3. El pueblo Chibuleo que hasta 1965 era una sola comunidad, desde 1985 se divide para formar las comunidades de Chibuleo San Francisco, Chibuleo San Alfonso, Chibuleo San Luis y Chibuleo San Pedro. En 1998, luego de promulgada la Constitución de la República del Ecuador y las políticas de reconstitución de pueblos y nacionalidades, el pueblo chibuleo "decidió constituir una sola gran organización" (García, 2013, p. 506) denominada Unión de Organizaciones del Pueblo de Chibuleo (UNOPUCH), en la que incluyen las comunidades de San Miguel, Chacapungo y Pataló Alto a las cuatro comunidades ya citadas. 4. El cantón Ambato "está conformado en su estructura político-administrativa por parroquias urbanas y rurales" (Gobierno Autónomo Descentralizado Municipalidad de Ambato, 2015, p. 5). Dentro de las 18 parroquias rurales de este cantón se encuentran Juan Benigno Vela, Pilahuín y Santa Rosa. En el transcurso de estas páginas, toda vez que se alude a Ambato, se hace referencia sólo a su zona urbana. 
5. Tungurahua, ubicado en la Sierra central de Ecuador. Limita con las provincias de: Cotopaxi al norte, Chimborazo al sur, al este las provincias de Pastaza y Napo, al sureste con Morona Santiago, y al oeste con las provincias de Cotopaxi y Bolívar. Su altura oscila entre los 1230 a los $4000 \mathrm{msnm}$, en los que se desenvuelve la actividad agrícola provincial (Naranjo, 1992).

La temperatura mínima que se registra en la provincia es de $7^{\circ} \mathrm{C}$ y la máxima de $24^{\circ} \mathrm{C}$, si bien es en las zonas más altas donde se registran las temperaturas inferiores (Naranjo, 1992).

6. Según los estudios de Ospina et al. (2011b), basados en los censos de población del INEC de 1962, 1974, 1982, 1990 y 2001. Desde 1962 hasta 1990, la presencia femenina de la población tungurahuense estuvo siempre por encima del promedio nacional; sin embargo, algunas provincias tuvieron un desempeño parecido. La diferencia de la participación femenina en la población económicamente activa (PEA) de la provincia, respecto al promedio nacional, se acentúa entre 1990 y 2001, lo que no sucede con sus ingresos, que son los más bajos del país respecto al de los varones. Entonces, Tungurahua tiene de manera simultánea, una alta participación femenina, y una alta discriminación de género en los ingresos (Ospina et al., 2011b).

7. Zona poblada en su mayoría por indígenas.

8. La agricultura se ha feminizado en la provincia, en la Sierra y en América Latina. "Los estudios cuantitativos y cualitativos confirman que conforme la agricultura deja de ser rentable, los varones la abandonan dejando a las mujeres a cargo de la finca" (Ospina, 2011, p. 178). Ese es un factor de disminución del ingreso femenino. Las mujeres están ocupadas en tareas agrícolas, que producen menores ingresos que otras actividades alternativas.

9. "En la actualidad los bancos comunales, una experiencia de diversificación económica conducida por mujeres, comienza a ser colonizada por hombres [...]. Según datos procedentes de fuentes oficiales, para el 2008 había 405 hombres activos dentro de los bancos comunales, lo que representa todavía un porcentaje pequeño (8\%) del total de socias" (Carrión, 2011, p. 242).

10. Las unidades educativas del milenio (UEM), se generan por la necesidad de crear instituciones que atiendan los derechos económicos y sociales de los ciudadanos, a partir del objetivo de educación de la Declaración del Milenio de Naciones Unidas (2000).

11. La "vestimenta indígena" es un sinónimo que emplean los chibuleo para referirse a la vestimenta propia.

12. Tránsito Manobanda, una mama chibuleo, presidenta de la UNOPUCH por tres períodos consecutivos, desde 2009 y hasta mediados de 2016.

13. Agustín Punina, dirigente político indígena de la comunidad chibuleo, técnico de la UMICT hasta enero de 2015, y ex-secretario de finanzas de la UNOPUCH. Además, participó como secretario de la CONAIE en el período 2008-2011. Vive en Chibuleo San Pedro y tiene 52 años de edad.

14. Juan José Lligalo es un tayta chibuleo que participó activamente como la voz de los chibuleo durante los levantamientos indígenas de 1990, 1992 y 1994. Profesor bilingüe en la UEM Chibuleo, jubilado en 2015. Vive en la Comunidad de Chibuleo San Francisco. 
15. Alberto Guapizaca, rector de la UEM Chibuleo, y ex subsecretario del Ministerio de Educación.

16. Luis Alfonso Chango, representante chibuleo y gerente general de la Cooperativa de Ahorro y Crédito Mushuc Runa. Nació en Chibuleo parroquia de Juan Benigno Vela. Actualmente vive en la parroquia de Pilahuín —aledaña a Juan Benigno Vela-.

17. Bernardo Tuza, (52 años), representante Kisapincha, dirigente político indígena y ex concejal de Ambato (2002)..

18. Isabel Capúz, de procedencia pilahuín, vivió en Chibuleo la mitad de su vida. Trabaja en el Departamento de Archivo en la Cooperativa de Ahorro y Crédito Mushuc Runa, estudia en la Universidad Técnica de Ambato. Casada con Tupac Caluña, hijo del difunto tayta chibuleo Nazario Caluña.

19. Pilahuín es un pueblo de nacionalidad kichwa —aledaño a Chibuleo-, ubicado en la provincia de Tungurahua. Sin embargo, este pueblo no se encuentra reconocido por el CODENPE (2003).

20. Tupac Caluña es Director del Distrito Educativo 2 de la ciudad de Ambato y coautor del libro titulado: Los chibuleos, escrito junto con su padre, el tayta chibuleo Nazario Caluña. Vive en Chibuleo san Francisco.

21. Martha Lligalo (43 años), hija del tayta Juan José Lligalo y la mama Andrea Pacari. Es docente de la UEM Chibuleo, trabajadora externa de una cooperativa de ahorro y crédito, y ex representante del Movimiento Indígena de Tungurahua (MIT).

22. El anaco también puede ser de color café, blanco (Jaramillo, 1990).

23. La jergueta, según Caluña, Tisalema, y Caluña es "un manto negro natural de lana de borrego, tejido en telares rudimentarias" [sic] (2008, p. 30).

24. A lo largo de estas páginas utilizo la palabra kichwa chumbi por ser la forma en que la mayoría de mis interlocutores chibuleo definen a la faja que ciñe el anaco. Sin embargo, en ocasiones me referiré como chumbe o chumpi, cuando los referentes bibliográficos utilicen este término.

25. Para analizar los usos que se da al chumbi por parte de los hombres - como sostén del pantalón-, se pueden consultar los estudios de Vicuña (2008) respecto a las fajas cañaris. 26. En la presente investigación utilizo el término lishta, en tanto pertenece al vocablo kichwa. Sin embargo, preciso aclarar que en mis investigaciones etnográficas, varios interlocutores se refieren a esta prenda también como lista, por lo que utilizo este último término sólo en dichas ocasiones.

27. Utilizo el termino fachalina en vez de fachallina, por ser un término kichwa y principalmente porque es la forma en que mis interlocutoras se refieren.

28. La adopción de indumentaria no indígena al repertorio indígena ha sido estudiada en otros pueblos como es el caso de los collas de Argentina (Karasik, 2010); los emberá de Panamá (Theodossopoulos, 2012) y los kayapó de Brasil (Turner, 1991).

29. Rowe $(1998,2011)$ se refiere al término blusas para definir a las camisas. Sin embargo, en mis estudios etnográficos, las camisas refieren a la tipología de prendas portadas por las mamas, y las blusas hacen referencia a las camisas modernas portadas por las profesoras y las de las cooperativas. 
30. Utilizo el término kichwa tupu, excepto cuando la bibliografía o mis informantes refieran al término "tupo", para identificar al prendedor de plata que sujeta a la lishta, bayeta o rebozo. 31. Para Wright (1998), la cultura entendida como un proceso dinámico, negociable y en permanente transformación, implica siempre un posicionamiento político.

32. Tránsito Amaguaña fue una líder indígena de Cayambe, que luchó por el acceso a la educación de los indígenas, de manera más amplia.

33. Las mamas chibuleo presentes en los levantamientos de la década de 1990, expresan tener pocos recuerdos al respecto y, luego de indicar que ellas lo han olvidado, me derivan con sus esposos para que sean ellos quienes relaten. Este hecho, implica que los hombres no sólo fueron la voz durante los levantamientos, sino que continúan en este rol. La ausencia de voz de las mamas, debe ser analizada en futuros estudios desde una perspectiva de género. No obstante, la presente investigación se ciñe al campo del diseño, en su cruce con la antropología de los pueblos indígenas, por lo que un estudio de esas características excede los límites de esta tesis.

34. La CONAIE se constituyó en la expresión del movimiento indígena, y organismo de representación política de las organizaciones indígenas a nivel nacional. Agrupó a las organizaciones ya existentes: Confederación de Pueblos de la Nacionalidad Kichwa de Ecuador (ECUARUNARI) que aglutina a las organizaciones de la sierra, y Confederación de Nacionalidades Indígenas de la Amazonía Ecuatoriana (COFENAIE), que aglutina a las organizaciones de la Amazonía; posteriormente se adhirió la Confederación de $\mathrm{Na}$ cionalidades Indígenas de la Costa del Ecuador (CONAICE), que - como su nombre lo indiga-congrega a las organizaciones de la Costa (Benítez y Garcés, 2014).

35. El Convenio 169 de la OIT, ha constituido un instrumento jurídico internacional para la protección de pueblos indígenas y tribales. Propone el reconocimiento y la participación de dichos pueblos — "El respeto a la cultura, idiomas, la religión, la organización social y económica, y a la identidad propia." (Benítez y Garcés, 2014, p. 271) - y garantiza el derecho de los pueblos a decidir sus prioridades, controlar su desarrollo económico, social y cultural según sea posible, y la participación en planes y programas de desarrollo nacional y regional que les afecten.

36. El reconocimiento de los derechos indígenas en Ecuador, es estudiado de manera extensa por autores como Jorge Sánchez Parga (2010) e Ileana Almeida (2008).

37. Antes de 1990, los reclamos por la tierra se habían realizado a través de canales jurídicos institucionales, sin obtener resultados. El Instituto Ecuatoriano de Reforma Agraria y Colonización (IERAC), daba respuestas que demoraban años y finalmente no solucionaban los problemas. Por estas razones "se conformó en la provincia de Chimborazo la Coordinadora de Movimientos de Tierras” (Porras, 2005, p. 221), que integró setenta y tres conflictos, provenientes de las provincias de Chimborazo, Bolívar, Cotopaxi e Imbabura, que se transformaron en una reivindicación concreta en el levantamiento de 1990.

38. Durante este levantamiento, los indígenas demandaban también el "reconocimiento de la medicina tradicional" (Almeida, y otros, 1992, p. 26), y reformas a leyes secundarias y exenciones tributarias para las organizaciones y comunidades indígenas (Porras, 2005). 
39. La apropiación de una serie de haciendas en conflicto desde 1988, había servido de ensayo al movimiento indígena para organizarse y planificar adecuadamente la toma de la plaza de Santo Domingo.

40. El diálogo se constituyó en el segundo acto del levantamiento, lo que evitó que terminaran siendo reprimidos (Guerrero, 1995, 125).

41. En esta instancia, es preciso indicar que, si bien se mencionan los levantamientos en estas tres fechas, obtuve más datos etnográficos del levantamiento de 1990, mientras que de los otros dos levantamientos mis informantes hacen escasas descripciones. No obstante, mis interlocutores concuerdan en que durante estos eventos portaron su vestimenta propia mientras demandaban respeto en el marco de lucha por la equidad étnica.

42. El protagonismo de la vestimenta de pueblos indígenas, en las normas supremas de Ecuador y Bolivia, no se replica en los otros dos países miembros de la Comunidad Andina (CAN), Colombia y Perú. Sin embargo, la Constitución Política de Colombia de 1991 que se encuentra vigente - con sus últimas actualizaciones de 2006-, nombra en reiteradas ocasiones a los pueblos indígenas para referirse principalmente a sus territorios. Mientras la Constitución Política de Perú de 1993 vigente, menciona a los "pueblos originarios" en un solo artículo $-\mathrm{N}^{\circ} 192$ - para indicar que se requieren porcentajes mínimos para acceder a una representación.

43. "El uniforme es una expresión de autoridad y ayuda al que lo viste a destacarse entre una multitud" (Jones, 2005, p. 27).

44. Nina Pacari es un ejemplo de ello: fue nombrada Ministra de Relaciones Exteriores en 2002, convirtiéndose en la "primera lideresa indígena al frente de la diplomacia ecuatoriana, así como la primera canciller indígena de Sudamérica" (Pequeño, 2007, p. 103).

45. Dolores Cacuango, líder indígena y militante de la Federación Ecuatoriana de Indios (FEI). Originaria de Cayambe, Ecuador (González, 2011).

46. Esta propuesta se desarrolla a partir de uno de los logros del 2007, del Plan Decenal de Educación 2006-2015 - ya concluido-, cuando se menciona al proyecto piloto de uniformes escolares en el marco de la eliminación de barreras de acceso a la educación. Proyecto que constituye una ampliación, que el ex presidente de la República del Ecuador, Rafael Correa (2007-2017), le realiza al Plan Decenal de Educación 2006-2015 — principal instrumento de la política pública en materia educativa-; pero que en ningún ítem incluía a la vestimenta con pertinencia cultural.

47. Los términos "uniforme con pertinencia cultural" y "vestimenta con pertinencia cultural", son categorías expresadas en las políticas educativas del Estado.

48. "Con el fin de contar con infraestructura adecuada culturalmente, equipamiento, alimentación, vestimenta con pertinencia cultural, incluyendo bibliotecas, tecnologías de la información y comunicación (TIC), huertos educativos y laboratorios, con el fin de incrementar la calidad educativa intercultural bilingüe" (Propuesta Plan Decenal de Educación 2016-2025, pp. 129-130).

49. La cooperativa de ahorro y crédito Mushuc Runa se conforma en 1997, con treinta y ocho jóvenes indígenas. En un principio, este grupo buscó estructurar un programa de capacitación, dado que no pudieron acceder al crédito por ser catalogados como sujetos de 
riesgo. En otras palabras eran considerados capaces para las tareas del campo pero no para las finanzas. De allí que decidieran fundar una cooperativa cuyo crecimiento continuo los ha llevado a manejar "75.000 socios y US\$ 37 millones en activos" (López , 2007, p. 78).

50. Para Saltzman (2004), "la silueta es la forma que surge al trazar el contorno de un cuerpo. En el campo de la indumentaria, atañe a la conformación espacial de la vestimenta según el modo en que enmarca la anatomía, define sus límites y la califica” (p.69).

51. Además de los chibuleo, dentro de la provincia de Tungurahua, los pueblos de nacionalidad kichwa son los salasaka, tomabela y kisapincha.

52. Con la esposa del tercer líder chibuleo no fue posible acceder a realizar entrevistas, debido a problemas de salud.

53. Los identificativos institucionales hacen referencia a la identidad corporativa (Costa, 2009) de las cooperativas de ahorro y crédito.

54. La semana laboral de los tres grupos de mujeres estudiadas difieren: las mamas trabajan de domingo a domingo en el campo; las profesoras acuden a la UEM de lunes a viernes, y las de las cooperativas trabajan de lunes a viernes, aunque puede extenderse un día más (sábado o domingo).

55. Preciso aclarar en este punto, que no es intención de la presente investigación, analizar los intercambios y adopciones vestimentarias intraculturales, por lo cual dejó abierta la posibilidad de este estudio en un futuro.

56. Las tipologías de sistemas de oclusión utilizadas por las mujeres chibuleo tanto para el chumbi como para el anaco, constituyen temas de interés cuyo estudio debería ampliarse en futuras investigaciones, involucrando además del Diseño y la Antropología, a la disciplina de la Ergonomía.

57. En el capítulo 1 analizo la coincidencia entre los términos lishta y fachalina. Aclaro que utilizo el vocablo lishta tal y como mis interlocutores se refieren a esta prenda, y también recurro al término fachalina cuando la bibliografía así lo dispone.

58. Los términos camisa moderna o blusa son utilizados por mis interlocutores como similares, dependiendo de la categoría de prenda que mencione. Camisa moderna es referida, por taytas, mamas y dirigentes chibuleo; mientras que blusa, es el término utilizado por las profesoras y las mujeres de las cooperativas.

59. Los intercambios vestimentarios intraétnicos, podrían ser analizados de manera más profunda en futuras investigaciones.

60. En el capítulo 1 explico el uso y reemplazo del tupulli y la camisa.

61. La camisa a la que se refiere Tupac Caluña tiene las mismas características morfológicas que mencionan Jaramillo (1990) y Rowe $(1988,2011)$ : de color blanco, cuello redondo y aberturas en el delantero - frente- y posterior del cuello. Esta camisa se describe más detalladamente en el capítulo 1.

62. En la entrevista con Tupac Caluña, estuvo presente su esposa Isabel Capúz de 36 años, quien complementó los datos expuestos por su esposo.

63. Tanto en la entrevista con Agustín Punina, como en la mantenida con Tupac Caluña, si bien ellos son la voz principal, se acompañan del criterio de sus esposas e hijas, para corroborar la información proporcionada. 
64. Este artículo se especifica en el capítulo 1 de la presente investigación.

65. El corpiño o básico de cuerpo: "se ajusta al torso y no incluye mangas ni cuello" (Chunman Lo, 2011, p. 44).

66. Las mujeres chibuleo, como "diseñadores difusos" (Manzini, 2015, p. 47) dentro de un proceso de cocreación (Fernández, 2015); como diseñadoras y usuarias, puede ser objeto de futuras investigaciones.

67. La indumentaria chibuleo portada por no chibuleos, constituye una propuesta para investigaciones futuras.

68. La copia de la vestimenta chibuleo - como mis informantes se refieren-, por otros pueblos de Ambato en la provincia de Tungurahua, puede ser también motivo de otra investigación.

69. El poncho, como elemento vestimentario de reconocimiento chibuleo, al ser una prenda utilizada por hombres, excede los límites de la presente investigación.

70. Tupac Caluña menciona que el tupu "es para sostener la bayeta" (Entrevista con T. Caluña, Chibuleo San Francisco, enero 2016); la mama Juana Pandashina, indica que el tupu se utiliza para sujetar los rebozos y la lishta (Entrevista con J. Pandashina, Chibuleo San Francisco, diciembre 2016). Otra de mis interlocutoras menciona que "el tupo [es] para coger a la bayeta” (Entrevista con M. Lligalo, Chibuleo San Francisco, Noviembre 2016).

71. Tupac Caluña explica que esta riqueza diferencial, provenía de mujeres cuyas familias tenían más hectáreas y, por ende, más animales, lo que les permitía adquirir estos accesorios (Entrevista con T. Caluña, Chibuleo San Francisco, enero 2016).

72. Las wallkas y orejeras de plástico, eran portados por "peones [que] se vestían al alcance nomás, al alcance de la economía” (Entrevista con T. Caluña, Chibuleo San Francisco, enero 2016).

73. La cocreación es asumida entre diseñadores y usuarios (Fernández, 2015b; Manzini, 2015). En el caso particular de los chibuleo, son ellos sus propios diseñadores, pero inexpertos. Según Manzini, "todo el mundo tiene la capacidad de diseñar [...], el diseño difuso es puesto en marcha por 'inexpertos', que hacen uso de su capacidad natural para el diseño" (Manzini, 2015, p.47). A la vez son usuarios, porque las mujeres, en la experiencia de uso de la vestimenta, resignifican la indumentaria tanto a nivel morfológico - función práctica y estética一, como de significación del artefacto vestimentario — función simbólica-.

74. Fernández (2016b) define al momento de la acción o momento de uso, como el cuarto ámbito para entender a la interfaz en el artefacto vestimentario desde el Diseño, además del cuerpo, el objeto - indumentaria- y el contexto.

\section{Lista de Referencias Bibliográficas}

Abram, M. (2004). Estado del arte de la educación bilingüe intercultural en América Latina. Washington DC: BID.

Abramoff, E. (2001). Etnocidio. Genocidio. Identidad de los Pueblos Indígenas. En Garreta, M. J.; Bellelli, C.; Bonaparte, P.; Abramoff, E.; Acosta, A.; Cañas, L.; Scheinsohn, V. La trama cultural. Textos de antropología y arqueología (2da. ed., pp. 155-163). Buenos Aires: Caligraf. 
Acuerdo Ministerial №321, para el año lectivo 2002-2003, de transformación del Plantel Central de la Red en la Unidad Educativa Intercultural Bilingüe Chibuleo.

Acuerdo del Ministerio de Bienestar Social Nº 1820 del 17 de Diciembre de 1997, sobre creación de la Cooperativa de ahorro y crédito Mushuc Runa.

Acuerdo Ministerial Nº 6582 del 23 de enero del 2003, sobre creación de la Cooperativa de ahorro y crédito Kullki Wasi.

Almeida, I.; Almeida, J.; Bustamante, S.; Espinosa, S. H; Frank, E.; Ibarra, H.; Rutz, L. (1992). INDIOS. Una reflexión sobre el levantamiento indígena de 1990 (2 ed.). Quito: Agya-Yala.

Almeida, I. (2008). El estado plurinacional. Valor histórico y libertad política para los indígenas ecuatorianos. Quito: Abya Yala.

Almeida, I., Arrobo, N. y Ojeda, L. (2005). Autonomía Indígena frente al Estado nación y a la globalización neoliberal. Quito: Abya Yala.

Anawalt, P. (2008). Historia del vestido. Barcelona: Blume.

Avenburg, K. y Matarrese, M. (2019). Introducción: Cruces entre Cultura y Diseño: repensando el diseño de los procesos culturales y los abordajes culturales del diseño. Cuaderno 71. Cuadernos del Centro de Estudios en Diseño y Comunicación, Facultad de Diseño y Comunicación, Universidad de Palermo, ISSN 1668-0227. Disponible en: https://fido. palermo.edu/servicios_dyc/publicacionesdc/archivos/694_libro.pdf

Ayala, E. (2012). Resumen de historia del Ecuador. Quito: Universidad Andina Simón Bolívar/Corporación Editora Nacional.

Barth, F. (1976). Los grupos étnicos y sus fronteras. La organización social de las diferencias culturales. México: Fondo de cultura económica.

Barthes, R. (2008). El sistema de la moda y otros escritos. Buenos Aires: Paidós.

Beckett, J. (1988). Past and present: the construction of Aboriginality. Canberra: Aboriginal Studies Press.

Benítez, L. y Garcés, A. (2014). Culturas ecuatorianas ayer y hoy (2 ed.). Quito: Abya-Yala. Bonfil Batalla, G. (1991). La teoría del control cultural en el estudio de procesos étnicos. Estudios sobre las Culturas Contemporáneas, 4(12), 165-204.

Bonsiepe, G. (1998). Del objeto a la interfase: mutaciones del diseño. Buenos Aires: Infinito. Bourdieu, P. (2001). Poder, derecho y clases sociales (2da. ed.). Bilbao: Desclée de Brouwer. Bourdieu, P. (2012). La distinción: criterio y bases sociales del gusto . Buenos Aires: Taurus .

Bourgois, P. (2010). En busca del respeto: vendiendo crack en Harlem. Buenos Aires: Siglo Veintiuno Editores.

Briones, C. (2005). Cartografías argentinas: políticas indigenistas y formaciones provinciales de alteridad. Buenos Aires: Antropofagia.

Briones, C. (1998). La alteridad del "cuarto mundo". Una deconstrucción antropológica de la diferencia. Buenos Aires: Ediciones del Sol.

Broncano, F. (2009). La melancolía del ciborg. Barcelona: Herder.

Buitrón, A. (1964). El vestido de la región Inca-Nayón-Calderón. En De Caravalho, P. Antología del Folklore Ecuatoriano (1653-1963) (pp. 160-167). Quito: Editorial Universitaria.

Caluña, N., Tisalema, M., y Caluña, T. (2008). Los chibuleos: origen, identidad, desarrollo y justicia de un pueblo indígena en los andes ecuatorianos. Quito: Artes gráficas Silva.

Camelo, D. (1994). Objetos textiles guambianos. Quito: IADAP. 
Carretero, P.; Calero, J.; Miranda, S.; y Malo, M. (2016). Estudios para la recuperación de la vestimenta tradicional en la comunidad Tolte, parroquia Pistishí (Alausí, Chimborazo, Ecuador). ASRI: Arte y sociedad. Revista de investigación(10). Disponible en: https:// dialnet.unirioja.es/servlet/articulo? codigo $=5410556$

Carrión, D. (2011). Colonialismo y capitalismo en Tungurahua: los antecedentes de la desigualdad. En Ospina, P. (coord.), El territorio de senderos que se bifurcan: Tungurahua, economía, sociedad y desarrollo (Vol. 68, pp. 209-243). Quito: Corporación Editora Nacional - UASB-E.

Chunman Lo, D. (2011). Patronaje. Barcelona: Blume.

Consejo de Desarrollo de las Nacionalidades y Pueblos del Ecuador (CODENPE). (2003). Disponible en: www.codenpe.gov.ec

Constitución Política de Colombia (1991). Disponible en: http://es.presidencia.gov.co/ normativa/constitucion-politica

Constitución Política de Perú (1993). Disponible en: http://www.pcm.gob.pe/wp-content/ uploads/2013/09/Constitucion-Pol\%C3\%ADtica-del-Peru-1993.pdf

Constitución de la República del Ecuador (1998). Disponible en: https://es.wikisource. org/wiki/Constituci\%C3\%B3n_de_Ecuador_de_1998/T\%C3\%8DTULO_I:_Los_Principios_Fundamentales

Constitución de la República del Ecuador (2008). Disponible en: https://www.acnur.org/ fileadmin/Documentos/BDL/2008/6716.pdf

Costa, J. (2009). La imagen corporativa en el siglo XXI (3 ed.). Buenos Aires: La Crujía.

Cruz, A. (2010). Pueblos originarios en América: guía introductoria de su situación. Pamplona: Aldea.

Deler, J. P. (1983). Estructuración y consolidación del área central (1830-1942). En Deler, J., Gómez, N. y Portais, M. El manejo del espacio en el Ecuador. Quito: Centro Ecuatoriano de Investigaciones Geográficas.

Douglas, M. (1978). Símbolos naturales: exploraciones en cosmología. Madrid: Alianza editorial.

Eicher, J. (2000). The anthropology of dress. The Journal of the Costume Society of America, 27(1), 59-70.

Eicher, J., y Roach, M. (1992). Definition and Classification of Dress. Implications for Analysis of Gender Roles. En J. Eicher, y R. Barnes, Dress and Gender: Making and Meaning in Cultural Contexts. (pp. 8-28). Berg Publishers.

Entwistle, J. (2002). El cuerpo y la moda. Una visión sociológica. . Barcelona : Paidós.

Femenías, M. L. (2013). El género del multiculturalismo. Bernal: Universidad Nacional de Quilmes.

Fernández, C. (2015a). La profundidad de la apariencia. Contribuciones a una teoría del diseño de vestuario. Medellín: UPB.

Fernández, C. (2015b). El vestido dentro del pensamiento del diseño ¿requiere un estudio diferenciado? Iconofacto, 11(17), 82-98. Fernández Silva, C. (2016). El vestido dentro del pensamiento del diseño. Disponible en: http://dx.doi.org/10.18566/iconofac.v11n17.a05

Fernández, C. (2016a). El vestido como artefacto del diseño. Contribuciones para su estudio y reflexión al interior del pensamiento de diseño (Tesis doctoral inédita). Manizales: Universidad de Caldas. 
Fernández, C. (2016b). El cuerpo-vestido en la filosofía ciborg y el esquema de la interfaz: hacia un conocimiento de la experiencia de uso del vestido. Pensamiento palabra y obra(16), 6-13.

Fernández, C. (2018). El vestido como artefacto del diseño: Contribuciones para un estudio y reflexión al interior del pensamiento del diseño. Encuentros, 16(2), 79-91.

Foucault, M. (2015). Vigilar y castigar: Nacimiento de la prisión (2da. ed.). Buenos Aires: Siglo Veintiuno editores.

García, H. (2016). La observación participante como una aproximación al diseño popular en el espacio público. En C. Rojas, y É. Saavedra, Reflexiones en torno a la metodología del diseño (comps.) (pp. 215-232). Tunja: Editorial UPTC.

Geertz, C. (2006). La interpretación de las culturas. Barcelona: Gedisa.

Gobierno Autónomo Descentralizado Municipalidad de Ambato. (2015). Actualización del plan de desarrollo y ordenamiento territorial. Disponible en: https://www.ambato.gob.ec/ wp-content/uploads/2016/09/PDOT-Ambato-07-06-2016.pdf

Gobierno Autónomo Desentralizado Parroquial Juan Benigno Vela. (2015). Actualización del plan de desarrollo y ordenamiento territorial parroquia de Juan Benigno Vela. Cantón Ambato- Provincia de Tungurahua 20015-2019. Disponible en: http://app.sni.gob.ec/ sni-link/sni/PORTAL_SNI/data_sigad_plus/sigadplusdocumentofinal/1865016590001_ PDOT_2015_JB_Vela_30-10-2015_18-57-17.pdf

Gómez, M. (2016). Guerreras y tímidas doncellas del Pilcotomayo: las mujeres tobas (qom) del oeste de Formosa. Ciudad Autónoma de Buenos Aires: Biblos.

González, M. (2011). Movimiento indígena y educación intercultural. México DF : CLACSO.

Grossberg, L. (1992). We gotta get out of this place. Popular conservatism and postmodern culture. New York: Routledge.

Guber, R. (2012). La etnografía: Método, campo y reflexividad. Buenos Aires: Siglo Veintiuno Editores.

Guber, R. (2013). La articulación etnografíca. Descubrimiento y trabajo de campo en la investigación de Esther Hermitte. Buenos Aires: Biblos.

Guerrero, F. (1990). Economía y estructura de poder en las comunidades campesinas. El caso de los Chibuleo. En Sánchez, J., (comp.). Etnia, poder y diferencia en los andes septentrionales. Cayambe: Abya Yala, 113-174.

Guerrero, F., y Ospina, P. (2005). El poder de la comunidad. Ajuste estructural y movimiento indígena en los Andes ecuatorianos. Buenos Aires: CLACSO.

Hansen, K. (2004). The world in dress: Anthropological perspectives on clothing, fashion, and culture. Annual Review Anthropology, 33, 369-392.

Hernández Sampieri, R., Fernández Collado, C., y Baptista Lucio , P. (2014). Metodología de la investigación (6ta. ed.). México D.F.: Mc Graw Hill Education.

Ibarra, H. (1987). Tierra, mercado y capital comercial en la sierra central: el caso de Tungurahua 1850-1930. Tesis de maestría. Quito: FLACSO.

Instituto de Desarrollo Económico y Social (IDES). (2011). De las notas de campo a la teoría. Descubrimiento y redefinición de nagual en los registros chiapanecos de Esther Hermitte. Alteridades, 11(21), 65-79. 
Instituto Nacional de Estadística y Censos (INEC). (2010). Censo de población y vivienda 2010. La población total de la parroquia rural de Juan Benigno Vela. Disponible en: https:// www.ecuadorencifras.gob.ec/base-de-datos-censo-de-poblacion-y-vivienda-2010-anivel-de-manzana/

Iturralde, D. (2000). Lucha indígena y reforma neoliberal: el movimiento indígena como actor político. Íconos-Revista de Ciencias Sociales(9), 22-30.

Iturralde, D, (1997). Demandas indígenas y reforma legal: retos y paradojas. Alteridades, 7 (14), 81-98.

Jackson, J. (1995). Culture, genuine and spurious: the politics of Indianness in the Del Vaupés, Colombia. American Ethnologist. The journal of the American Ethnological Society, 22(1), 3-27.

Jaramillo, A. (2010). Universos de vestuario. Medellín: inexmoda.

Jaramillo, H. (1990). Indumentaria indígena de Otavalo. Sarance(14), 127-141.

Jones, S. J. (2005). Diseño de moda. Barcelona: Blume.

Juez, F. M. (2002). Contribuciones para una antropología del diseño. México DF: Gedisa.

Karasik, G. (2010). Subalternidad y ancestralidad colla: transformaciones emblemáticas y nuevas articulaciones de lo indígena en Jujuy. En G. Gordillo, y S. Hirsch (comps.), Movilizaciones indígenas e identidades en disputa en la Argentina (pp. 259-282). Buenos Aires: La Crujía.

Krippendorff, K. (2006). The semantic Turn, a New Foundation for Design. Boca Ratón: Taylor y Francis.

Leborg, C. (2013). Gramática Visual. Barcelona: Gustavo Gili.

Lipovetsky, G. (2013). El imperio de lo efímero. La moda y su destino en las sociedades modernas . Barcelona: Anagrama.

Lobäch, B. (1981). Diseño Industrial. Bases para la configuración de los productos industriales. Barcelona: Gustavo Gili.

López, K. (2007). Mushuc Runa: indígenas del Ecuador impulsan la sostenibilidad de sus comunidades a través de microfinanzas. INCAE Business Review, 1(2), 78-79.

Maffesoli, M. (2009). El tiempo de las tribus. El ocaso del individualismo en las sociedades posmodernas. México D.F.: Siglo XXI editores.

Maldonado, G. (2012). Matices y texturas de la identidad cultural étnica en contextos urbanos. En el caso de los kichwas de Chimborazo. En Kigman, E. San Roque: indígenas urbanos, seguridad y patrimonio. Quito: FLACSO, HEIFER .

Malinowski, B. (1975). Los argonautas del Pacífico Occidental. Barcelona: Península.

Manzini, E. (2015). Cuando todos diseñan. Una introducción al diseño para la innovación social. Madrid: Experimenta Theoria.

Matarrese, M. (2011). Disputas y negociaciones en torno al territorio pilagá (Provincia de Formosa) (Tesis doctoral inédita). Argentina: Universidad de Buenos Aires, Facultad de Filosofía y Letras.

Matarrese, M. (2013). Antropología y Estética: el caso de la cestería pilagá (Gran Chaco, Argentina). PROA: Revista de Antropologia e Arte, 1(4). Disponible en: http://www. revistaproa.com.br/04/?page_id=92> 
Margolin, V. (2005). La investigación sobre el diseño y sus desafíos. Margolin, V.; González, C.; Salinas, O.; Rodríguez, L.; Morales E.; Losada, A. M.; Giménez del Pueblo, J. L. Las rutas del diseño. Ensayos sobre teoría y práctica (pp. 9-31). México DF: Designio.

Margolín, V. (2012). Las políticas de los artificial. Ensayos y estudios sobre diseño. México DF: Designio.

Milton, A., y Rodgers, P. (2013). Métodos de investigación para el diseño de producto. Barcelona: Blume.

Naranjo, M. (coord.). (1992). La cultura popular en el Ecuador. Tomo VII Tungurahua. CIDAP.

Organización Internacional del Trabajo (OIT) (1989). Convenio $N^{\circ} 169$ sobre Pueblos Indígenas y Tribales en países independientes. Disponible en: https://www.ilo.org/wcmsp5/ groups/public/---americas/---ro-lima/documents/publication/wcms_345065.pdf

Ospina, P.; Alvarado, M.; Camacho, G.; Carrión, D.; Chiriboga, M.; Hollenstein, P.; Torres, A. (2011b). Los senderos actuales y las amenazas al jardín: la reproducción del desarrollo económico en Tungurahua. En Ospina, P. (coord.). El territorio de senderos que se bifurcan. Tungurahua: economía, sociedad y desarrollo (Vol. 68, pp. 147-208). Quito: Corporación Editora Nacional - UASB-E.

Ospina, P.; Alvarado, M.; Camacho, G.; Chiriboga, M.; Larrea, A.; Larrea, C. y Torres, A. (2011a). El rastro de los senderos que se bifurcan: breve historia de las vías alternativas del desarrollo económico en Tungurahua. En P. Ospina (coord.), El territorio de senderos que se bifurcan: Tungurahua, economía, sociedad y desarrollo (Vol. 68, pp. 97-146). Quito: Corporación Editora Nacional - UASB-E.

Ossenbach, G. (1999). La educación en el Ecuador en el período 1944-1983. Estudios Interdisciplinarios en América Latina y El Caribe, 10(1).

Pequeño, A. (2007). Imágenes en disputa. Representaciones de mujeres indígenas ecuatorianas. Quito: Abya-Yala; FLACSO, sede Ecuador .

Plan Educativo Institucional (PEI) 2012-2013. Unidad Educativa Intercultural Bilingüe "Chibuleo". Disponible en: https://docplayer.es/60460807-Ministerio-de-educacionsubsecretaria-de-administracion-escolar-proyecto-nueva-infraestructura-educativa.html

Plan Educativo Institucional (PEI) 2013-2014. Unidad Educativa Intercultural Bilingüe "Chibuleo". Disponible en: https://docplayer.es/60460807-Ministerio-de-educacionsubsecretaria-de-administracion-escolar-proyecto-nueva-infraestructura-educativa.html

Plan Nacional del Buen Vivir (PNBV) 2013 - 2017. Disponible en: https://observatorioplanificacion.cepal.org/sites/default/files/plan/files/Ecuador\%20Plan\%20Nacional\%20 del\%20Buen\%20Vivir.pdf

Porras, A. (2005). Tiempo de indios. La construcción de la identidad política colectiva del movimiento indio ecuatoriano (Las movilizaciones de 1990, 1992 y 1997). Quito: Abya-Yala.

Prieto, M.; Cuminao, C.; Flores, A.; Maldonado, G. y Pequeño, A. (2005). Las mujeres indígenas y la búsqueda del respeto. En Prieto, M. Mujeres ecuatorianas: entre las crisis y las oportunidades 1990-2004 (pp. 155-194). Quito: CONAMU, FLACSO Sede Ecuador, UNIFEM, UNFPA.

Propuesta de la comunidad educativa como insumo para el nuevo Plan Decenal de Educación 2016-2025 (febrero 2016). Red de Maestros y maestras por la revolución educativa. 
Proyecto emergente de Unidades Educativas del Milenio y Establecimientos Réplica (2012). Ministerio de Educación. Disponible en: https://educacion.gob.ec/proyecto-emergentede-unidades-educativas-del-milenio-y-establecimientos-replica/

"Punto de orden" (13 de octubre 1992). Diario El Heraldo. Ambato.

Quinatoa, E. (2013). Los Otavalos. Símbolos, signos y significados de su vestimenta. Artesanías de América(73), 58-65.

Ramos, A. (1994). The hyperreal indian. Critique of Anthropology,, 14(2), 153-171.

Resolución de la CZ3 N 1385 del 9 de octubre del 2014), sobre fusión de cuatro centros educativos pertenecientes al Distrito 18D02, para la generación de la Unidad Educativa del Milenio Chibuleo.

Roach, M., y Eicher, J. (1992). Dress and identity. Clothing and textiles research journal, 10(4), 1-8.

Rodas, R. (2009). Tránsito Amaguaña, su testimonio. 4ta. Ed. Colección los centenarios del bicentenario. Quito: Trama Ediciones.

Rowe, A. P. (ed.) (1998). Costume and identity in highland Ecuador. Washington DC, Seattle: The Textile Museum, University of Washington Press.

Rowe, A. P. (ed.) (2007). Weaving and Dyeing in Highland Ecuador. Austin: University of Texas Press.

Rowe, A. P. (ed.) (2011). Costume and History in Highland Ecuador. Austin: University of Texas Press.

Saltzman, A. (2004). El Cuerpo Diseñado. Buenos Aires: Paidós.

Sánchez, J. (2010). El Movimiento indígena ecuatoriano. 2da. Edición. Quito: Abya Yala.

Sánchez, J. (2013). Qué significa ser indígena para el indígena. Más allá de la comunidad y la lengua. (2da. ed.). Quito: ABYA YALA.

Spadafora, A.; Gómez, M. y Matarrese, M. (2010). Rumbos y laberintos de la política étnica: organizaciones unificadas y faccionalismos indígenas en la provincia de Formosa (pilagá y toba). En Gordillo, G. y Hirsch, S. Movilizaciones indígenas e identidades en disputa en la Argentina (pp. 237-257). Buenos Aires: La Crujía.

Saulquin, S. (2010). La muerte de la moda, el día después. Buenos Aires: Paidós.

Secretaría Nacional de Planificación y Desarrollo (SENPLADES). (2015). Agenda Zonal ZONA 3-Centro. Provincias de: Cotopaxi, Tungurahua, Chimborazo y Pastaza 2013-2017. Quito. Disponible en: http://www.planificacion.gob.ec/wp-content/uploads/downloads/2015/11/Agenda-zona-3.pdf

Simmel, G. (1938). Cultura femenina y otros ensayos . Buenos Aires: Espasa Calpe.

Simón, G. (2016). Investigación para la docencia en diseño. En Rojas, C. y Saavedra, E. Reflexiones en torno a la metodología del diseño (Vol. 3, pp. 53-82). Tunja: UTPC.

Tello, E. (2012). Movimiento Indígena y sistema político en Ecuador. Una relación conflictiva. Quito: Abya Yala.

Theodossopoulos, D. (2012). Indigenous attire, exoticization, and social change: dressing and undressing among the Emberá of Panama. Journal of the Royal Anthropological Institute, 18(3), 591-612.

Travers-Spencer, S. y Zaman, Z. (2008). Directorio de formas y estilo para diseñadores de moda. Barcelona: Acanto. 
Turner, T. (1991). Representing, resisting, rethinking. Historical Transformation of Kayapó Culture and Anthropological Consciousness. En Stoking, G. Colonial Situations. Enssays on the contextualization of ethnographic knowledge (Vol. 7, pp. 285-313). Madison: The Univ. of Wisconsin Press.

Ulloa, A. (2005). Las representaciones sobre los indígenas en los discursos ambientales y de desarrollo sostenible. En Mato, D. Políticas de economía, ambiente y sociedad en tiempos de globalización. (pp. 89-109). Caracas: Facultad de Ciencias Económicas y Sociales.

Vicuña, B. (2008). Los Tejidos de América Surandina. Artesanías de América. Revista del CIDAP(66), 135-168.

Vilchis, L. (2014). Metodología del diseño. Fundamentos teóricos (4ta ed.). México DF: Designio.

Vilchis, L. (2016). Diseñar significa investigar: lo diseñado es obra de la reflexión. En Rojas, C. y Saavedra, E. Reflexiones en torno a la metodología del diseño (pp. 19-52). Tunja: Editorial UPTC.

Weaver, S. (1984). Struggle of the Nation-State to Define Aboriginal Ethnicity: Canada and Australia. En G. Gold (ed.), Minorities and Mother Country Imagery. Newfoundland: Social and Economic Papers 13. Institute of Social and Economic Research, Memorial University of Newfoundland.

Wright, S. (1998). The Politicization of 'Culture'. Anthropology Today, 14(1), 7-15.

Yépez, P. (2015). La cosmovisión de los pueblos y nacionalidades indígenas. Su permanencia en el Ecuador intercultural y plurinacional. Quito: Abya Yala

Ynoub, R. (2015). Cuestión de método. Aportes para una metodología crítica. (Vol. Tomo I). México DF.: Cengage Learning.

Zambrini, L. (2019). Diseño e indumentaria: una mirada histórica sobre la estética de las identidades de género. Cuaderno 71. Cuadernos del Centro de Estudios en Diseño y Comunicación, Facultad de Diseño y Comunicación, Universidad de Palermo, ISSN 1668-0227. Disponible en: https://fido.palermo.edu/servicios_dyc/publicacionesdc/ archivos/694_libro.pdf

\begin{abstract}
This thesis covers the uses and transformations of Chibuleo women's apparel between the years 1990 and 2016. Based on the analysis of the changes in apparel that occurred in this process, three apparel typologies are identified and analyzed. In turn, and as part of the analysis, these typologies are related to three historical, social and political moments. These milestones were, in the first place, the indigenous uprisings of 1990, which helped to acheive the consequent constitutional recognition of ethnic rights. Secondly, the creation of bilingual educational institutions, specifically the Chibuleo Millennium Educational Unit, and lastly, the creation of savings and credit cooperatives. This historical process, which had the fight and the vindication of the rights as common thread —called "the acquired respect" by the Chibuleos-, is intimately related to the use and apparel transformations of this people. In particular, in this thesis we study the groups of women identified as "las mamas", "las profesoras", and "las de las cooperativas".
\end{abstract}


Keywords: apparel design - chibuleo - identity - transformations - apparel typologies.

Resumo: Na presente dissertação é estudado o uso e transformações da indumentária da mulher chibuleo entre os anos 1990 e 2016. Com base num análisis das transformações da indumentária nesse processo, são identificadas e examinadas três tipologías da vestimenta. Por sua vez, como parte do análisis, são relacionadas tais tipologías com três momentos históricos, sociais e políticos. Esses marcos contextuais foram, em primeiro lugar, os levantamentos indígenas de 1990, com o consequente reconhecimento constitucional dos direitos da etnia; em segundo lugar, a criação das instituições educativas bilíngues, especificamente a Unidad Educativa del Milenio Chibuleo; e finalmente, a criação de cooperativas de poupança e de crédito. Esse processo histórico, cujo fio condutor foi a luta e reivindicação dos direitos —-segundo os chibuleos "o respeito adquirido" - , está profundamente ligado com o uso e transformações na vestimenta desse povo. Na presente tese se estuda, particularmente, os grupos de mulheres identificadas como "las mamas", "las profesoras" e "las de las cooperativas".

Palavras chave: desenho de indumentária - chibuleo - identidade - transformações - tipologias de vestimenta.

[Las traducciones de los abstracts fueron supervisadas por el autor de cada artículo] 